Portland State University

PDXScholar

Summer 8-27-2013

\title{
Faulty Measurements and Shaky Tools: An Exploration into Hazus and the Seismic Vulnerabilities of Portland, OR
}

\author{
Brittany Ann Brannon \\ Portland State University
}

Follow this and additional works at: https://pdxscholar.library.pdx.edu/open_access_etds

Part of the Geophysics and Seismology Commons, Urban, Community and Regional Planning Commons, and the Urban Studies and Planning Commons

Let us know how access to this document benefits you.

\section{Recommended Citation}

Brannon, Brittany Ann, "Faulty Measurements and Shaky Tools: An Exploration into Hazus and the Seismic Vulnerabilities of Portland, OR" (2013). Dissertations and Theses. Paper 1410.

https://doi.org/10.15760/etd.1410

This Thesis is brought to you for free and open access. It has been accepted for inclusion in Dissertations and Theses by an authorized administrator of PDXScholar. Please contact us if we can make this document more accessible: pdxscholar@pdx.edu. 
Faulty Measurements and Shaky Tools: An Exploration into Hazus and the Seismic Vulnerabilities of Portland, OR

by

Brittany Ann Brannon

A thesis submitted in partial fulfillment of the requirements for the degree of

Master of Urban Studies

Thesis Committee:

James Strathman, Chair

Carl Abbott

David Banis

Portland State University

2013 


\begin{abstract}
Events or forces of nature with catastrophic consequences, or "natural disasters," have increased in both frequency and force due to climate change and increased urbanization in climate-sensitive areas. To create capacity to face these dangers, an entity must first quantify the threat and translate scientific knowledge on nature into comprehensible estimates of cost and loss. These estimates equip those at risk with knowledge to enact policy, formulate mitigation plans, raise awareness, and promote preparedness in light of potential destruction. Hazards-United States, or Hazus, is one such tool created by the federal government to estimate loss from a variety of threats, including earthquakes, hurricanes, and floods. Private and governmental agencies use Hazus to provide information and support to enact mitigation measures, craft plans, and create insurance assessments; hence the results of Hazus can have lasting and irreversible effects once the hazard in question occurs. This thesis addresses this problem and sheds light on the obvious and deterministic failings of Hazus in the context of the probable earthquake in Portland, OR; stripping away the tool's black box and exposing the grim vulnerabilities it fails to account for.
\end{abstract}

The purpose of this thesis is twofold. First, this thesis aims to examine the critical flaws within Hazus and the omitted vulnerabilities particular to the Portland region and likely relevant in other areas of study. Second and more nationally applicable, this thesis intends to examine the influence Hazus outputs can have in the framing of seismic risk by the non-expert public. Combining the problem of inadequate understanding of risk in Portland with the questionable faith in Hazus alludes to a larger, socio-technical situation 
in need of attention by the academic and hazard mitigation community. This thesis addresses those issues in scope and adds to the growing body of literature on defining risk, hazard mitigation, and the consequences of natural disasters to urban environments. 


\section{Acknowledgments}

It took less than six minutes for a tornado to ravage my home town; taking with it my home, high school, and many of the surroundings I held dear. This EF5 tornado met Parkersburg, IA on Sunday, May 25, 2008 at 4:59pm, exactly one week after I graduated high school. Five years later, Parkersburg has returned to vibrancy, and has rebuilt itself beautifully. Yet scars remain. Half of the town has deformed or nonexistent trees. Some residents have chosen not to rebuild, or did not have sufficient insurance money to restore their homes properly. Non-physical, psychological scars also permeate Parkersburg dwellers. Residents, including myself, still feel anxiety when a storm siren goes off, or when witnessing similar tornado disasters in other Midwestern towns. Lives were altered and fears were realized on that sunny day.

Sadly, these events are increasing in frequency and magnitude. Parkersburg is not a unique case. Forces of climate change continue to alter weather patterns and cause destruction in towns, cities, homes, and neighborhoods; all beloved areas assumed to be immune to destruction by their inhabitants. Thus planning for these disasters is of extreme importance in the mitigation process; a process that I would like to see improved.

I do not want to thank Mother Nature for leading me here, but I do acknowledge the influence she has had in my life. I would not be the person I am now were it not for that fateful day. Adversity is a strong motivator, and I have been driven accordingly.

I would also like to thank the beautiful people that have inspired, motivated, and supported me throughout this process. I thank my mother for her passion and my father 
for his rationality; both traits I have discovered in myself and extremely grateful for. Their love and care cannot be described in words, and I am eternally indebted to their sponsorship. Thank you to my siblings, who have kept me sane for the past twenty-three years, and provided me with fantastic role models to look up to. Lastly, my indescribable friends that were there with me on that fateful day and are my rocks in life - Abby, Sam, and Jordan - their camaraderie continues to amaze me. I am incredibly blessed.

Lastly, I would like to acknowledge all those affected by natural disasters. The pain that is felt in these events is indescribable. I hope that the future will be brighter; that we can mitigate these events, reduce their effect, and realize the impact climate change and knowledge perception has on mitigation efforts. The prosperity of future generations depends on it. 


\section{Table of Contents}

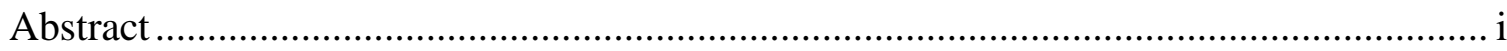

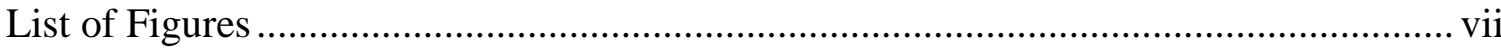

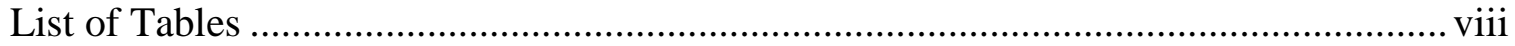

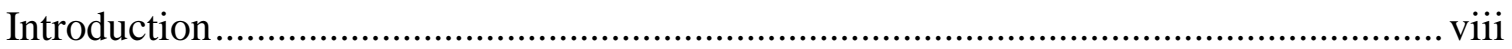

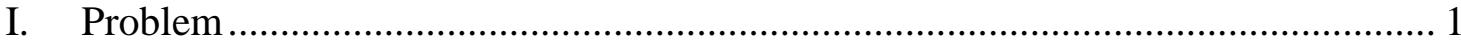

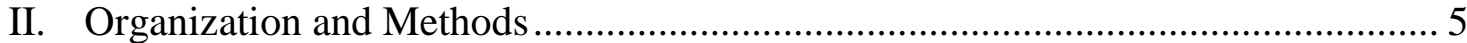

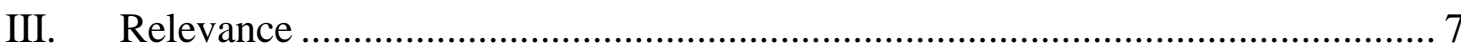

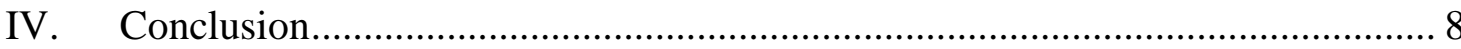

Chapter 1: Conceptualizing Risk .......................................................................... 10

I. Hazards and Risk: A Theoretical Review ........................................................... 11

II. Decrease Risk and Increase Resilience............................................................ 20

III. Modeling Risk According to Economic Metrics............................................... 24

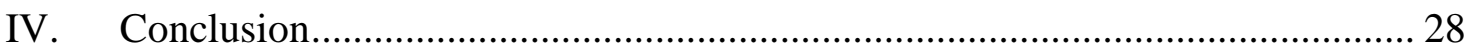

Chapter 2: Geology, Earthquakes and Building Resilience in Oregon.............................. 29

I. The Evolution of National Earthquake Knowledge ……………………………...... 29

II. A Brief Earthquake Lesson .............................................................................. 35

III. Pacific Northwest Earthquake Awareness …………………………………..... 37

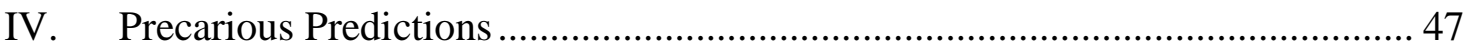

V. The Built Environment vs. the Environment: Mitigating Structural Risk ............. 52

VI. Taking Action - Local, State, and National Policy on Earthquake Risk ............ 57

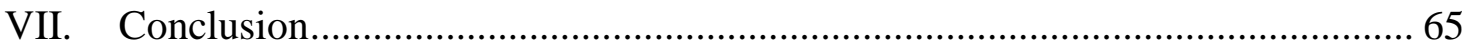

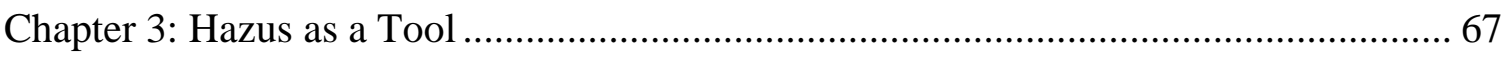

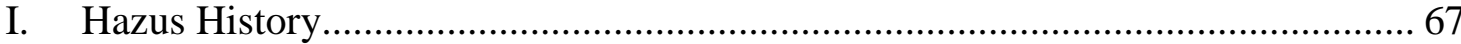

II. Current HAZUS Earthquake Model ………………....................................... 70

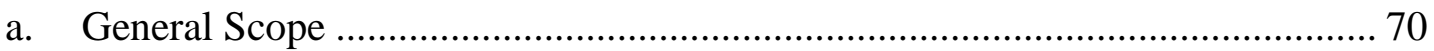

b. Hazus Inventory Data ................................................................................... 75

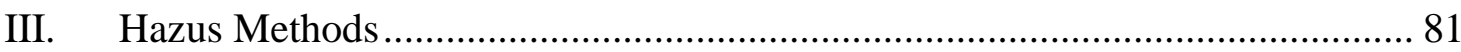

a. Potential Earth Science Hazards ……………………...................................... 82 
b. Direct Physical Damage - Building Stock, Essential Facilities, Transportation,

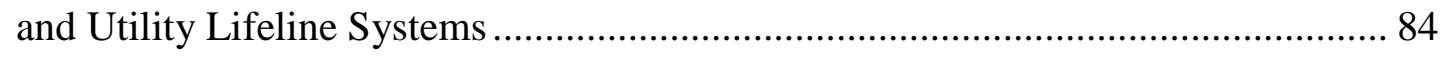

c. Indirect Physical Damage - Hazards Resulting from Earthquakes.................... 88

d. Direct Loss - Casualties and Displacement .................................................. 90

e. Direct and Indirect Economic Losses............................................................ 96

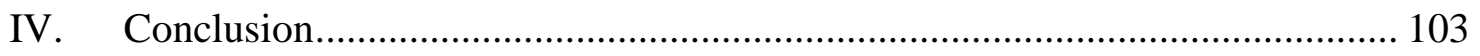

Chapter 4: Hazus Critique and Analysis ................................................................. 105

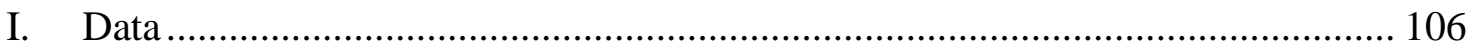

II. Additional Hazards ...................................................................................... 110

III. Measuring Casualties ....................................................................... 116

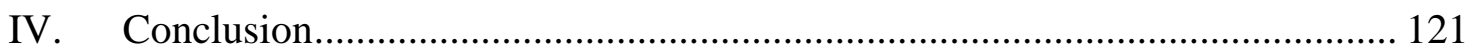

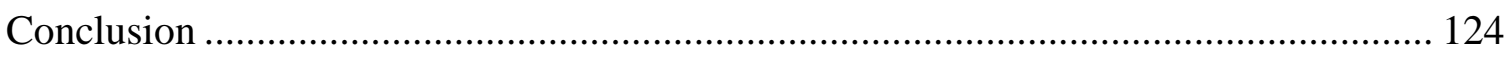




\section{List of Figures}

Figure 2.1 Organizations and Functions within NEHRP ......................... 34

Figure 2.2 Lithosphere descent......................................... 36

Figure 2.3 Extent of Earthquake Awareness in Oregon, 1987.....................39

Figure 2.4 Extent of Earthquake Awareness in Oregon, $1987 \ldots \ldots \ldots \ldots \ldots \ldots \ldots \ldots . \ldots 40$

Figure 2.5 The Movement of Juan de Fuca.................................43

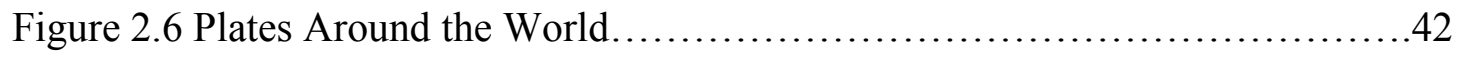

Figure 2.7 Local Faults in Portland, OR.................................. 45

Figure 2.8 Ariel View of Portland Faults....................................46

Figure 2.9 Japan as Oregon's Mirror.....................................49

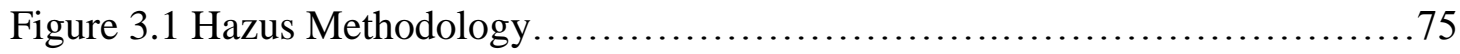

Figure 3.2 Hazus Casualty Event Tree Model..................................93 


\section{List of Tables}

Table 3.1 Hazus Modules and Outputs............................................ 74

Table 3.22000 Census Data.................................................... 80

Table 3.3 Injury Levels Calculated in Hazus.....................................92

Table 3.4 User-Supplied Inputs for Calculating Economic Loss....................101 


\section{Introduction}

I. Problem

The city of Portland, Oregon is facing a looming threat from nature in the form of an earthquake. This earthquake threatens multiple cities and locations within the Pacific Northwest due to the region's placement atop the Cascadian Subduction Zone. This zone comprises of the most dangerous fault lines in the United States, running 600 miles from northern California, along the Oregon and Washington Coast, and into Canada (Montoya 2011). The state of Oregon is estimated to have a $10 \%$ chance of a magnitude 9 earthquake over the next 50 years, and a $37 \%$ chance of a magnitude 8 or less in the same time period (OPB 2012). In addition to the Cascadian threat, the city of Portland was built upon three shallow faults that coincidentally cut beneath the most populated parts of the city. Geologists estimate the local faults to be less of a threat, yet still necessitate cause for concern (Rojas-Burke 2011).

Due anxiety has arisen among residents and government officials alike in response to these estimations. The potential danger to human life and the built environment are hard to imagine, yet necessary to consider. Some of the harrowing facts on Portland's vulnerabilities are as follows:

- Portland currently has approximately 1200 unreinforced masonry buildings, all of which would likely collapse in the instance of a large earthquake. Many of these buildings include schools, businesses, and homes (OPB 2012).

- Roughly half of downtown Portland is on potentially liquefiable soils (OPB 2012). 
- Forty percent of Portland's schools are prone to collapse in the case of an 8.0magnitude quake (Montoya 2011).

- Portland is a city of bridges, many of which are likely to collapse unless properly retrofitted in the near future (Montoya 2011).

These facts, among many others, are but a few of the reasons to be concerned about the risk from the inevitable quake. Earthquakes cause unimaginable destruction and leave lasting economic, social, and psychological scars on residents and cities.

Portland's earthquake risk embodies extreme uncertainty, however. The randomness of earthquakes and incomplete geographic knowledge both globally and within Portland completely negates the ability to predict these events and their precise effect on the built environment. Accordingly, the governing bodies in Portland have expressed their concern and taken action to raise awareness among residents and businesses in hopes of countering the uncertainty and reduce vulnerabilities. Grassroots organizations have also played an important role in communicating seismic risk and lobbying for increased state effort.

It is impossible for politicians, grassroots members, stakeholders, and the public at large to adequately comprehend the risks at hand. Understanding seismic threats to cities requires intricate and esoteric knowledge on seismicity, geology, and engineering. Thus tools exist to combine and translate these threads of knowledge into tangible numbers understood by the greater public. Problems arise, however, when the tools estimating loss are grossly inaccurate and fail to account for all hazards. 
The tool most commonly employed by government agencies and others to assess and communicate risk is the ArcGIS extension "Hazards-United States," or more commonly known as Hazus. This tool is a nationally applicable standardized methodology that contains models for estimating potential losses from earthquakes, floods, and hurricanes (FEMA 2012b). Hazus was first developed in the 1990's exclusively for earthquakes and has been expanded to include other hazards within the past ten years. The scope of this thesis pertains only to the earthquake model, yet many of the details, methodologies, and criticisms could apply to the other hazards.

Specifically, Hazus is a computational algorithm built around an input-output transactions table and incorporates numerous loss accounting principles (Cochrane 2004). Algorithms in Hazus operate using complex formulas according to the magnitude of quake, location of fault line, time of day, and day of the week (FEMA 2012). The complexities of these algorithms, details on each factor, and examination into missing or unnecessary factors will be elaborated upon and explored in subsequent chapters.

In the context of an earthquake, Hazus will produce estimates such as the following:

- Structural repair costs (\$ per square foot) for the region's buildings;

- Non-structural repair costs (\$ per square foot) for all occupancies;

- Value of building contents as a percentage of building replacement value of overall occupancies;

- Business inventory damage as a function of damage state for agricultural, commercial, and industrial occupancies.

Many beneficial outputs are provided through Hazus. Plans and insurance assessments for neighborhoods, cities, states, and other geographic regions are created based off of the 
tool's outputs and estimations, thus the information Hazus provides is understandably powerful. Yet further inquiry must be performed. Concern arises over the effectiveness of the tool, especially given the Office of Management and Budget rating of Hazus as merely "moderately effective" at estimating hazard risk (Moffatt and Laefer 2009). Therefore it is left to be wondered how Hazus received this rating, why it is inadequate at estimating risk to the built environment, and which vulnerabilities it fails to account for.

The inaccuracy of Hazus is especially concerning given the "black box" status allotted to it by planners and government agencies. Tools such as Hazus are often accused by scholars as being "black-boxed" due to the tendency of users to place complete trust in complicated tools and neglect to question their potential faults or weaknesses. As noted by Bastrom et al. (2006), private, local, and federal agencies use Hazus to provide financial information and support regarding earthquake mitigation measures; hence the results of Hazus can have lasting and irreversible effects once the earthquake in question occurs. This thesis addresses this problem and sheds light on the obvious and deterministic failings of Hazus, thereby stripping away the black box and exposing the grim vulnerabilities it fails to account for.

The purpose of this thesis is twofold. First, to examine the critical flaws within Hazus and the omitted vulnerabilities in the tool that are particular to the Portland region and likely relevant in other regions. Second and more nationally applicable, this thesis intends to examine the influence Hazus outputs can have in the framing of seismic risk by the nonexpert public. Combining the problem of inadequate understanding of risk in Portland with the questionable faith in Hazus alludes to a larger, socio-technical situation in need 
of attention by the academic and hazard mitigation community. This thesis will address those issues in scope and add to the growing body of literature on defining risk, hazard mitigation, and the consequences of environmental hazards within urban environments.

The questions asked by the thesis are as follows: (1) How is seismic risk perceived by the public and how does the framing of risk affect their decisions? (2) Is Hazus an accurate tool for assessing and communicating risk? (3) What vulnerabilities does Hazus fail to account for in the Portland region and how adequately has Portland addressed these risks? These questions have guided the research and analytic process employed in this thesis, and serve as overarching parameters for the study's scope.

\section{Organization and Methods}

This thesis is an exploration into the technological success and failure of Hazus, with specific attention given to the tool's ability to account for all risks and vulnerabilities within the Portland Metro region. A mixed methods approach was used for analysis, with each chapter building upon information presented prior. Research for this thesis was performed using content analysis of existing sources, and supplemented by interviews with relevant personnel.

Examination on risk assessment performed by other scholars has not been as comprehensive as the analysis set forth here. To further investigate Hazus, the methods employed will synthesize previous literature, and incorporate measures and assessments that are both qualitative and quantitative in nature. Therefore the thesis has been divided into four distinct parts according to method and necessary objectives. 
Chapter 1 of the thesis presents a sound review of hazard mitigation literature and risk theory. Multiple sources were consulted for the literature review, including books, peerreviewed articles, government publications, and non-governmental organization reports. The topic of resiliency is presented to shed light on the buzzword's increasing importance in disaster mitigation efforts and risk awareness. Lastly, the use of economic loss as a metric to communicate risk is explored as pretext for discussion and analysis of Hazus. These elements are necessary in order to build a foundation for the subsequent exploration of risk within Portland and Oregon.

Chapter 2 provides a historical overview of the evolution of earthquake knowledge and policy in Portland and Oregon. This information was gathered through research of geologic text, existing historical accounts, academic literature, and archival research within Oregon historical records. This chapter also provides an account of national, state, and local seismic policy relevant to the Portland region to link earthquake knowledge and awareness with legislative and grassroots action. This background information is vital in the assessment of Hazus for three reasons. First, the geologic and seismic information grants essential scientific perspective to understanding the danger earthquakes pose to the built environment. Second, a basic understanding of geologic knowledge is necessary to comprehend the schemes employed by Hazus to model nature's anticipated behavior. Lastly, information on policy and historical awareness of earthquake hazards in Portland is necessary to analyze the factors that influence public risk perception and political mitigation efforts. 
The information on geologic and seismic knowledge given in Chapter 2 provides context and structure for understanding the models used in Hazus, presented in Chapter 3. This chapter was built through an extensive review of the $700+$ page Hazus software handbook, and required translating the handbook from purely geologic and engineering speak and into a non-expert, readable, and summarized format. The chapter was also supplemented by literature on Hazus, risk estimation, and modeling methods. The complete analysis of the handbook is essential to this thesis, as it allowed exploration into the inadequacies of the software and the ability of these inadequacies to have adverse effects on the model's output.

An analytic lens is turned to the Hazus software in Chapter 4 to assess its practicality as a tool for policymakers and planners. The analysis presented in Chapter 4 incorporates literature on seismic hazards, information from recent earthquakes, and Portland-specific vulnerabilities to test against the gaps discovered in Hazus. This is essential to the hazard estimation process and communication of risk, as failing to account for specific elements prevents complete understanding of a region's vulnerabilities. Thus the final synthesis combines analyses from a variety of sources to derive a conclusion on Hazus, its effectiveness in communicating risk, and Portland's status as a seismically vulnerable city.

\section{Relevance}

The risks posed to society by nature are obvious, yet our methods for preparing for those risks and preventing maximum damage must be continuously questioned. Questions must 
be asked to the holders of the knowledge, tools, and power to prepare the greater public and ensure the ultimate amount of safety. Portland, along with the greater United States, must realize the power embedded in planning for the known risks. The use of Hazus and mapping in this process has had a profound effect on mitigation and risk assessment in the past twenty years, and will continue to affect a region's response and recovery as disasters increase in frequency and magnitude. Therefore the questioning of this tool is of vital importance to the academic realm, disaster management field, and safety of the greater public.

This thesis will add to the growing field of risk theory, science and technology studies, emergency management, and hazard preparation in multiple ways. The unprecedented analysis of Hazus on a conceptual level will shed light on the tool's functionality and failures while providing information to those using it both in Portland and across the nation. Equally important is the examination of particular vulnerabilities in Portland that Hazus fails to account for and communicate to the public. The conclusions presented in this thesis are thus valuable in both a theoretical and practical sense.

\section{Conclusion}

It is unnecessary to repeat the statistics and fear-mongering hypotheses on Portland's pending earthquake. It is, however, absolutely necessary to realize the power embedded in hazard framing mechanisms and the neglect of governing structures to adequately prepare for natural disasters. A whole host of strategies converge to help society and cities better prepare for a range of risk. A community's capacity to be prepared for, 
respond to, and recover from these horrendous events depends on the actions of institutions and their efforts to equip communities with necessary information and support.

No city can become disaster proof. Steps can be taken, however, to assure that governments, residents, and the built environment are conscious of the pending dangers and act in the best way to minimize that danger. Hazus is but one of the tools agencies use to influence mitigation decisions and quantify potential danger, casualties, and cost. In reality, the worth of the human lives and cities threatened by natural disaster risk is monetarily immeasurable and impossible to completely safeguard. I can only hope that the exploration provided in this thesis can contribute to our understanding of natural disasters in order to move forward in protecting what we can, and realizing the dangers in the unknowable. 


\section{Chapter 1: Conceptualizing Risk}

The attempts to quantify the impact of nature on humans range from purely theoretical notions of risk and natural destruction to scientific laws that cement nature's wielding capabilities. The realm of disaster planning and risk assessment attempts to merge the fields of human interaction with the laws of nature through the use of geological and meteorological knowledge, assessment of the built environment, and the study of human behavior and patterns.

A variety of scholarly fields have been involved in studying these phenomena, including, but not limited to, geography, sociology, systems science, psychology, earth science, urban studies, and economics. The methods employed in each field vary on the spectrum of qualitative vs. quantitative, thereby typically making most work interdisciplinary in scope. The research and production of new knowledge on this topic is intended for policy-makers as they attempt to create resilient and disaster ready entities. Accordingly, tools to aid in the preparation and resiliency-building process have been produced by various academics and agencies with the hope of preventing loss prior to environmental disasters and improving mitigation methods after destructive events occur. HazardsUnited States, or more commonly known as Hazus, is one such tool used to translate the multiple variables contributing to risk into logical estimations of cost, casualties, and effects to the region of study.

This chapter introduces literature regarding the theoretical notions of risk, the attempts to build "resiliency" to combat risk in the built environment, and the framings used to 
communicate risk to the general public. This exploration is necessary to provide a conceptual background and justification for the thesis.

\section{Hazards and Risk: A Theoretical Review}

The following section will discuss the means by which "risk" to the built environment is defined according to literature produced by a variety of disciplines including urban studies, sociology, psychology, and economics. The variety of fields required to study risk is necessary due to the multifaceted nature of natural disasters and the effects they have on society. This section examines natural disaster risk by stratifying it according to individual, collective, and state perceptions. The levels of risk perception are important to consider due to their ability to influence disaster response and recovery.

The literature on perceived risk and its impact upon policymakers can be separated into three strands as defined by Jasanoff (1999). The first form of critique is taken in a positivist light and assesses the bureaucratic-rationalistic policy implications of risk, seeing it as a tangible by-product of actually occurring natural and social processes. The second explanation of risk grounds itself in scientific knowledge, proposing that liberal and pluralistic solutions can be formed by combining knowledge with action. Finally, risk is critiqued by scholars in a constructivist manner through examining the relationship between knowledge and power in the use of risk mitigation strategies (Jasanoff 1999). These three strands differ in a theoretical sense with respect to the nature of environmental knowledge and also in their prescriptions for linking knowledge to political action. The differences in defining risk are important to note due to the potential 
framing of risk by policymakers, planners, and scholars and their influence on the public's perception of the hazard at hand.

Jasanoff's first strand of risk, that produced by the intersection of nature and the built environment, has been defined and elaborated on in Charles Perrow's 1984 book, Normal Accidents. Perrow terms the end occurrence from risk as an "eco-system accident". These "accidents" are a result of an interaction of systems thought of as independent, but in reality are dependent upon each other within the built environment due to the tight coupling between human-made and natural systems. Risk in this sense is purely physical, as it focuses on interactions between the nature and the built environment.

Jasanoff's second strand of risk, on the combination of knowledge and action, has taken particular interest in the realm of sociology. May (2001), observed that determining levels of risk is a value judgment that requires some form of collective decision making and knowledge of relevant risk considerations, technical details, and costs. Individual knowledge on a hazard will influence perception, perception of the hazard will influence preemptive action, and action determines ability to cope with a hazard if and when it occurs.

Yet substantial action to reduce risk may depend more on local politics and power than on the technical measures of earthquake risk noted in the first strand, or individual actions noted in the second (Bostrom, Turaga, and Ponomariov 2006). Thus Jasanoff's last strand of risk, regarding hazard knowledge and power to act on that knowledge, must be considered. Past disasters and events present this strand exceptionally well. For 
example, state knowledge on hazard risk has been used to enact evictions or forced action regardless of the uncertainty of the hazard. Zeiderman (2011) takes particular notice of eviction methods in the city of Bogota, Columbia. His analysis notes how 10,715 properties within Bogota's slum districts were forced to move as a result of the city planners' perceived landslide risk (Zeiderman 2012). Similarly, Davis, in his 2007 book, Planet of Slums, notes the gargantuan slums of the world's largest cities and how these cities have evicted the urban poor in the name of building natural disaster resilience or decreasing risk. Forced evictions are extreme cases of the negative and unjust actions that can occur as a result of misinformed information through hazard estimation tools such as Hazus.

Scholars within the field of science, technology, and society (STS) studies have only recently studied the power relationships involved with disaster planning. Their research highlights the lack of academic study on disaster science, expertise on risk planning, and the knowledge of the two in shaping the built environment. As noted by Fortun and Frickel (2012), the failure of the academic community to question the holders of risk knowledge in planning is disconcerting. The academic realm could contribute to this field and have great relevance in understanding how technoscientific knowledge, experts holding this knowledge, and institutions interpreting the knowledge prepare for and respond to catastrophic events (Fortun and Frinkel 2012). This relationship is currently of questionable status and in need of additional study. Fortun and Frinkel note, "Given the critical role of technoscientific expertise in assisting governments and communities to better understand the nature of disaster events, honing effective responses to disaster, and 
reducing social vulnerabilities to disaster, this mismatch arguably constitutes a form of inequality that can have profound geopolitical, economic, and humanitarian impacts." The impacts Fortun and Frinkel warn of range from the forced evictions in Bogota to under-preparation in Katrina; both of which have lasting and irreversible consequences on the communities affected.

In a perfect world, all governments would do everything in their capacity to protect their residents from the risk embedded in nature. In reality, governments and citizens are constrained by a variety of factors that prevent them from fostering a danger-free society. They must prioritize and weigh risk in light of particular constraints. May (2001) notes that determining risk is a judgment requiring the following: participative and collective decision-making; knowledge of the relevant risk and technical details; and costs and benefits to establish meaningful standards to countering risk (May 2001). In this context, earthquake mitigation policy is constrained by low public perception and understanding, high upfront costs, uncertain benefits of mitigation actions, lack of technical and financial resources, competing interests among stakeholders, and differences in the values of the population (Bostrom, Turaga, and Ponomariov 2006). As a result of incomplete knowledge and competing interests, decisions to enact policy are NOT made through the explicit expression of concern for consequences. Rather, decisions are made with regard to a given context and set of options constrained by available resources and attitudes, thereby revealing a level of acceptable consequences. A community's vulnerability can be considered a function of wealth, since the mitigation choices will be framed as a question of how much safety the community or region can afford. 
Scale must also be considered when analyzing risk. The perception of risk on a societal and public welfare level varies substantially from the perception of risk by individuals. Specifically, individual preparation for earthquakes calls for purchasing of earthquake insurance, performing household seismic upgrades, and creating family-based mitigation plans. In the context of an earthquake, individuals sometimes have economic incentives to reduce losses, but the calculus of decision making is such that a host of perceptual factors alter their rationality (May 2001). The collective level scale for preparation and risk mitigation, at the very least, calls for minimum seismic safety standards communicated in building codes, strategic mitigation plans produced by emergency management bureaus, and promotion of basic seismic safety and awareness. These efforts done at the collective scale will signal to individuals the importance of the risk at hand.

Yet disconnect exists between the effect of mass, state initiated measures and those done by the individual. Most often, the elements most endangering the public can only be overcome or mitigated by government will. For example, the seismic capacity of a locality's public utilities and infrastructure can only be improved through large and expensive infrastructure improvements. Thus enacting influential risk reduction strategies presents a collective action problem, since individuals will not have the capacity to make the improvements unless they unite to persuade the government to take action. Despite the heightened benefit of massive, state-oriented improvements, governments will choose to push preparedness and risk mitigation onto the individual level due to the high upfront costs and uncertain benefits. Soft strategies to build individual resiliency are promoted 
instead (i.e. storing personal water supplies or safety kits), as they are cheaper and require fewer resource commitments from the state.

The divide between hard and soft strategies was demonstrated unambiguously in Portland, OR through a survey performed by Flynn (1999). Flynn found strong support for the suggestion that the city provide "better public earthquake information programs" and "better community emergency preparedness." Conversely, the majority of respondents opposed the idea of mandatory strengthening of privately owned buildings. This implies that individuals prefer grand soft solutions to mitigating risk as opposed more expensive and physical initiatives such as seismic upgrades that would be more expensive yet have a larger impact on safety in the long-run (Flynn et al. 1999). The public can therefore be expected to have varying support for mitigation and risk reduction strategies according to their perception of the risk at hand and price tag of the strategies proposed.

Steinberg, in the 2000 book Acts of God: The Unnatural History of Natural Disasters in America, elaborates on the problems of collective action to persuade government policy from a historical standpoint. His narrative details the divide between holders of risk knowledge at the governance level, and the decision to disregard that knowledge despite its ability to influence the effects of natural disasters. He notes how natural calamities do not just happen, but are produced through a chain of human choices on multiple levels and natural occurrences, and Steinberg questions these relationships in a chronicle of various cities. As he notes, "The constrained vision of responsibility, and the belief that disasters stem solely from random natural forces, is tantamount to saying that they lie 
entirely outside human history, beyond our influence, beyond moral reason, and beyond control.” (T. Steinberg 2006). Steinberg places a large amount of blame on the government's ignorance and inability to act or remove risk from the public, and sees the individual-level strategies as inadequate to risk reduction.

Wetmore (2007) highlighted the lack of individual vs. state oriented accountability and coordination in the status of New Orleans pre and post Katrina. Each level of actors perceived the city's risk differently, thus their actions did not cohesively form into a successful mitigation and recovery plan. Westmore states, "Contemporary societies have not developed a good sense of how to deal with distributed responsibilities that are a necessary part of any complex system."'(Wetmore 2007). As noted, the responsibilities of the state, local, and federal levels of government are palpably different than those taken at the individual level, especially in a post-disaster situation.

The manifestation of personal vs. societal risk perception on the individual side is supremely evident in the decision to purchase insurance in anticipation of an earthquake. This topic has gathered considerable attention by economists due to the unique and uncertain environment that individuals must operate in (Palm 1995). For example, some individuals may choose to forego insurance and take on the risk of a major catastrophe by assuming disaster assistance will come from the federal government or a nongovernmental organization. Others may not see a large risk, and underestimate their true loss probability (Picard 2008). To purchase insurance, a consumer must be seen as assessing the probability of loss distributions for each risk and deciding if the presented policy warrants its premium (Johnson and Hershey 1993). 
Johnson and Hershey (1993) divide the insurance decision into three components: the risk itself, the policy premium, and the benefit. In regards to the risk itself, for most hazards, a standard insurance company will have a portfolio where the risk is typically shifted across a large number of people, for a variety of independent events, and diversified over different risk categories. This is not necessarily true in the case of insuring catastrophic events. Massive catastrophes can cost upwards of $\$ 100$ billion and sink the entire portfolio of an insurance company. Thus risk itself is high for the providers.

For the purchasers of earthquake insurance, perceived risk itself is entirely dependent on the purchaser's disposition. Consumers do not make insurance choices rationally, even when it is subsidized and priced far below its actuarially fair value, as with flood insurance. Whether they see the earthquake as a given natural hazard, a low-probability event, a consequence of their own building location, or as a substantial threat will ultimately influence their perception of risk and decision to purchase insurance (Shaw, K. S. H. Kobayashi, and M. Kobayashi 2004). Mostly, purchase of insurance is completely detached from any realistic measure of seismic risk or geologic knowledge that is likely to be familiar to home owners (Kunreuther 1996). This research infers that consumers tend to act on fear as opposed to geologic data explicitly warning them of a future catastrophe.

Individuals choose their level of acceptable risk through their decision to participate in risk-reduction efforts such as purchasing insurance, performing seismic retrofits, or creating personal mitigation plans. Insurance decisions reveal a level of acceptable consequences, and demonstrate how mitigation and preparatory decisions are made with 
regard to a given context and a given set of options (Bostrom, Turaga, and Ponomariov 2006). Decisions are made at the governance level with the same structure in mind. High upfront costs, uncertain benefits of costly mitigation actions, competing financial interests, and differences in stakeholder values define the context and given set of options. Large risk mitigation strategies can therefore be inferred as a function of wealth, requiring the community to define how much safety they can afford (Bostrom, Turaga, and Ponomariov 2006). Thus the constrained budgets of governments coupled with competing demands prevent optimal mitigation strategies from being realized.

The effect of risk perception and affordable safety on disaster planning and responsibility also applies in a historical perspective. Collier and Lakoff (2006) highlight the monumental shift from exclusively local and state based disaster coordination to federal government involvement and accountability. National safety became a greater concern in light of post-WWII national security strategies, thus the national government's heightened perception of risk allowed for greater attention to be paid to natural disasters (Collier and Lakoff 2008). Specifically, the use of vulnerability mapping involved a new form of knowledge about urban life and the risks nature poses to residents. The federal government had a greater amount of resources at their disposal, and was able to use techniques of imaginative enactment to generate knowledge about events whose likelihood could not be known but whose consequences could be catastrophic. This paradigm shift in judging risk is essential to natural disaster mitigation and Hazus evolution, as it allowed governing bodies to communicate risk on a nationally applicable scale through a centralized unit. 
This section has reviewed the theoretical barriers to enacting risk-reducing strategies on an individual and collective level. Power, knowledge, communication of risk, and state involvement all have a substantial role in defining a community's disaster disposition, and contribute to its capacity to manifest action. Most recently, the manifestations to reduce risk are quantified as metrics for "building resilience" in a community. This phenomenon will be outlined in the proceeding section, and is useful to consider within the context of this thesis due to the term's unrestrained use in hazard mitigation.

\section{Decrease Risk and Increase Resilience}

The process of mitigating risk has been termed as "building resilience" by many scholars, urban planners, politicians, and the greater public. In the most basic form, "resiliency" is used as a metaphor to describe the ability for a system to absorb a shock and bounce back into a new normalcy. Initially applied in the physical and natural sciences, "resiliency" has since been used to describe the adaptive capacities of individuals, human communities, and larger societies (Norris et. al. 2008). Outside of academia, policymakers have used the term on local, national, and global scales for various reasons. Potential resiliency-related policy includes promoting sustainable development, effective water policy, energy efficiency, and ensuring preparedness against shocks such as natural disasters, terrorism, economic crisis, and other forms of disruption. Whether the policy is initiated to ensure resilience against anticipatory or completely unexpected events, "building resilience" has nevertheless become a noble crusade in global context. Hence it is assumed that promotion and initiation of resiliency-related policy will increase future sustainability and adaptability and decrease recovery time and suffering. 
Historically, the concept of resilience has been most applied in the realm of psychology, as it was used to describe an individual's "process of, capacity for, or outcome of successful adaptation despite challenging or threatening circumstances" (Matsen, Best, and Garmezy 1990). Having heightened resilience in a given situation allows for fluid response to change and possession of "adaptive capacities," or resources with dynamic attributes. The term "adaptive capacities" is important in examining resilience, as it has taken on various connotations and roles in the preparation and response process. According to Klein et al. (2002), "adaptive capacity" is defined as the ability to plan, prepare for, facilitate and implement adaption options. Factors determining a group or society's adaptive capacity include its economic wealth, technology and infrastructure, the information, knowledge, and skills it possesses, the nature of its institutions, its commitment to equity, and its social capital (Smit and Wandel 2006). Building resilience and possessing adaptive capacities implies that people, groups, and societies are dependent upon certain assets or resources in responding to crises. This dependency relates to communities and individuals whose social order, livelihood, and stability are a direct function of their resource production and localized economy (Machlis 1990). Thus the physical and mental resources available prior to and following instances of shock will have a direct impact on the population involved.

Varying definitions of resilience are also found in the policy realm. Thus applying the multiple uses to global policy requires consideration of many different variables. Adger (2000) contextualizes the indicators of socially constructed resilience through two overarching premises. The first premise is the nature of economic growth, and the 
stability and distribution of income among populations or persons within an environment. In the context of environmental risks and hazards, economic stability is directly tied to the variance in an environment, or whether certain natural events, such as droughts, floods, or diseases on agricultural systems are more likely. The stability of livelihoods can be directly tied to economic well-being and an overall stable economy. Formal sector employment, crime rates, demographic factors, and other culturally defined variables all are taken into consideration in the building of resilience in this form (Adger 2000). It is important to note that resilience is not a one-size-fits-all concept, therefore the ability to build resiliency within the context of a given culture is vital to its success. Adger's second theme is defined through demographic make-up. The rate of mobility and migration within a given population can determine their state of resilience. Yet this is also specific to a population and type of migration, as significant population movement can be evidence of instability or stability. Such flows of resources and demographic composition can help to reduce particular dependency upon a specific resource and thus enhance resiliency in the context of a disaster (Adger 2000).

As highlighted, global, national, and local actors have assumed resilience to be an optimal solution to many of their problems. Yet the notion of "resilience" has not gone without scrutiny on the academic front. According to O'Hare and White (2013), "Resiliency is matched neither by certainty regarding its definition nor by agreement regarding its application through policy and practice" (O'Hare and White 2013). The April 2013 special edition of Planning, Practice, and Research devoted an entire special edition to critiquing resilience in its various forms, and the academics have uncovered 
many flaws in resilience promotion. The combination of studies concluded that there is a series of disconnects between three key areas--meaning, policy milieu, and place - all of which are brought into sharp focus by the integrative, political, and special dimensions of planning (O'Hare and White 2013). Thus resilience planning is often divorced from meaning and is abstracted from the realities of the world of practice. This causes resilience planning to succumb to ambiguity and results in the failure to connect with practical solutions.

In addition to ambiguity, the overtly positive narrative of "resiliency" has replaced negative discussions of climate change and vulnerability, according to McEvoy, Funfgeld, and Bosomworth (2013). Their analysis suggests that this shift could have unanticipated consequences, such as allowing the harsh realities of climate change to escape the minds of the public in favor of abstract notions that promote false or absent strengthening.

Davoudi, Brooks, and Mehmood approach resiliency by stratifying it into a fourdimensional framework: persistence, adaptability, transformability, and preparedness. The dimensions are stratified further according to three broad perspectives: engineering ecological, and evolutionary. The researchers discovered that engineering (persistence focused) interpretations dominate policy expressions, which ultimately fail to explore alternative features at different temporal and physical scales (Davoudi, Brooks, and Mehmood 2013). Thus the words spoken and plans drafted in promotion of resiliency could very likely result in ineffective decisions and empty promises. 
Unfortunately, resiliency is swiftly on track to becoming a cliché in the same manner as "sustainability". While "sustainability" was pushed, promoted, and jargonized by governments, businesses, and organizations, the word became, according to the Centre for Policy Studies, "a vacuous buzzword” whose "very looseness and lack of clarity makes it a perfect prefix for any activity where approval is being sought." (Jamieson 2009). Resiliency has not achieved the same amount of overt criticism or standard of cliché as of yet, but it is undoubtedly headed in the same direction of ambiguity. For example, Time magazine published an article entitled "Resiliency, Inc.", and claims that "'Resilience' has become the new buzzword inside the Pentagon. It's shorthand for "our Army's too small to fight the wars we've been fighting." (Thompson 2012). Thus the word is becoming questionable in many spheres beyond disaster management and should be used with caution.

This section has provided a review of literature on the utility of "resiliency" in a disaster mitigation context. The narrative of resiliency has many positive connotations and may be useful to communicate political concern over threatening environments. The trajectory of the term's practical value is not positive, however, as nebulous and unwarranted use of the term has diluted its value and allowed for intense and justified critique by the academic community. The proceeding section examines another metric of hazard mitigation in the form of economic risk.

III. Modeling Risk According to Economic Metrics 
Defining conceptual and numeric forms of risk is exceptionally difficult for the academic and policy community. The previous sections have elaborated on attempts to conceptualize risk by individuals and collective entities, as well as through buzzwords used to rally the public into action. Economic loss is another important risk-framing mechanism requiring consideration. Specifically, economic risk resulting from natural disasters has been a concern of the insurance industry and government for an extended period of time, but is increasingly being recognized as an important part of urban planning and business strategies for risk control and reduction (Tseng and Chen 2011). Economic risk must be examined prior to Hazus analysis given the economic loss models and outputs that the tool provides.

To successfully examine the varying definitions of economic risk, an employment of Jasanoff"s metrics for the broader term of "risk" can also apply to "economic risk". The academic realm has taken a careful analytic eye to the framing of economic risk by policymakers, planners, and other relevant persons. Most definitions fall within Jasanoff's first and second categories, and are relevant to prescription of policy after the assessment of the known risk. Many of the economic risk definitions tend to employ the word "resiliency" or "economic resilience" when examining the disaster scenarios to assess a region's preparedness. Resiliency in an economic sense can be roughly defined as the ability to cushion or mute potential monetary losses from a natural hazard, and can be applied to individual firms, households, institutions, and the economy as a whole (Rose 2004). 
Recent trends in national natural disaster policy show an increasing emphasis on the mitigation of prospective losses in order to determine which risk-reduction strategies should be employed to save the most amount of money if the event occurs. This information is of significant importance to emergency planners, civil protection services, local government agencies, and reinsurers, as well as global organizations such as the United Nations and World Bank (Erduran and Lindholm 2012). In addition to organizational use, the monetary estimates allow residents of the risk-prone area or building to translate their personal risk from the abstract (i.e. you will possibly have structural damage) to reality (i.e. you will lose $\$ 50,000$ in structural damage).

Thus it is useful for policy-makers to have a grasp of the potential losses and fund riskmanagement strategies accordingly. Yet, as this thesis attests, no loss estimation methodology is perfect. The specific processes used by Hazus, the user capabilities, and input data substantially affect the output. Rose (2004) highlights the varying approaches in hazard estimation and asserts that the sounder the data, the more reliable and accurately reflective the results. The type and source of data used can vary drastically from using sources of primary data (i.e. questionnaires, interviews, and telephone surveys), secondary data (government agencies, philanthropic organizations, and private companies), or independent research. Statistical data, macroeconomic models, deterministic simulation analysis, and stochastic simulation analysis also exist to assess risk (Rose 2004). Hazus uses purely quantitative data to measure economic risk, which as will be explored in Chapters 3 and 4, can be beneficial or harmful to the overall output. 
Cochrane (2004) highlights the problems with using economic loss as a metric for calculating risk. His assessment concluded most problems to stem from double counting, failure to clearly identify an accounting stance, ignoring non-market losses, confusion as to whether post disaster economic trends are a product of the event or some other unrelated factor, and the employment of too limited of a timeframe (Cochrane 2004). Furthermore, variables such as the loss of leisure, a sense of place, historic monuments/cultural assets, and governmental services have monetary values as well, but are never included in these types of assessments produced through tools such as Hazus.

The decision to calculate for direct vs. indirect losses has the largest effect on the output of a risk-estimation study. For example, an earthquake may cause a building to collapse, with the direct losses arising from building replacement costs and inventory losses - all related to physical materials. Indirect losses, however, are considered on a long-term basis and can include measurements of lost profit upstream and downstream to the businesses hit in the building. Insurance to account for these indirect and costly losses is lacking, and leads to hampered recovery and misperception of risk. Methods exist, however, to measure the potential loss. More detail on the methods employed by Hazus will be explored in Chapter 3 .

Assessment tools such as Hazus provide information to allow the at-risk parties to see the hazards either as legitimate or unworthy of their attention. Measurement tools can therefore make a substantial difference in defining the metric for risk characterization and enactment of risk-reduction strategies. As noted, performing risk-reduction strategies and enacting policy is a function of wealth, or the amount of safety that a community can 
afford given the variety of interests at play. Damage estimates provided by Hazus will explicitly influence these decisions by providing cost estimates and influencing stakeholder perception. If the model does not account for the full spectrum of loss, however, certain parties will be disinterested and fail to take proper steps to mitigate the hazard at hand. Thus the accuracy of the models is of absolute importance in assessing risk.

\section{Conclusion}

This chapter has provided a review of literature surrounding risk, resiliency, and economic values as a metric for risk in relation to natural disasters. These topics offer conceptual background for proceeding analyses of hazard knowledge in the Portland area, the use of Hazus in measuring risk, and the consequences of failing to account for all vulnerabilities within a region. The next chapter will examine the history of geologic knowledge in order to give a rounded understanding of the variables that should be accounted for in analyzing seismic hazards and their prominence in Portland, OR. 


\section{Chapter 2: Geology, Earthquakes and Building Resilience in Oregon}

Conceptualizing and predicting earthquakes is a relatively recent phenomenon. Until the twentieth century, the sporadic nature of earthquakes and inability for scientists to travel globally and communicate in a rapid manner prevented the field from being closely examined. The knowledge on earthquakes and the geology behind them has progressed significantly in the past forty years. This chapter describes how present geologic knowledge on earthquakes developed in a national and Pacific Northwest context. The two tracks of knowledge are related, yet distinct in their realization of risk to the relative locations, and each uniquely nonlinear in their contributions to geologic knowledge.

First, the chapter will provide information on the history of national support for earthquake research and the role of government in managing earthquake knowledge. An overview of plate tectonics will be offered to give context to the present-day known risks and the variables to be accounted for when assessing risk. The chapter will then give a historical account of the consciousness of seismic risk in the Pacific Northwest to set a framework for assessing Portland's current status of preparedness. Finally, this chapter overview the policies produced in response to the risks. This information is important to consider prior to discussions on Hazus, its history, the assumptions behind the tool, and disaster loss models in general.

I. The Evolution of National Earthquake Knowledge

Various factors in the 1960s allowed for the advancement of seismic and geologic knowledge. First, the establishment of the Worldwide Standardized Seismograph 
Network (WWSSN) significantly added to the ability to monitor earthquake activity (R. Yeats, Sieh, and Allen 1997). The purpose of the WWSSN in 1961 was twofold: first and more publicized, to monitor geologic movement, and second, more discretely important, to detect underground nuclear weapons testing by the Soviet and Chinese governments (R. S. Yeats 1998). Thus the Worldwide Seismograph Network (WWSSN) was born and built across the world in the name of geology and national security.

While the WWSSN was in place in 1960, national attention was not drawn to reducing earthquake hazards until the 1964 Good Friday Alaskan earthquake (Mileti and Fitzpatrick 1993). Earthquakes were common in California and happened infrequently in other various parts of the United States, yet a singular approach to deal with earthquakes was not formulated by the federal government up until that point. Because of the slim scientific knowledge, earthquakes were designated as a freak occurrence and hypothesized to occur anywhere in the United States. California in particular, with observable high seismic activity, repeatedly pronounced earthquakes as invariable and not particular to the state in order to rationalize the continued development and discount the region's seismic past and future risk (T. Steinberg 2006). The 1964 Alaskan earthquake was cause for concern, as the horrendous devastation that occurred in the sparsely populated Alaskan countryside demonstrated the potential for enormous losses in other parts of the United States (Hamilton 2003). Thus the opportunity for American people to see earthquake damage through their television screens and national media undoubtedly contributed to increased public awareness and outcry for governmental research on these bizarre events. 
In response to the public call, President Lyndon B. Johnson directed the National Academy of Sciences (NAS) to conduct a comprehensive study of the Alaskan disaster, the first time in national history that a multidisciplinary approach was used to investigate a damaging earthquake. As of that time, geologic knowledge was not advanced, as a 1966 panel chaired by the USGS noted, "All areas of the United States experience earthquakes at some time and no area should be considered as free of potential earthquake hazard." Additionally, the 1966 panel stated that "many moderate, a few severe, and probably one great earthquake can be expected within the United States between now and the year 2000. Billions of dollars in damage may be expected and loss of life may be hundreds to thousands." (Mileti and Fitzpatrick 1993). The organization and panel's comments on potential earthquake damage demonstrate the scientific ignorance and lack of knowledge on earthquake science.

The United States substantially increased research and funding for geologic pursuits over the twenty years following the Alaskan Good Friday earthquake. Most of these efforts, however, were done under separate bureaucratic or ad hoc organizations. The competition among disciplines and between agencies, combined with the waning concern after the Alaskan earthquake, contributed to a lack of budgetary attention to the earthquake threat (Hamilton 2003). Thus the mangled coordination and uncertainty of earthquake events, their estimated location, and the science behind it prevented national insurance policies and localized state awareness from ensuing in the United States.

As outlined thus far, the fragmented studying of earthquakes in the 1960's and 1970's by the federal government prevented national earthquake policy from being produced. 
However, the ability to monitor seismic activity on a global basis allowed for the Theory of Plate Tectonics to reach fruition in the 1960s. Geologists were able to produce this theory with improved knowledge on earthquakes and crustal movements, largely due to the WWSSN. This theory states that the earth's surface consists of a series of tectonic plates. Each plate consists of the crust and the lithosphere, or more rigid part of the upper mantle containing all of the world's earthquakes, all of which is underlain by the weaker asthenosphere zone (R. Yeats, Sieh, and Allen 1997). With this theory in place geologists could begin to explore the exact location of the separate plates, eventually leading them to discover more information on seismic activity and risk.

It was not until 1977, however, that the Earthquake Hazard Reduction Act of 1977 was enacted. This act established the National Earthquake Hazards Reduction Program (NEHRP). The initial objectives of NEHRP included the following (R. S. Yeats 1998):

- Retrofit existing buildings, especially critical facilities such as nuclear power plants, dams, hospitals, schools, public utilities, and high-occupancy buildings;

- Design a system for predicting earthquakes and for identifying, evaluating, and characterizing seismic hazards;

- Upgrade building codes and developing land-use policies to consider seismic risk;

- Disseminate warnings of an earthquake and organizing emergency services after an earthquake;

- Educate the public, including state and local officials, about the earthquake threat, including the identification of locations and buildings that are particularly susceptible to earthquakes; 
- Focus existing scientific and engineering knowledge to mitigate earthquake hazards, and considering the social, economic, legal, and political implications of earthquake prediction; and

- Develop basic and applied research leading to a better understanding of control or modification of earthquakes.

Routinely underfunded and structurally challenged, NEHRP had substantial difficulties in reaching any of the aforementioned goals. Furthermore, the organization was faced with the unsolvable challenge of formulating a sound earthquake prediction model. The seventies and early eighties were marked with optimism for crafting a model, yet by 1983 NEHRP became more realistic about whether or not this scientific feat would be possible (Nigg 2000). By the mid 1980's, NEHRP's efforts shifted away from immediate predictive models and into long-term forecasts.

Eventually, NEHRP became coordinated to compliment multiple other agencies including the Federal Emergency Management Agency, the National Science Foundation, the National Institute of Standards and Technologies, and the United States Geological Survey (FEMA 2013a). Over time NEHRP has served many important roles in the formation of a national identity to responding to natural disasters. Figure 2.1 below demonstrates the multiple functions of NEHRP and the organizations operating within it. 


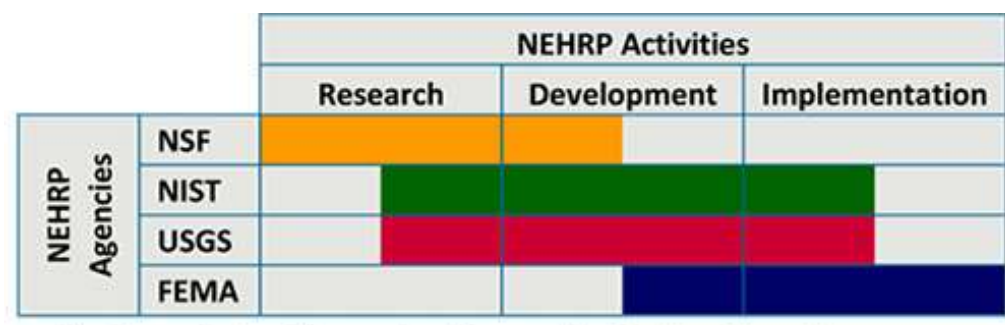

National Earthquake Hazards Reduction Program

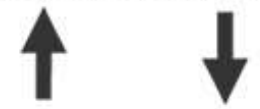

Earthquake Risk-Reduction Partners

Natural and Built Environments

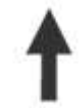

Earthquakes

Figure 2.1 Organizations and Functions within NEHRP (FEMA 2013b)

As shown above, the United States Geological Survey (USGS) performs earthquake research under NEHRP and receives the largest portion of its funding. The USGS pursues four general goals in the contribution to earthquake knowledge: 1) understanding what happens at the earthquake source; 2) determining the potential for future earthquakes; 3 ) predicting the effects of earthquakes; and 4) developing applications for earthquake search results (R. S. Yeats 1998). Therefore the progress of the USGS can play a major role in the progression of earthquake knowledge, establishing earthquake policy, and fostering awareness of given hazards.

This section has outlined the political structures that have set earthquake research agendas and furthered seismic awareness on a national level. The creation of NEHRP provided substantial progress in the pursuit of geological knowledge on earthquakes and how to properly prepare for them. The establishment of an umbrella agency to monitor 
earthquake activity, centralize the study of and advancements in seismic knowledge, coordinate recovery activities, and distribute federal funding helped to elevate the status of geologic epistemology and give value to their warnings to the greater public. This information is useful in the examination of Hazus and consideration of seismic risk awareness.

\section{A Brief Earthquake Lesson}

The previous section explained the progression of earthquake knowledge on an organizational level. The following section will present a basic framework on the geologic nature of earthquakes. It is of absolute importance to have a basic understanding of the science behind earthquake risk in order to critique the tools that attempt to model the phenomena's behavior.

As shown in Figure 2.2 below, the most common earthquakes are caused due to the descent of the lithosphere into the asthenosphere. The standard premise of earthquake theory asserts that as new crust is made and plates shift, old crust must be destroyed at the same rate as plate creation, as the Earth must remain the same size throughout time (R. S. Yeats 1998). Determining plate movement is done by observing change in the Earth's magnetic field preserved in oceanic crust and by drilling core holes in the deep-ocean floor to determine the age of the oldest sediment overlaying the basaltic crust at various places (R. Yeats, Sieh, and Allen 1997). 


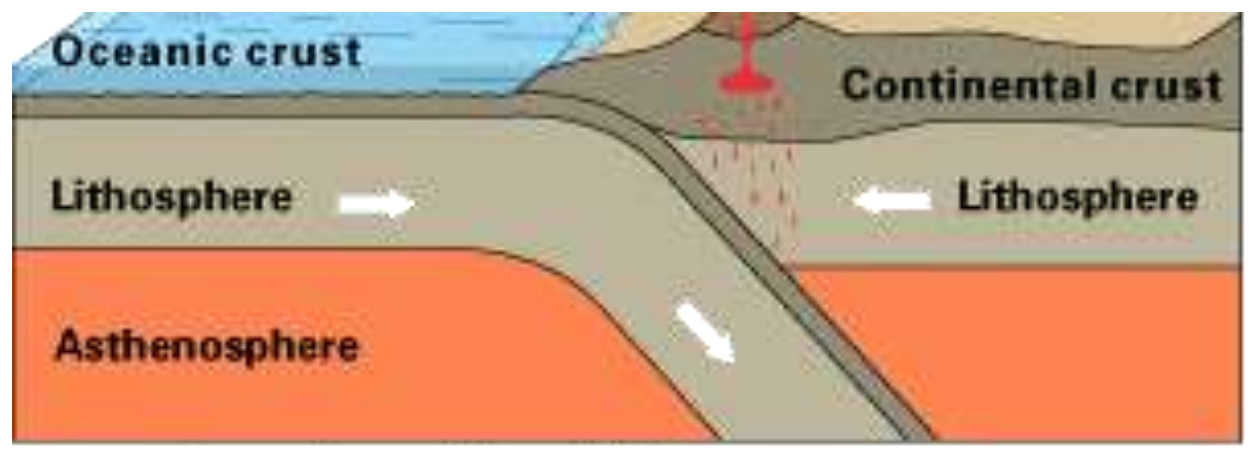

\section{Qceanilecontinental conver gence}

Figure 2.2 Lithosphere Descent (USGS 2012)

The epicenter of an earthquake is defined as the point on the surface of the earth that is directly above the focus, or place within the earth where the earthquake rupture starts. The discovery of epicenters and investigation into soil type has substantially helped to further earthquake knowledge. Prior to seismographs, the epicenter was generally assumed to be the place where the damage was the greatest. Geologists eventually discovered, however, the degree of damage to be more strongly influenced by nearsurface ground conditions and by the progression of the fault rupture than by proximity to the epicenter (R. Yeats, Sieh, and Allen 1997). The type of soil a building, city, or larger area sits upon has more of an impact on damage inflicted than proximity to the epicenter.

Generally, harder soil equates to less damage. This is due to the way waves travel through soil. The soft soils will amplify the seismic waves, which results in much more vigorous shaking than would be expected at a rock site (R. S. Yeats 1998).

Soil will provide the highest amount of risk when it is sandy, soft, or weak in nature. Geologists equate a high level of unstable soil, also known as liquefaction, to Jell-O, claiming that buildings that stand upon Jell-O have a harder time staying intact than 
buildings atop rock. Liquefaction is defined as the act or process of transforming any substance into a liquid. In a geologic sense, liquefaction refers to the time in which a saturated soil loses substantial amount of strength due to high excess pore-water pressure generated by and accumulated during strong earthquake ground shaking. This type of vulnerability is the hardest to structurally mitigate and typically provides the most amount of threat to regions.

This section has noted the advancement of earthquake knowledge and risk that accompanies geologic and seismic tendencies. Despite the increasing amount of information, no substantial method has been developed to seriously predict earthquakes. Geologists know that tectonic plates will move, but there is no underlying theory stating explicitly why they move as they do. The absence of this information is the greatest hindrance in allowing geologists to holistically understand earthquakes. Elaboration on this problem will be explored in later sections of this chapter.

\section{Pacific Northwest Earthquake Awareness}

The previous sections have presented the evolution of geologic knowledge on a national scale. Undoubtedly, the slow progression of this knowledge contributed to unnecessary fear for those in non-hazardous areas, as well as lack of awareness of risk in areas of high seismicity. Most of the Pacific Northwest and Portland in particular, were blindly unaware of their earthquake risk until the 1980's, making the region very late to the earthquake awareness game. Sporadic minor earthquakes in British Columbia and Washington allowed for geologists to realize the possibility, but no serious work to 
search for seismic risk within the region was done until the 1980s. Up until then, geologists believed the Cascadian region to have the lowest instrumental, geographic, and historical distribution of earthquakes, also known as seismicity, of any subduction zone on the margin of the Pacific Ocean, and insisted that the near faults posed no major risk to the populated cities in the Northwestern US. At the time, geologists insisted that the Cascadian fault was so different from other similar zones and thus shouldn't be considered worrisome (Monroe 1987a). Furthermore, the lack of national recordkeeping on seismic activity prevented the region from knowing whether or not a serious earthquake occurred in the past 300 years. Geologists, therefore, were skeptical of serious seismic risk in the Oregonian region.

The start of Oregon's large wake-up call came to the Pacific Northwest in the early 1980s. In 1983 John Adams, a New Zealand geologist, while working for the Geological Survey of Canada stated that there may be an earthquake hazard in the Pacific Northwest. Adams discovered this by comparing old US highway survey marker level lines with recent ones and found substantial changes in the relative elevation of these monuments, thereby providing evidence of the slow buildup of tectonic strain (R. S. Yeats 1998). Adams' findings, however, were mostly ignored by the public and greater scientific community and were not considered to be substantial evidence for concern.

Further progress came in 1984 with a published comparison of the Cascadian Subduction Zone to others around the world. This study, performed by Tom Heaton and Hiroo Kanamori from the California Institute of Technology, found the Cascadian Subduction Zone to be comparable in risk to other subduction zones which have had earthquakes 
greater than magnitude 8 within the past century. Despite this announcement, many were still very skeptical about the risk of a major earthquake in the Pacific Northwest.

Finally, to quell the rumors in the scientific community, the Oregon Academy of Sciences held a scientific workshop in February of 1987 entitled, "Is there a major earthquake hazard in Oregon or not?" This conference was attended by both supporters and skeptics of a major Cascadian fault. The atmosphere at the conference was "electric" and the

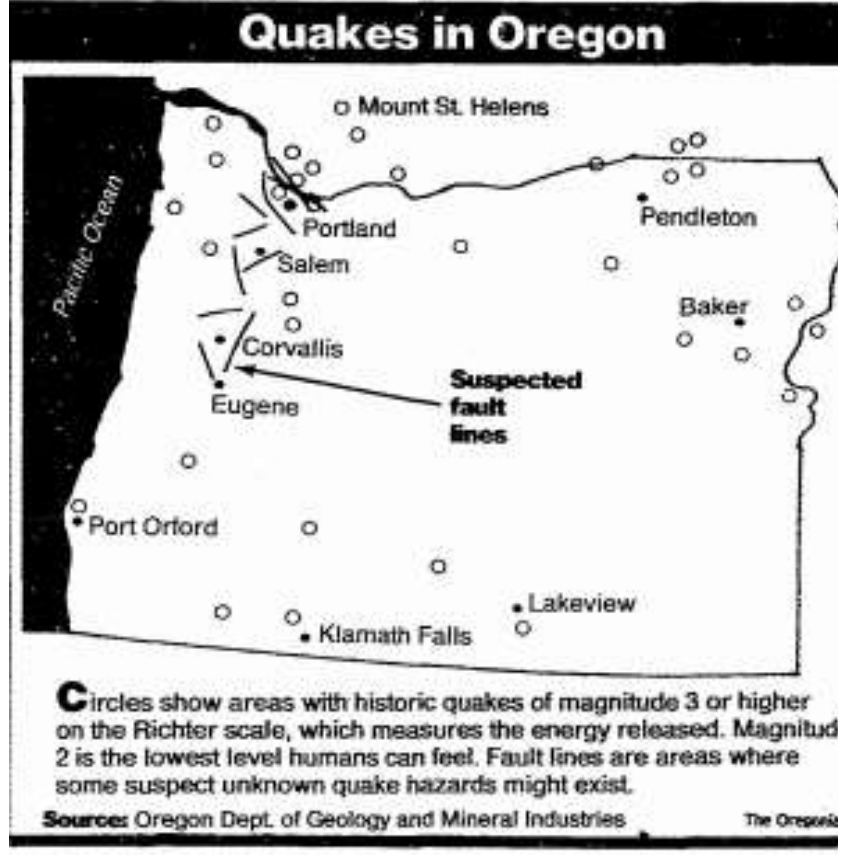

Figure 2.3 Extent of Earthquake Awareness in Oregon, 1987

presentations by proponents

eventually won over the skeptics, marking a paradigm change in thinking about earthquakes in the region (R. S. Yeats 1998). A reporter from the Oregonian was in attendance and relayed the paradigm shift to the greater public. 
This Oregonian article, published on February 26, 1987, provided readers with introductory information on the seismic risk in Oregon. The Oregonian newspaper clips presented in Figures 2.3 and 2.4 portrayed to the Oregon public the estimated location of the Juan de Fuca plate and fault lines in Oregon. The author also included dramatic descriptions of the 1985 Mexico City earthquake, noting that Oregonians felt relief at the time of that earthquake because they believed "it can't happen here" (Monroe 1987b). The article attests to the uncertainty of earthquake risk, but also notes that most of Oregon's buildings were designed and built at a time when Oregon was thought to be one of the lowest earthquake-hazard zones in the country. Monroe realizes public and scientific disconnect by noting the lack of seismic knowledge "despite the fact that the state is sandwiched between two earthquake-prone areas California and the Puget Sound."

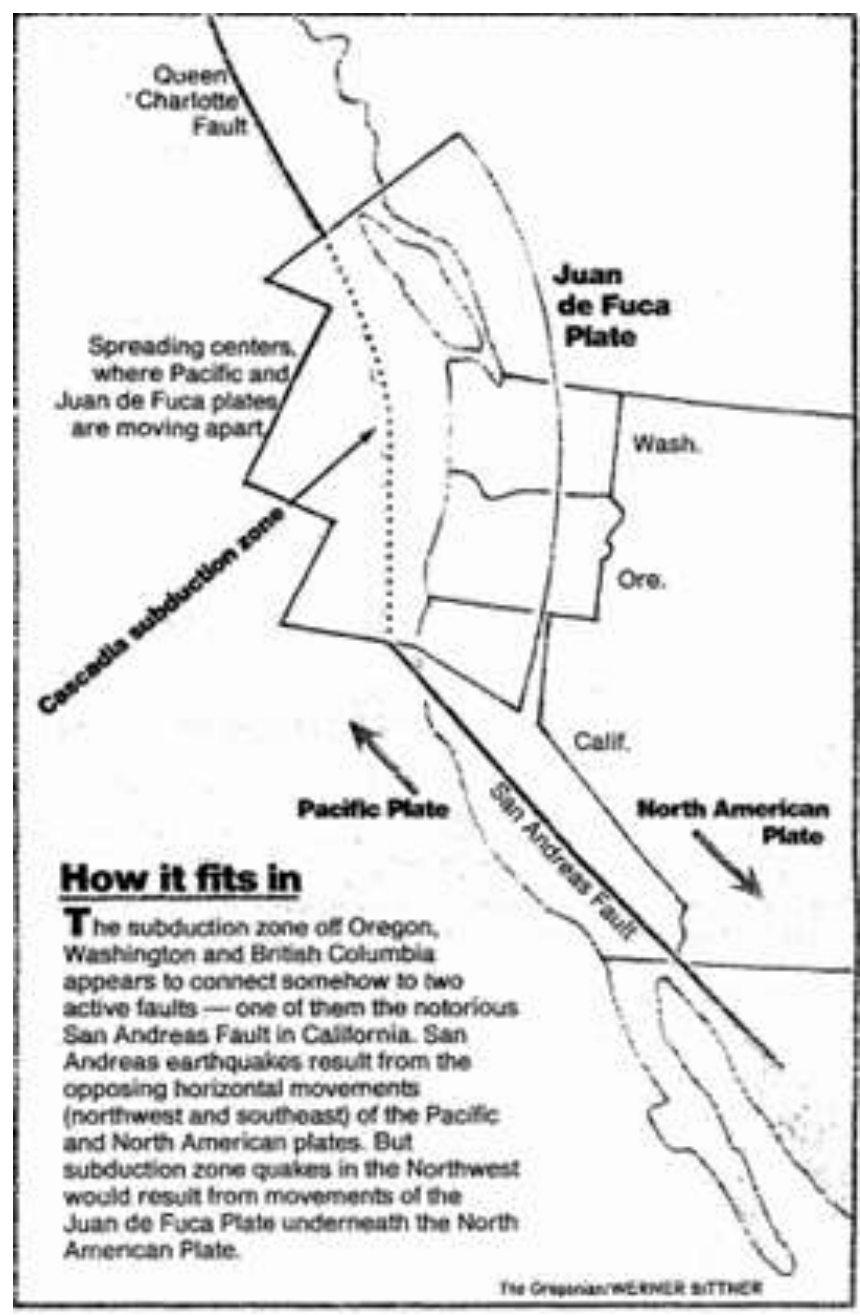

Figure 2.4 Extent of Earthquake Awareness in Oregon, 1987 (Monroe 1987b)

(Monroe 1987a). 
A later article, published on December 17, 1987, presented the facts on Oregonian risk, noting that muddy marsh banks, land deformation, computer models, and statistics suggest that the Northwest should prepare for a big jolt. These warnings, however, were accompanied by a cautionary remark from seismologist Thomas Heaton, "All these pieces don't nail the coffin, but certainly they would be pretty hard to explain without earthquakes.”(Monroe 1987b). Other skeptics at the meeting noted that sediments are lubricating Northwest subduction and preventing strain from building up, thereby providing evidence against a large Cascadian fault. Thus a concrete agreement could not be reached between scientists, confusing the public at large and preventing political address of the issue.

Debates over the specificities of the potential Oregon quake continued into the 1990s. A particular concern was of the historical patterns of the Cascadian fault. Academic debates were held on whether the geologic evidence pointed a "decade or two of terror" in the form of many small Cascadian earthquakes, or an "instant of catastrophe" (R. Yeats, Sieh, and Allen 1997). Much of the debate subsided with the publication of research by Jim Savage and his colleagues of the USGS in 1991. Savage and his team performed repeated measurements of surveying benchmarks around Seattle, in Olympic National Park, and at the Hanford Nuclear Reservation in Washington. Following prolonged observation, they concluded these networks showed the crust to be slowly deforming by built up elastic strain. The team additionally concluded that there were no minor earthquakes or "decade of terror" in the subduction zone. Evidence was provided to determine the subduction zone to be completely locked, thus strain will build up along 
the zone at 1.6 inches per year until the zone eventually ruptures in a massive earthquake (R. S. Yeats 1998).

Skeptics remained despite the aforementioned geologic evidence. The closing confirmation of a single, large Cascadian quake was provided from across the Pacific, surprisingly enough. Historical accounts of an eighteenth century Japanese tsunami and tree-ring dating were discovered in the mid-nineties to provide the much-needed historical anecdotes for geologists. Japanese records at five different coastal sites stated that on January 27 and 28, 1700, a tsunami hit the coast and produced waves as high as 9 feet. Process of elimination by geologists concluded this tsunami to be a direct result of a singular Cascadian quake (Satake et al. 1996). Furthermore, computer models concluded this wave to be a result of a magnitude 9 quake, as a magnitude 8 would not have left a noticeable tsunami in Japan. The final concluding evidence of a large rupture was provided through trees on the coast of northern Oregon and Washington. The trees were sampled at the core, cross dated, and checked for irregularities in growth that indicate seismic shaking disturbances. This team of researchers concluded a serious disturbance in growth to have occurred between the growing seasons of 1699 and 1700 , and that their analyses gives independent evidence for a subduction earthquake that could be related to the historical tsunami of January 1700 (Jacoby, Bunker, and Benson 1997).

With written historical anecdotes and tree rings to supplement the geologic evidence, geologists and seismologists finally agree with a fair degree of confidence on the movements of Juan de Fuca and its potential impact on Oregon. They maintain that new oceanic crust is being created at the Juan de Fuca Ridge in such a way that the Pacific and 
Juan de Fuca plates are spreading apart at a rate slightly faster than 2 inches $(60 \mathrm{~mm})$ per year, and that Juan de Fuca is moving towards and beneath the stable North American continent at a little less than 2 inches $(45 \mathrm{~mm}$ ) per year (R. S. Yeats 1998). Figure 2.5 below displays the movement of the Juan de Fuca as it slides beneath the North American plate.

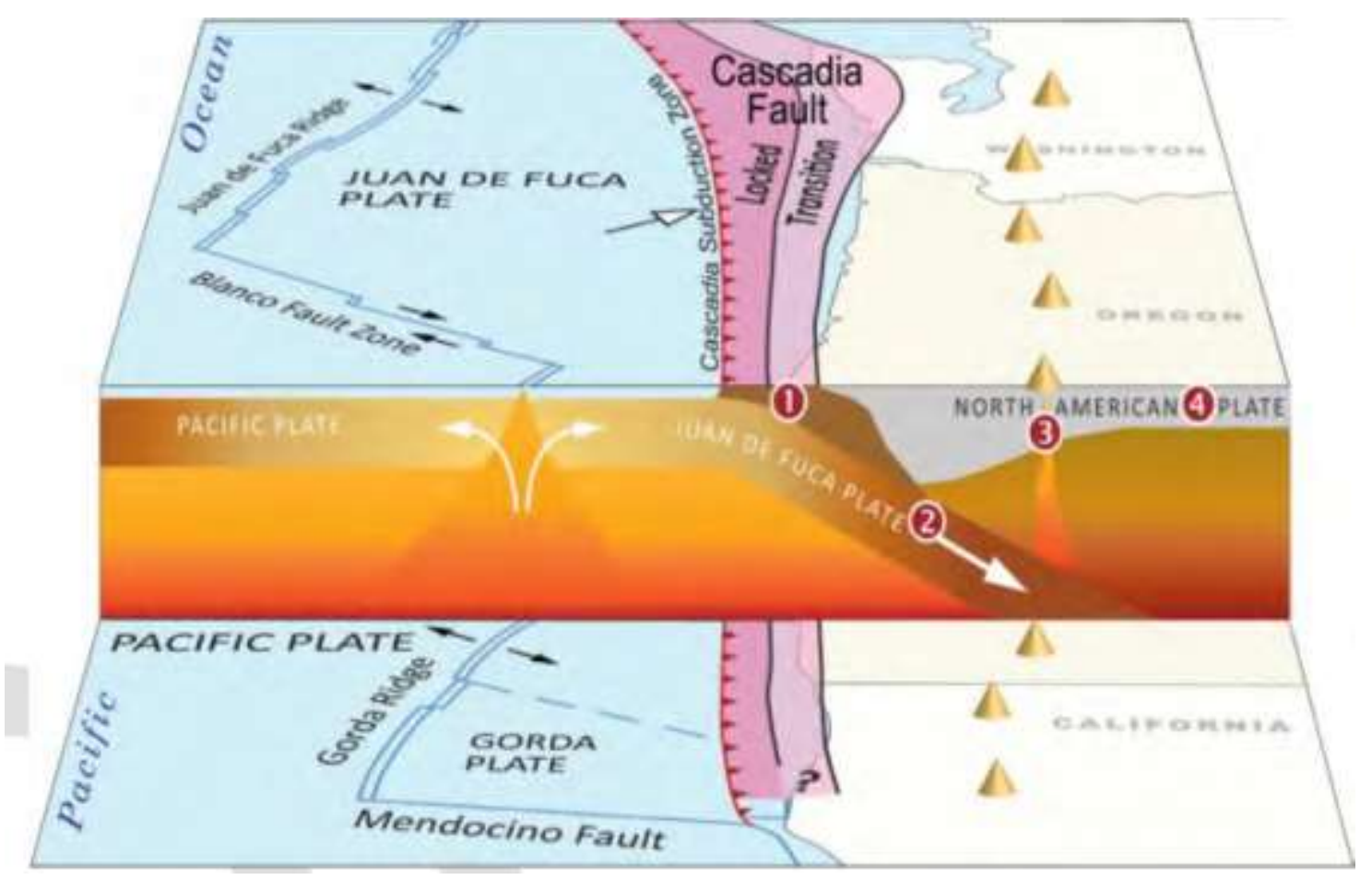

Figure 2.5 The Movement of Juan de Fuca (OSSPAC 2013)

Figure 2.6 on the proceeding page is provided to give context to the Juan de Fuca Plate in relation to the other lithospheric plates of the world. The Juan de Fuca plate sits directly to the left of the North American Plate, which extends all of the way across the United States and Canada and into the middle of the Atlantic Ocean. The Juan de Fuca Plate lies 
off of the Pacific Northwest Coast and is slightly smaller than Washington and Oregon taken together.

The uncertainty of Juan de Fuca is commented on by Yeats (1998): "We know much less about how the motion of the Juan de Fuca Plate with respect to North America is distributed between the subduction zone itself and the active crustal faults east of the plate boundary... if we knew the rates of movement on the crustal faults as well as we do the rates of plate motion, we would be much further along in forecasting the future behavior of crustal faults and of the Cascadian subduction zone as a whole." (R. S. Yeats 1998). In non-geologic speak, Yeats is commenting on the difficulty in knowing how much strain needs to be built, and in what direction, before a major quake occurs.

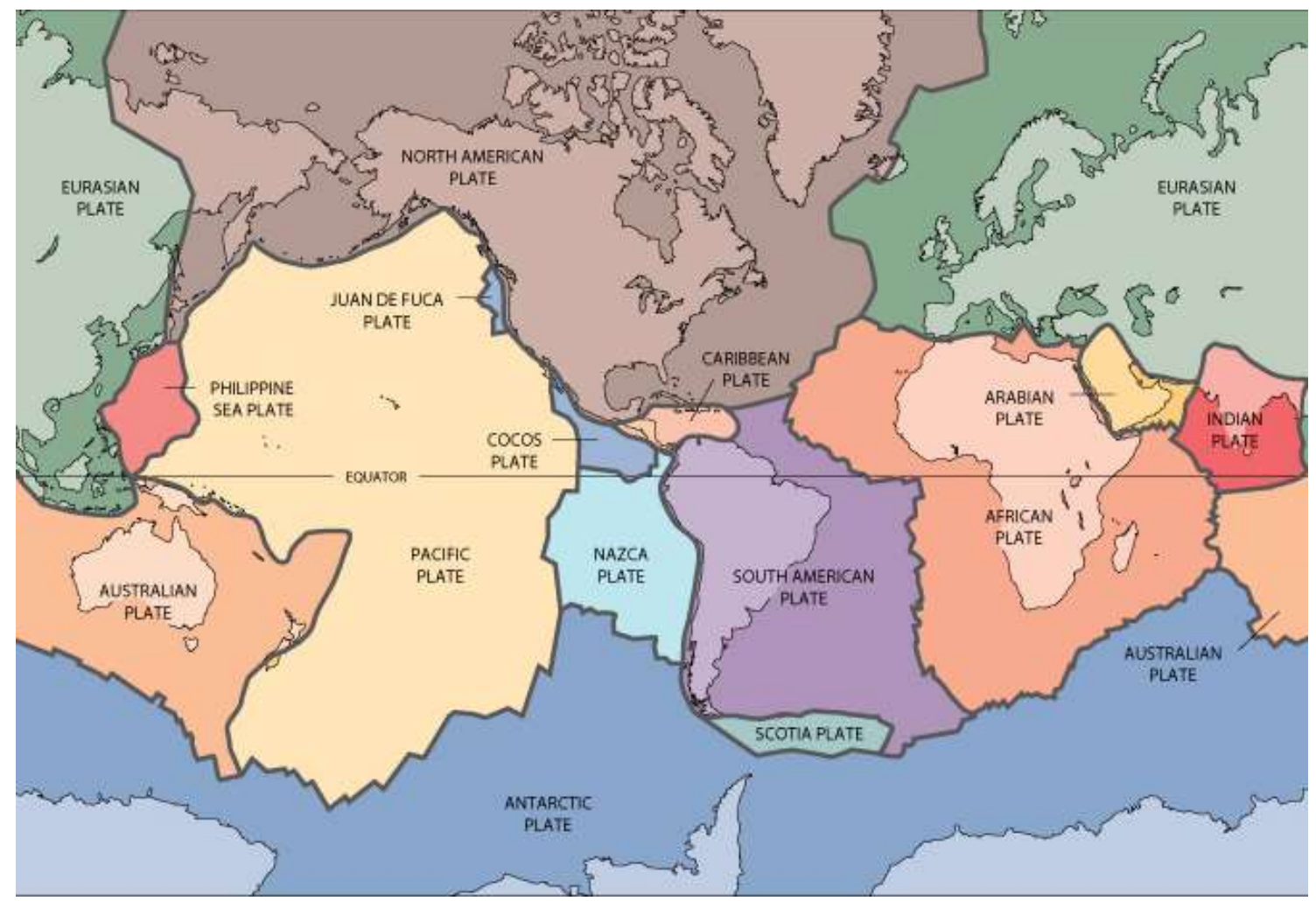

Figure 2.6 Plates Around the World (R. S. Yeats 1998) 
Oregon and the greater Northwest have many reasons to be concerned over Juan de Fuca. The possible rupture of this plate will cost, at least, an estimated $\$ 30$ billion dollars for the state of Oregon alone and wreak havoc on the residents of the area. Portland, specifically, is estimated to lose at least $\$ 17.43$ billion in building stock, according to a Hazus pilot study performed in 1997. Problems with this estimation will be explored in subsequent chapters on estimating economic losses. For now, this section will focus on the specific faults and geologic hazards unique to the city of Portland.

According to Yeats, et al., downtown Portland is next to the Portland Hills Fault extending along the foot of the Portland Hills, as shown in Figure 2.7 below. This fault is approximate 30 miles long and actually is a complex fault zone containing multiple fractures (Hill and Crombie 2001). The Oatfield and East Bank Faults also run within the city limits, and the three faults are essentially parallel to one another.

Geologists are yet debating the riskiness of these faults, however, and

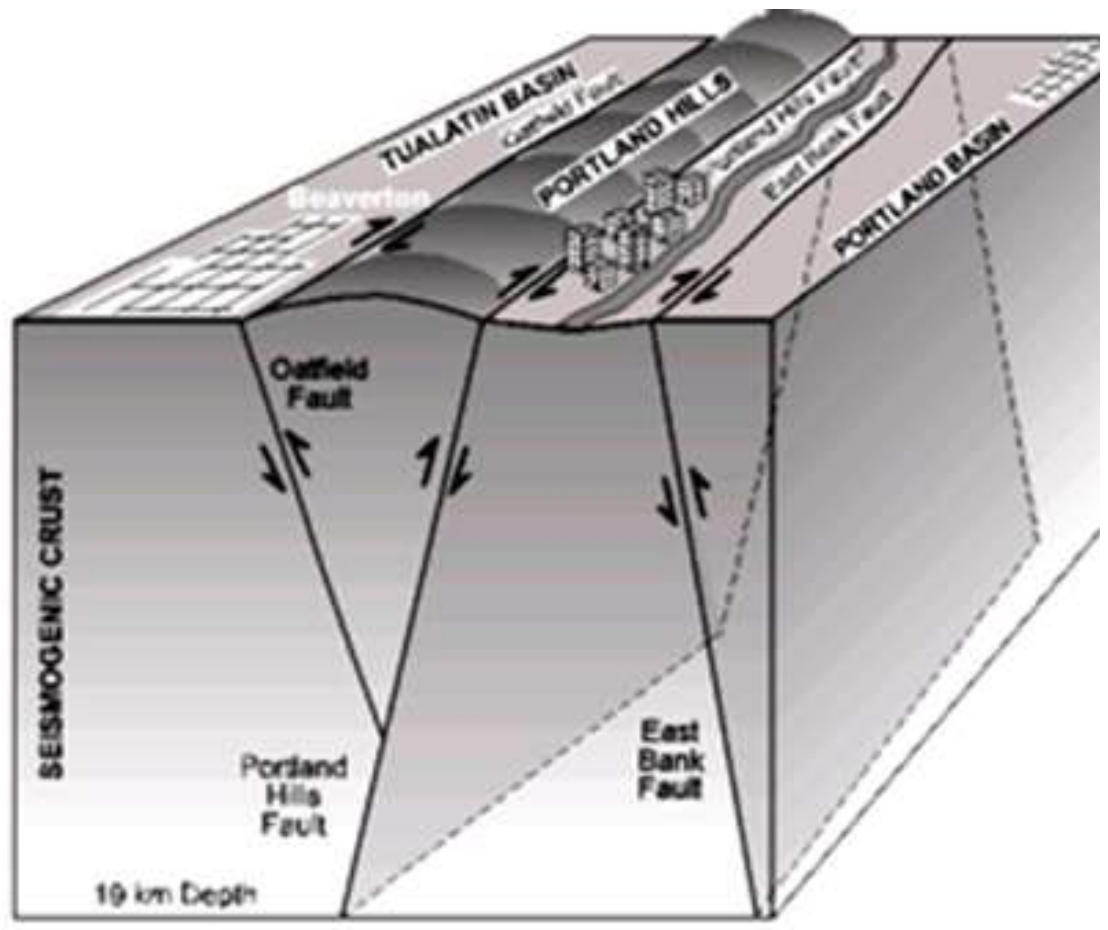
were initially

Figure 2.7 Local Faults in Portland, OR (Hill and Crombie 2001) 
skeptical of the faults' seismicity due to the lack of geomorphic expressions on the land surface and scarcity of historic record (Liberty, Hemphill-Haley, and Madin 2003a).

Eventually, evidence in favor of a heightened activity level for the faults was provided in 2001 following geologic observation during construction at the Rowe Middle School in Portland. Geologist Ian Madin spotted deformed soil layers and speculated that the faults ruptured approximately 10,000 years ago, thus recent enough to be noted as "active" (Hill and Crombie 2001).

Geologic publications on the Portland Hills Fault prior to discovery of active seismicity reiterate the implications that prediction, scientific knowledge, and its influence on planning and development can have on a region. Specifically, Yeats, et al., state in 1998, prior to the active discovery, "The [Portland Hills Faults] can be marked on the maps of areas being considered for urban development, and developers, local government, and potential buyers can

make up their own

minds about the

potential for fault

rupture" (R. S. Yeats

1998). This statement,

in light of the discovery

of activity in the

Portland Hills, supports

the notion that risky

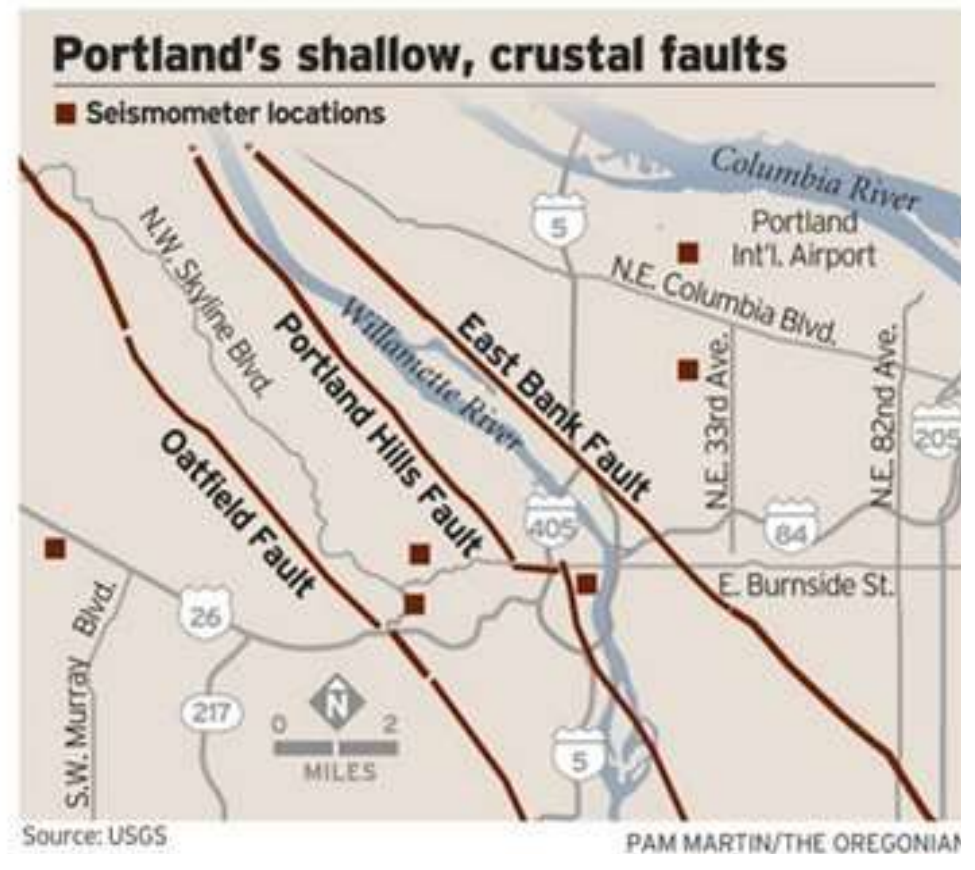

Figure 2.8 Ariel View of Portland Faults (Rojas-Burke 2011) 
and dangerous development can occur without complete knowledge on a given hazard.

The discovery under the Rowe Middle School, in combination with additional tests, has allowed geologists to suggest that the Portland metropolitan region is historically the most seismically active region in Oregon (Liberty, Hemphill-Haley, and Madin 2003b). The faults are much shallower in the earth when compared to the larger, more damaging faults such as Juan de Fuca, discussed previously. Although the largest earthquakes occur along the subduction zone, deep earthquakes occur within the Juan de Fuca Plate, these smaller, more focused hazards exist from the shallow earthquakes ( $<25 \mathrm{~km}$ deep) in the upper crust of the North American plate (Liberty, Hemphill-Haley, and Madin 2003b). The consequences of the smaller earthquakes are not as dire on a state-wide level, but have the potential to cause a considerable amount of damage to the Portland metropolitan region. The strength of buildings, infrastructure, and type of soil these fixtures sit upon will unquestionably have a massive impact on Portland's amount of damage.

\section{Precarious Predictions}

The preceding sections have highlighted the major reasons for Oregon and Portland residents to have concerns. An earthquake or multiple earthquakes are undoubtedly coming. Yet the exact timing of the "big one" and smaller, more local quakes remains a puzzling mystery. The previous sections have explained the evolution of seismic knowledge in a national and Oregonian context. The information presented has highlighted some of the missing gaps in earthquake knowledge. The largest gap, arguably, centers on the ability to predict earthquakes. It is not enough to simply point 
out the fault lines and warn people accordingly. The variability of earthquake hazards relies greatly upon the timeframes provided by geologists for fault rupture and the built environment that is susceptible to damage. The following section will describe the difficulty in defining these risks from geologic, governance, structural, and residential perspectives. Defining risk for the Pacific Northwest according to scholarly literature, geologic knowledge, and governmental perspectives will highlight the variance between the groups.

It is first important to note the seriousness of this issue in light of recent events. The inability of geologists to predict earthquakes and warn the public properly has gathered a considerable amount of attention in the past year. The increased attention is a direct result of an earthquake in L'Aquila, Italy on April 6, 2009. This earthquake killed more than 300 people in L'Aquila, and injured approximately 1,600. As a result, the scientists who knew of the earthquake threat have been convicted with manslaughter for failing to adequately communicate the risk of a possible earthquake (Clark 2012). This group of scientists, known as "The Seven," met one week prior to the earthquake to assess whether a sequence of small earthquakes recently shaking the town indicated a heightened risk of a large, destructive tremor in the near future (Sarewitz 2012).

According to New Scientist, the scientists were not charged specifically for failing to predict the earthquake, as many geologists and scientists fear, but rather failing to communicate the risk of an earthquake. New Scientist notes how the scientists were employed by the Italian government to assess earthquake risk and communicate them to the government and public. The scientists, however, left the communication job to a civil 
protection official with no specialist knowledge of seismology. This specialist then gave a grossly inaccurate reflection of the situation, telling the public, "The scientific community tells us there is no danger, because there is an ongoing discharge of energy. The situation looks favorable.” ("Italian Earthquake Case..." 2012).

The Italian earthquake trial brought hazard and natural disaster prediction into a completely new realm. The realization that scientists could be convicted with manslaughter for having bad public relations instills fear into the minds of scientists and possibly discourages further study of disaster phenomena. Regardless, this case alludes to a larger epistemological problem of scientifically defining risk and presenting that risk to the public.

The uncertainty of a Cascadian fault rupture causes both under preparation and excessive dramatization of the risk. It is understandable for people to underprepare given geologists

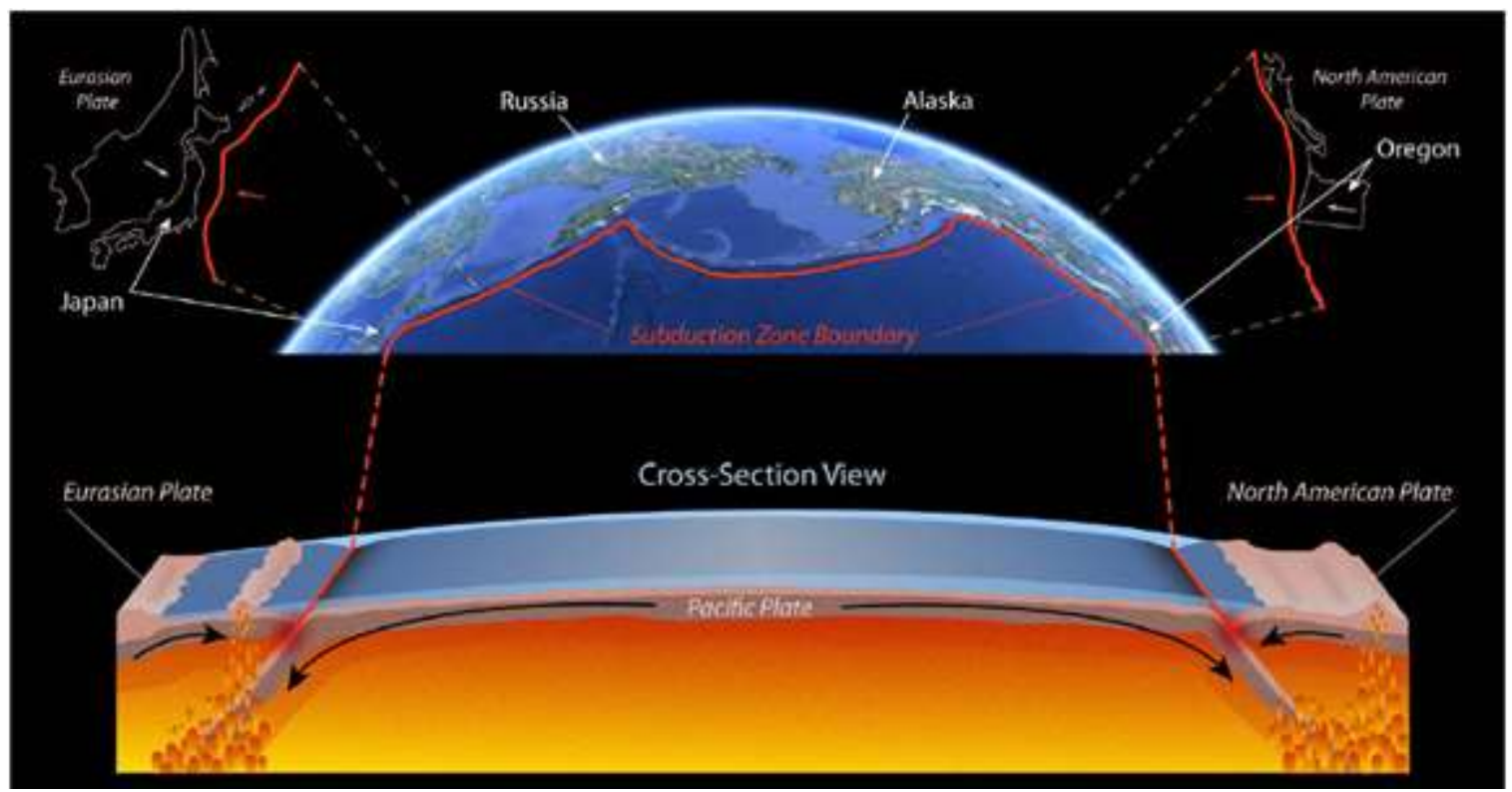

Figure 2.9 Japan as Oregon's Mirror 
predict the fault to rupture anytime in the next three hundred years, and because Portland has not experienced a serious earthquake in the past. Conversely, in light of this seismic realization and geologic relationship, Oregon and the greater Cascadian Zone have been dramatically deemed as a "geologic mirror image of northern Japan." (OSSPAC 2013). Figure 2.9 below, created by Dan Coe at DOGAMI demonstrates the similar placement of each location along the Pacific fault. The decision to equate these two areas communicates to the public that similar devastation that occurred in Japan could indeed happen in Portland.

Despite the difficulty involved in understanding geologic timeframes, demands for earthquake and other climactic predictions from scientists have increased (Oreskes 2000). This has led to an explosive growth in models, including Hazus, and the reliance of models on questionable or unproven scientific knowledge. Prediction is important, however, as it serves two important goals. First, prediction has come to occupy a position of scientific authority and legitimacy, thus if prediction matches an event, public support for scientific theory increases. Second, prediction is needed as a potential guide for decision making (Sarewitz and Pielke 2000). Akin to risk and damage estimations, predictions provide the necessary ammunition for enacting policy to reduce risk to a given hazard and give accreditation to a given scientific body of knowledge. Transferring policy discourse away from politics and morality and onto science allows for political risk to be reduced and rationality to be increased (Sarewitz and Pielke 2000). Prediction to serve political goals must be precluded with caution, however, as Oreskes notes, "If the value of predictions is primarily political or social (rather than epistemic) then we 
may need to be explicit about the uncertainties on the theory or model that produced them." (Oreskes 2000).

Uncertain and faulty models have wreaked havoc on the geologic community. Many false predictions have been made that have caused the public to question science and geology. In the past, scientists have claimed to have discovered the means to predict quakes on specific dates, notified the press, received large public attention, and scared many accordingly. For example, Brian Brady of the US Bureau of Mines created an earthquake "clock" that would provide the precise time, place, and magnitude of a forthcoming quake based on his laboratory studies of rock fracture (Cowen 1981). Brady forecasted a large earthquake off the coast of Central Peru to occur on June 28, 1981 at a magnitude greater than 9. While the National Earthquake Prediction Evaluation Council rejected his claim, officials at the Office of Foreign disaster were on Brady's side (R. S. Yeats 1998). The estimated earthquake date came and went with no shaking involved, thereby proving Brady's prediction to be off-base and contributing to the discrediting of future earthquake predictions. As the Christian Science Monitor noted in 1981, "This would be merely an interesting scientific dispute were not the public safety involved." The only scientifically validated earthquake prediction ever made in the United States was made in 1985 following an extensive scientific peer-review, with a 95 percent probability that there would be a moderate-sized earthquake on the Parkfield segment of the San Andreas Fault in central California at some time over an eight year period (Sarewitz 2012). This prediction did not come true in Parkfield, and contributed to increasing frustration in the 
geologic community, as causing mass hysteria in hopes of furthering the field of geologic knowledge or advancing one's career and reputation is questionable.

This section has highlighted the difficulties involved in predicting earthquakes, and why having accurate predictions could be useful for policymakers and the public at large. The inability to have precise earthquake estimates hinders the public from fully realizing their risk, and forces ambiguity and extreme uncertainty into scientific knowledge, often invalidating scientific conjectures in the public eye. Cost estimates, policy, and campaigns are therefore intended to raise awareness for the unknown in light of uncertainty.

V. The Built Environment vs. the Environment: Mitigating Structural Risk The previous sections have articulated the known seismic hazards within the Pacific Northwest and Portland, the destruction these faults could cause, and the problems that stem from epistemic gaps in seismic knowledge. This section will explain the risk that the built environment can expect given the various factors influencing its seismic health. Not only is seismic risk important to consider when contemplating human safety, but it also plays a role in several important real-estate decision-making processes. For example, buyers must consider seismic design of new structures, seismic rehabilitation of existing buildings, and decisions regarding the purchase of earthquake insurance. Structural risk can therefore impact both the value of a building prior to an earthquake, and, more importantly, play a determining role in the survival of dwellers and recovery time of the region as a whole. 
Generally, a structure's seismic health depends on two overarching, simplified factors: the ground below it, and the materials used to make it. Proximity to the fault lines obviously has a substantial impact on risk, yet additional soil variables must be considered when assessing structural risk. Seismologists and engineers consider three specific and different earthquake-related problems to be associated with surface sites: 1) amplification of seismic waves by soft surficial deposits; 2) liquefaction of near-surface sediments; and 3) landslides (R. S. Yeats 1998).

First, seismic waves are amplified in soft foundation materials, which results in more vigorous shaking than would be expected on a rock surface. Higher frequency waves tend to affect smaller buildings, while low frequency, elongated waves tend to affect tall high rises at a heightened rate. Second, the liquefaction risk of an area is entirely dependent upon soil quality and type, which can turn the soil to mush and cause "ground failure". This problem generally affects buildings in a manner that cannot be easily reduced through seismic upgrades and codes. Lastly, landslides affect hilly or mountainous terrain and the buildings that reside on them. Earthquakes less than 5.5 in magnitude generally generate dozens of landslides, while earthquakes greater than magnitude 8 generate thousands (R. S. Yeats 1998). Thus buildings that rest upon liquefiable and landslide prone soil can generally expect greater damage.

Structural components play a large role in a building's seismic health and can substantially affect how the building fares in ground-shaking conditions. As previously noted, scientific knowledge on earthquakes was not formally articulated and monitored until the 1960's. Yet within the United States, the awareness of earthquakes as a frequent 
occurrence was prevalent in states such as California. This allowed for mild, but insufficient, adaptation to building codes and form in areas of high seismicity. Architectural and structural knowledge on preferred building codes and structural resiliency became articulated and more effective as time passed. California, as a result of being the most seismically active state in the nation, developed the strictest building codes and became a national reference for structurally sound buildings.

Generally, brittle structures and single-story buildings with large parts of their walls not tied together are known to behave poorly in earthquakes. Buildings such as these typically are constructed out of unreinforced masonry or have nonductile concrete-frames with weak, unconfined columns. Oregon generally began using earthquake-safe concrete masonry (CMU) after 1970, unbeknownst to designers that this material was improving the building's seismic performance in light of earthquake threats. Thus Hazus, along with other tools, tend to generalize structures built prior to 1970 as being more dangerous than those built after. These materials were also used prior to 1970, but were used in conjunction with unreinforced masonry, steel, and wood.

Owners of unreinforced buildings have been given options to improve their structures. Walls may be strengthened by infill walls, bracing, external buttresses, addition of exterior or interior frames, or by base isolation (R. S. Yeats 1998). In light of national pressure, Oregon adopted a statewide building code that mandated mild seismic resistance for new construction in 1974. It was not until 1993, however, that Oregon building codes changed to require design that would accommodate shaking from a Cascadian subduction zone quake, almost doubling the earthquake forces used in earlier 
codes (OSSPAC 2013). The Oregon Structural Specialty Code mandated that new building designs must incorporate seismic provisions, as many buildings built before 1994 are not considered able to withstand shaking from earthquakes (DOGAMI 2010). Unfortunately, the only specific state requirements for upgrading presently dangerous older buildings are enforced after the event of an earthquake.

While new codes exist to improve safety for new buildings, tens of thousands of older buildings remain unsafe and at risk of causing serious damage to the public. The State of Oregon has received criticism in the past for neglecting to upgrade their buildings, many of which house children, elderly, and a lot of people in general. In 2002, Ballot Measures 21 and 22 allowed, but not explicitly granted, for approximately $\$ 1.2$ billion of state bonds to be offered for seismic upgrades to public schools and emergency facilities. It was not until 2009, however, that the Seismic Rehabilitation Grant Program provided $\$ 30$ million in state bond funds to begin seismic mitigation of schools and emergency facilities. The state hopes that by 2022 seismic mitigation will be completed for all emergency facilities, and by 2032, seismic mitigation will be completed for public highoccupancy schools. Currently half of Oregon schools, 649 buildings total, face a high or very high risk of collapse in a strong quake, or are constructed of materials not designed to withstand shaking (Wolf 2011).

Buildings at risk that are not emergency facilities or schools must fare on their own to perform seismic retrofits. The 2012 Oregon Resilience Plan specifically recommends the state to develop mandates, tax credits, and other incentives to require or strongly encourage building owners and tenants to properly brace and anchor deficient 
nonstructural elements within their buildings. No incentives or subsidies currently exist for business to perform upgrades, but measures are being considered at the state level to allow business to receive credits and initiate a star rating system similar to LEED for buildings to be rated as resilient (Yu, K. personal communication, April 5, 2013). Hopefully future policy and codes will enable Portland and Oregon to improve their earthquake resistant profile.

Seismic upgrades are not cheap. There is a major cost tradeoff, as upgrading seismic resistance may add up to 5 percent of the cost of a new building, and the increase is higher for retrofitting existing buildings (R. Yeats, Sieh, and Allen 1997). According to the Oregonian, seismic upgrades can cost about $\$ 3$ to $\$ 4.50$ per square foot of basement or crawl space, with the typical retrofit costing between $\$ 3,000$ and $\$ 6,000$ total (Hunsberger 2010). Other estimates for larger structures have placed the cost per square foot at $\$ 9$ to $\$ 10$, with nonductile concrete frame structures costing two to three times higher (R. S. Yeats 1998).

The seismic risk of a location is sometimes reflected in the real estate values of the properties residing in that area. This observation is more prominent in California than in Oregon, but is useful to consider if Oregon were to begin experiencing more frequent quakes. According to Porter, et al., economic seismic risk to properties is assessed every time a property changes hands, thus the best time to bring about seismic-risk mitigation measures for properties is at the time of sale. Anecdotal evidence, however, suggests that these are missed opportunities: risk is typically not mitigated, even in more vulnerable buildings (Porter, Beck, and Shaikhutdinov 2004). Thus disconnect can be observed 
between owners, buyers, and the public at large in building codes and decisions to seismically upgrade. This phenomena and problem of taking action in light of the earthquake problem will be explored in the proceeding section.

VI. Taking Action - Local, State, and National Policy on Earthquake Risk Awareness of possible earthquakes is high in some communities, but concern is not. This is problematic because concern motivates action, but awareness does not. Thus while many in Portland may be aware of the earthquake risk, the lack of concern will prevent residents from performing necessary seismic upgrades or rallying the government to improve infrastructure. Furthermore, support for earthquake awareness policies may depend more on local politics and resources than on technical measures of earthquake risk provided by Hazus and more general geological assessments. The following section examines government efforts to raise awareness and concern, as well as reduce risk. The section will begin with a generalized observation on earthquake policies and then move to specific policies enacted in the Portland region.

Earthquake policies can be regulatory (as in mandatory building codes), based on different incentives (tax relief development rights, etc.), or based on information reporting (disclosure requirements). Different levels of government do not share the same responsibilities due to the variety of roles that each level plays in regulating and/or providing services for a given population (Bostrom, Turaga, and Ponomariov 2006). For example, the national government provides the majority of influence in post-disaster funds. Conversely, the local government will attempt to promote personal awareness and 
housing policies to foster resilience and build capacity. A mix of players and forces is therefore involved in the hazard mitigation process.

Adoption of elaborate mitigation policies and agendas is constrained heavily by several factors. As previously noted, low public perceptions of earthquake risk prevent pressure from being applied to governmental entities. Tangibly, the high upfront costs and uncertain benefits of soft mitigation actions, such as raising awareness on a general level, make these difficult to enact, as it is impossible to measure the exact cost-benefit ratio of such efforts. The ability to measure and quantify benefits is further compounded by the basic lack of technical and financial resources. Tight budgets on all levels of government leave little room for building resiliency or providing resources for the public to independently reduce their seismic risk. For example, the Oregon Resiliency Plan was written and organized completely pay-free, and the seismic assessments involved were already established and provided by DOGAMI.

Lastly, just as the public's concern with earthquakes varies, stakeholders' and policymakers' perceptions have a large effect on whether or not a risk measures are implemented (Bostrom, Turaga, and Ponomariov 2006). Typically, earthquake mitigation efforts will be prioritized on local agendas when an earthquake event occurs within close proximity to the relative location. Once again, the Oregon Resiliency Plan falls into this theory, as its creation was mandated after outcry from the legislature following the Japanese earthquake of 2011(OSSPAC 2013). Yet this is not enough. It is not sound to expect the relative governments to act only when a tragedy happens elsewhere. 
Despite this mismatch in perception, policy exists to help build resiliency prior to an earthquake, as well as mitigate risk following an event. Many of these polices have been influenced by Hazus, including the Oregon Resiliency Plan, hence it is useful to review the relevant influential policies that could influence Portland and have a lasting effect on the city's ability to respond to an earthquake. The proceeding paragraphs give an overview of these policies.

As outlined earlier in this chapter, the national government has played a large role in funding seismologic research and furthering earthquake awareness. The National Earthquake Hazards Reduction Program (NEHRP) leads the federal government's efforts to reduce the fatalities, injuries, and property losses caused by earthquakes. Most of NEHRP's implementation activities are conducted through FEMA's ability to prepare and sponsor a variety of published materials that help various group leaders learn about and use the research conducted by NEHRP (NEHRP 2009). Accordingly FEMA maintains several grant programs to help state and local governments plan and implement earthquake mitigation methods. Training for first responders and other state and local government personnel involved in responding to natural and man-made disasters is also performed by FEMA. Lastly, FEMA provides substantial support following major disasters, with a flexible structure that enables local disaster recovery managers to operate in a unified and collaborative manner. FEMA's support efforts are organized according to the following six functions and associated agencies:

- Community Planning and Capacity Building Recovery Support - FEMA

- Economic Recovery Support - U.S. Department of Commerce 
- Health and Social Services Recovery Support Function - U.S. Department of Health and Human Services

- Housing Recovery Support Function - U.S. Department of Housing and Urban Development

- Infrastructure Systems Recovery Support Function - U.S. Army Corps of Engineers

- Natural and Cultural Resources Recovery Support Function - U.S. Department of Interior

As this list displays, the nationally provided support for a region following a serious event entails multiple actors. Together, these Recovery Support Functions help facilitate local stakeholder participation and promote intergovernmental partnerships to enable recovery.

In moving from national to regional, the Cascadia Region Earthquake Workgroup (CREW) operates under FEMA's banner, and meets quarterly to produce planning guides and other resources, respond to media requests for information and expertise, and maintain a gateway website to the many community, state, and federal resources devoted to earthquake hazards and how to plan for them (CREW 2011). The CREW organization most recently produced multiple roundtable meetings to provide resources for business people to discuss their concerns and improve their current level of preparedness. CREW has done minimal outreach in addition to the aforementioned activities. Yet these connections could prove necessary in the instance of a major Cascadian quake, as previously established regional connections could be utilized. 
In moving from the regional to state level of governance, the Oregon Office of Emergency Management (OOEM) serves to oversee the state's planning, preparing, and response mechanisms. This department has the responsibility of coordinating the partnerships between public and private organizations, administer grants related to emergency program management and emergency services for the state, enforce compliance requirements of federal and state agencies for receiving funds and conducting designated emergency functions, and perform other duties related to emergency management.

OOEM currently oversees the aforementioned Seismic Rehabilitation Grant Program to provide funding for the seismic rehabilitation of critical public buildings, particularly public schools and emergency services facilities. This program was launched in 2009 and authorized $\$ 22.5$ million in state treasury bonds for eligible buildings to be retrofitted to standards set by the American Society for Civil Engineers. Sixteen schools and eleven emergency service buildings have been completed as of April 2013. Each project cost approximately $\$ 500,000$, thereby limiting the available funds and making the grant process competitive. Unfortunately, approximately 649 schools remain in high or very high risk of collapse in a strong quake, or are constructed of materials not designed to withstand shaking (Wolf 2011). Grassroots groups such as the Oregon Parents for QuakeResistant Schools exist in Oregon to raise awareness to this threatening problem, yet the serious risk remains.

The Oregon Department of Geology and Mineral Industries (DOGAMI) operates as the geologic information gathering bureau for the state of Oregon. Initially created in 1937 as 
an independent state agency, it has evolved from its early focus on mining to become Oregon's major source of information to help Oregonians understand and prepare for a wide variety of hazards (DOGAMI 2013). The department creates geologic and hazard maps to help inform Oregonians understand the risks faced from earthquakes, tsunamis, landslides, and other hazards. A five-member governing board of citizens is appointed by the Governor and confirmed by the Senate to set policy and oversee general operations in order to guide DOGAMI's mission and objectives.

The City of Portland's Bureau of Emergency Management (PBEM) has also played a large role in preparing Portland for the potential quake. PBEM provides a vast amount of information and resources for the residents of Portland, and occasionally holds seismic upgrading workshops across the city. The bureau must also update the Portland Natural Hazard Mitigation Plan every five years in order to prepare for a variety of natural hazards. In regards to earthquakes, the plan hopes to focus on critical infrastructure strengthening of water, sewer, and energy facilities (Rueter 2010).

In addition to the Oregon Office of Emergency Management and DOGAMI, the state of Oregon has provided direct guidance and centralization for the enactment of earthquake policy in 1991 with the introduction of Senate Bill 96. This bill created the Oregon Seismic Safety Policy Advisory Commission (OSSPAC), which serves to positively influence decisions and policies regarding pre-disaster mitigation of earthquake and tsunami hazards, increase public understanding of hazard, risk, exposure, and vulnerability through events and other outreach, and to be responsive to the new studies 
and/or issues raised around earthquakes and tsunamis (OOEM 2013). This group operates with the following goals in mind:

- Develop and influence policy at the federal, state and local levels;

- Facilitate improved public understanding and encouraging identification of risk;

- Support research and special studies;

- Support appropriate mitigation;

- Support response and recovery; and

- Support and assist in the coordination of a grant program for the disbursement of funds for seismic rehabilitation of schools and emergency facilities.

As previously noted, OSSPAC delivered the Oregon Resiliency Plan in February 2013. This document provided a state-wide plan for building resiliency and will hopefully fuel the enactment of additional policy and action by the state government to increase seismic awareness and decrease risk. OSSPAC created this plan with the help of DOGAMI and 150 other stakeholders throughout the state. Four scenario impact zones (Eastern, Valley, Coastal, and Tsunami) were identified and assessed to determine the likely impacts of a magnitude 9.0 Cascadian earthquake and tsunami. Specific attention was given to the amount of time required to restore each sector's necessary functions if the earthquake were to strike under present conditions. This information could then be used to create timeframes for restoration and recovery post-earthquake.

The Oregon Resiliency Plan is of extreme relevance to this thesis for its use of Hazus in its assessment of Oregonian risk. The plan has provided the necessary ammunition for 
those calling for greater resilience in Oregon by claiming findings listed above, largely calculated through the use of Hazus. The Plan fails to mention the methodologies or assumptions behind Hazus, despite the frequent use in calculating the harrowing estimates. As will be explored in Chapter 3 and 4, the use of this software in the Resiliency Plan and other assessments can be critiqued.

The notable assessments and findings of the Oregon Resiliency Plan are as follows:

- Fatalities ranging from 1,250 to more than 10,000 .

- At least $\$ 30$ billion in direct and indirect economic loss.

- Debris totaling to 10 million tons, or 1 million dump truck loads.

- Complete destruction of 24,000 buildings.

- Extensive damage of 85,000 buildings requiring months to years of repair.

- Approximately 27,600 displaced households.

- An extremely vulnerable liquid fuel supply.

- Resilience gaps that could lead to decades of economic and population decline, in effect, a "lost generation" of Oregonian residential prosperity.

To reduce the vulnerabilities, the Plan insists that Oregon follow the following four recommendations: 1) undertake comprehensive assessments of key structures and systems that underpin Oregon's economy; 2) launch a sustained program of capital investment in public structures such as schools and transportation systems; 3) provide incentives for seismic upgrades and resilience; and 4) upgrade Oregon's public policies to raise individual awareness and improve mitigation strategies to bring services and necessities to effected individuals following an event. 
Progress is slowly being made on implementing the recommendations, according to discussions with Kent Wu, the Chair and Structural Engineer Stakeholder of the project. The Oregon State Legislature held a hearing on the plan on March 14 to approve the plan, and future meetings will be held in order to decide on specific strategies for its implementation. According to $\mathrm{Mr}$. Wu, plans for creating incentives for businesses to perform seismic upgrades are in the works, as well as a "resilience rating system" akin to LEED accreditation. Mr. Wu also spoke of legislative interest in replicating the San Francisco Earthquake Hazard Mapping Act, which requires responsible planning agencies to approve only projects within seismic hazard zones following a site-specific investigation to determine if the hazard is present (CGS 2007). Acts such as these serve to protect the public against hazards that are not readily visible.

Additional time is needed before the Resiliency Plan can take full effect through enacted legislation and additional publicity. In the meantime, a considerable amount of grassroots-led events and non-governmental groups have served to raise awareness among Oregonian residents. These groups are valuable to increasing resilience despite their lack of real power to create or change policy. Listing and detailing all of the groups is outside of the scope of this thesis, yet is important to note of their existence. These groups use information generated from Hazus and reported in various governmental reports such as the Resiliency Plan, therefore the accuracy of the tool can affect their perception and efforts.

\section{Conclusion}


This chapter has given a wide overview of the history of earthquake research and knowledge, the evolution of Pacific Northwest seismic awareness, the difficulties in making predictions, and the ability of the federal, Oregonian, and Portland government to mitigate the known risks. Each component is of considerable importance in the current state of earthquake awareness and state of resilience. This information is also noteworthy in the context of Hazus for two reasons. First, the scientific knowledge on earthquakes, what causes them, and their effects on the built environment, are explicitly woven into the Hazus model. Thus it is necessary to understand the science that helped form the model and create its necessity. Second, it is worthy to make note of the present structures affecting mitigation activity and the state of preparation within the region, as these variables can also have a lasting effect on the damage inflicted upon the region, or the estimated losses in Hazus. Thus the information presented provides context for the examination and assessment of Hazus in the proceeding chapters. 


\section{Chapter 3: Hazus as a Tool}

The previous chapters have presented the topic of risk on a theoretical level, the real seismic hazards that contribute to Portland's risk, and the actions that have been taken by the government to mitigate the risk. This chapter builds upon the previous two by providing specific information on Hazus, the loss estimation tool used to assess risk in a given region. To explore Hazus as a tool, this chapter first provides an overview on the history of Hazus to give context to the tool's current state. The chapter then describes the specific details of Hazus, including its inputs, inventory data, methodologies, and outputs. The information required to build this chapter was gathered from reading the 700 page “Hazus - MH 2.1 Technical Manuel," noting relevant details, and translating them into a readable format suitable for non-experts. The chapter will only examine Hazus as it is used for earthquakes. While the tool is also used for other natural hazards, the scope of this thesis and research question relates specifically to earthquakes and the risk they pose to the built environment.

\section{Hazus History}

National earthquake loss estimation officially began with the 1972 National Oceanic and Atmospheric Agency study for the San Francisco, California region (Kircher, Whitman, and Holmes 2006). Approximately thirty assessments were performed following the San Francisco study and prior to the creation of Hazus, with each varying in methodology, assumptions, and approaches. As noted in Chapter 2, geologic and seismic knowledge progressed slowly until the 1970 s, thereby contributing to varying estimation methodologies and inputs. Furthermore, the lack of methodological standardization in 
risk models prevented comparisons to be performed across regions, and contributed to confusion amongst insurance assessors.

The federal government eventually countered this confusion and used its organizational and monetary resources to begin a national standardization for methodologies and assessments. In 1989, FEMA, in conjunction with the National Academy of Sciences, released the report "Estimating Losses from Future Earthquakes," thereby giving roots to Hazus and providing steam for further collaboration (Kircher, Whitman, and Holmes 2006). This report listed a set of guidelines for conducting loss studies, laid the groundwork for a loss methodology structure, and provided necessary momentum for methodology development.

Three years later, FEMA entered into a cooperative agreement with NEHRP and the National Institute of Building Sciences (NIBS), a congressionally authorized nonprofit organization established to serve as an interface between government and the private sector. Their goal was to develop a nationally applicable standardized methodology for estimating potential earthquake losses on a regional basis. NIBS organized an eightmember Project Work Group (PWG) consisting of earthquake experts to provide technical oversight and an eighteen-member Project Oversight Committee (POC) to represent user interest in the earthquake community. Together, these two groups defined the components of the loss estimation methodology, and prepared a detailed standardized list of desired methodology outputs according to their expertise (Kircher, Whitman, and Holmes 2006). 
NIBS also contracted a joint venture between Risk Management Solutions, Inc. (RMS) of Melno Park, California and the California Universities for Research in Earthquake Engineering (CUREE) to identify and evaluate the potential of existing studies for use in developing the standardized loss estimation methodology (Schneider and Schauer 2006). Accordingly, RMS and a group of thirty earthquake experts developed the earthquake loss estimation methodology using exiting literature and damage data from Northridge, Loma Prieta, and other earthquakes (Kircher, Whitman, and Holmes 2006).

By combining the methodology from RMS, the desired outputs from the POC, and technical oversight from PWG, Hazus was born. The first release of the Hazus earthquake model occurred in 1997, and has since been revised multiple times (Schneider and Schauer 2006). The initial model included substantial methodological and data achievements, including the adoption of USGS hazard maps, use of census tracts as the most detailed reference unit for a study site, use of national databases to make the model nationally applicable, development of occupancy and structural building classification systems, the use of spectrum-capacity analysis for determining building damage, and development of models for determining casualties, shelter requirements, debris, and indirect economic loss. All of the aforementioned variables set precedence for subsequent nationally applicable hazard estimation models produced by private agencies.

Multiple changes have been made since the inception of Hazus and its first release in 1997. Within two years of its completion, significant improvements and updates were made to the software to fix bugs and compatibility issues. The most notable change, arguably, is the adaptation of Hazus to work exclusively with the ArcGIS software 
platform. This change allowed users to be more flexible in their study area and relative inputs, thereby producing more accurate outputs. The other notable change is the extension of loss estimation for other hazards. Flood and wind loss estimate capability was added in 2004. In Spring 2010, Hazus released the 2.0 version complete with hurricane storm surge risk analysis capability (Berman 2011). Future releases will include tsunami estimates, and possibly tornado estimates.

Hazus users totaled approximately 1,700 users prior to addition for floods and hurricanes (Schneider and Schauer 2006). Numbers are expected to increase substantially with the release of the software in an online format. The online format is not included in the scope of analysis, but could undoubtedly affect the accessibility, user count and ease of use.

\section{Current HAZUS Earthquake Model}

The following section provides an overview of the software and methodology used and examines the datasets provided in the software's inventory. Each module will be explored in detail to provide groundings for the proceeding chapter's analysis. Lastly, this section examines the results and outputs provided by Hazus, thereby examining the tool in full scope. The most recent version of the software released in 2012, Hazus - MH 2.1, will be the prime focus of this analysis. This analysis will also exclusively focus on the use of Hazus for earthquake hazards. Hazus applied to estimation for floods, hurricanes, and other events will not be considered, although many of the methodologies and inputs are similar.

\section{a. General Scope}


Hazus is a loss estimation tool that attempts to combine explicitly geologic and seismic knowledge of the built environment with engineering tools and data that can assess loss. The software can be used for three broad applications: emergency preparedness, mitigation, and response and recovery. First, Hazus aids in developing emergency response plans by providing necessary estimates for temporary housing needed by those rendered homeless, potential debris, emergency medical services from injuries, and evacuation/emergency route clearance. Response exercises can then be performed with these estimates in mind.

Second, mitigation can be strengthened through the tool's output by identifying "at-risk" structures, communities, and land parcels. This information can provide evidence for the adoption and enforcement of hazard resistant building codes and upgrades, as well as project at-risk areas for land-use planning processes. Planning and emergency management bureaus can assess the level of readiness and preparedness to deal with disasters and target at risk communities for mitigation improvement accordingly.

Lastly, Hazus can aid in the creation of post-disaster damage assessment. This can be done by fostering response planning for critical transportation outages, identifying critical infrastructure, creating recovery action plans, and aiding in long-term economic recovery planning. Users can then modify inputs to account for projected upgrading of vulnerable infrastructure to discover the positive effects that these improvements can have. This information will allow users to allocate resources for the most effective and efficient upgrades. 
There are three general types of Hazus users according to the software guidebook. First, the "Default Data Analyst," who performs an analysis mostly on the input data provided with the methodology. This user does not need extensive technical knowledge nor does their analysis include the following important pieces of information: damage or loss due to liquefaction, landslide or surface fault rupture, damage or loss due to tsunamis, and seiche or dam failure. This user receives the most basic information, and since their data may not be as complete or accurate, the outputs may not be preferable. This level of analysis is typically very granular, and the results from this process should serve only as a baseline for further analysis ( $\mathrm{Ng} 2010)$.

The second and most common user is defined as the "User-Supplied Data Analyst". This user requires a more extensive inventory data collection processes and analytical effort. The typical purpose of this user is to generate the best estimates of earthquake damage and loss by employing consultants to assist in implementation of certain methods. This type of Hazus user will also employ default inventory data. Unfortunately, this user also does not have the capacity to include all available and updated information in the analysis, depending on the experts consulted and data included. According to the guidebook, this user also needs approximately one to six months to obtain all of the necessary input for this type of analysis.

The final user of Hazus is the "Advanced Data and Models Analyst". This user incorporates results from engineering and economic studies carried out using methods and software not included with the methodology. This user will need typically six months to two years to complete the analysis. These users employ the software on a very specific 
level, and will likely be examining one component of the overall hazard assessment, such as effects of ground shaking on a hospital or the additional safety that could result from updated water infrastructure. This type of expert-user will likely modify or substitute the model parameters and/or equations relevant to a given hazard.

On the most basic level, performing an analysis in Hazus typically proceeds as follows:

1. Define the geographic area of analysis;

2. Define the hazard

3. Overlay inventory and provided data

4. Estimate damage

5. Estimate losses and needs

To perform the above tasks, the following six primary components (modules) are used:

- Potential Earth Science Hazards - Ground shaking and site effects;

- Inventory - classification system, default databases, data collection and handling;

- Direct Damage - general building stock, essential facilities, transportation and utility lifeline systems;

- Induced Damage - inundation, fire flowing, hazmat release, debris;

- Direct Loss - economic loss, causalities, shelter requirements, loss of function;

- Indirect economic loss - long term effects of direct impacts

Table 3.1 on the following page presents the outputs of Hazus from each module. Figure 3.1 on the Page 72 presents the basic structure of Hazus, and should be used as a reference for the entire chapter. As the figure displays, all of the modules mentioned above are interdependent of one another, thereby providing users with a very large amount of information to work with. 


\begin{tabular}{|c|l|}
\hline Module & \multicolumn{1}{c|}{ Outputs } \\
\hline \multirow{4}{*}{ Direct Damage } & General Building Stock \\
& Essential Facilities \\
& Transportation Systems \\
& Utility Systems \\
\hline & Inundation \\
& Fire Following (limited) \\
& Hazardous Materials Release \\
(limited) \\
& Debris Generation (limited) \\
\hline Induced Damage & Cost of Structural Damage \\
& Income Loss \\
\hline \multirow{2}{*}{ Direct Losses } & Casualties \\
& Shelter Needs \\
\hline & Supply Shortages \\
& Sales Decline \\
& Opportunity Costs \\
& Economic Loss \\
\hline
\end{tabular}

Table 3.1 Hazus Modules and Outputs 


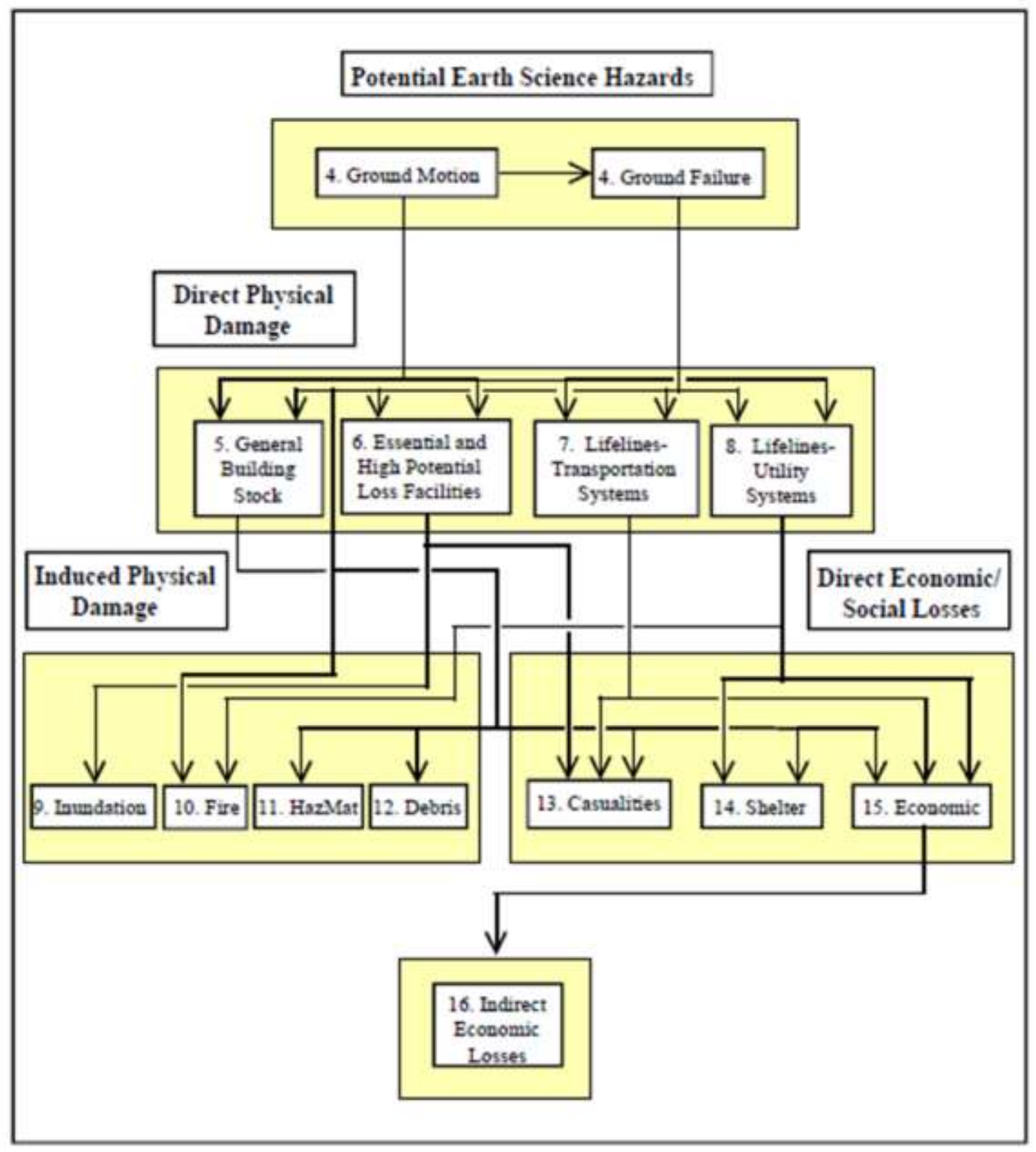

Figure 3.1 Hazus Methodology (FEMA 2012a)

\section{b. Hazus Inventory Data}

The Hazus software includes a substantial database with a nationwide inventory of persons, buildings and facilities, transportation systems, utility systems, and hazardous material (hazmat) facilities. The proceeding sub-section will examine the data provided 
in the Hazus-MH software. This is important to note as it is used by all user levels and can thereby significantly affect outputs.

Hazus includes three types of inventory data: aggregate, site-specific, and hazardspecific. Aggregate data represents inventory that is common across all hazard models and includes demographics (i.e. age, income, ethnicity, ownership, and gender) and general building stock. Site specific data includes independent points representing various facilities and systems of inventory (i.e. hospitals and other essential facilities). Hazard-specific data includes building inventory and mapping schemes uniquely defined for each of the hazards ( $\mathrm{Ng} 2010)$.

The general building stock includes residential, commercial, industrial, agricultural, religious, government, and educational buildings. The database includes square footage by occupancy, full replacement value by occupancy, building count by occupancy, general occupancy mapping, and demographics of residents. The inventory was developed from multiple government sources, including the Census Bureau and Department of Energy, as well as private sources such as the firm Dun and Bradstreet, which was used to acquire demographics for commercial buildings and businesses. Square footage for different occupancies of buildings is also included. Buildings are then categorized into structural categories according to five general characteristics, listed below:

- Structural parameters affecting structural capacity and response. This includes the building's basic structural system (type of frame), height, and seismic design criteria; 
- Nonstructural elements affecting nonstructural damage;

- Occupancy, affecting casualties, business interruption, and contents damage;

- Regional building practices, such as codes; and

- Variability of building characteristics within the classification.

These buildings are then grouped according to seven occupancy groups: residential, commercial, industrial, religion/nonprofit, government, education, and lifelines. The seven groups are stratified further into thirty-three specific classes according to square footage inventory. The data collected on building stock is then rolled up and computed at the centroid of the census tract to simplify analysis.

Essential facility loss estimations are considered separately from those listed above. These buildings include hospitals, fire stations, police stations, and schools - all essential to mitigation and recovery efforts. The inventory data for these buildings is dated from 2000-2003, and provided from the American Hospital Association, InfoUSA, Inc., National Center for Education Statistics, and the US Department of Education. The module for these special buildings is slightly different than others since its purpose is to determine the expected loss of functionality as opposed to explicit monetary losses. Users are encouraged to include the number of hospital beds and fire trucks to improve accuracy. Detailed analysis of recovery time and resources available to the community will be then computed according to structural components of the building and seismic effects. To calculate general economic losses, users are instructed to move the essential facilities into the analysis of total building stock and disregard their functional purpose. 
High Potential Loss Facilities and Hazardous Material Facilities are also given their own specific categories, and are considered to be buildings likely to cause extremely high losses if damaged. High Potential Loss Facilities include nuclear power plants, dams, and some military installations. Hazardous Material (Hazmat) Facilities include buildings with an inventory of toxic, radioactive, flammable, explosive, or reactive substances that can pose significant hazards and a unique risk to the surrounding environment. Damage from these materials can vary depending on the type and quantity of substance released, meteorological conditions, and timeliness and effectiveness of emergency response. Hazus inventory provides the geographical location of the facilities, but damage and loss estimation calculations are not performed. The handbook notes that significant casualties or property damage could occur from a small number or even a single hazardous materials release induced by an earthquake. Further elaboration on the problems of avoiding analysis of hazmat and high potential loss facilities is examined in Chapter 4.

Transportation systems provided by Hazus 2000 inventory include highways, roadways, bridges, tunnels, railways, light rail, bus, ports, ferries, and airports. During the creation of a study area, transportation system geometries from feature classes are transferred to a geodatabase for users. For some of the transportation systems, classification is based on whether the equipment is anchored or designed with special seismic tie-downs or tiebacks. Unanchored equipment refers to equipment designed with no special considerations. These inputs are generally classified to allow for differentiation between components with substantially different damage and loss characteristics.

The inventory data for lifeline utility systems includes the following: 
- Potable water: pipelines, water treatment plants, wells, storage tanks, and pumping stations

- Waste water: pipelines, waste water treatment plants, and lift stations

- Oil: pipelines, refineries, pumping plants, and tank farms

- Natural gas systems: pipelines and compressor stations

- Electric power: substations, distribution circuits, generation plants, and transmission towers

- Communication: telephone central offices.

This data is stored in feature classes and tables, and is used to consider problems and losses caused by infrastructure damage.

Default demographic data is gathered from the 2000 Census and reported by census tract, and includes data on all census tracts in the United States. The demographic data was collected from the Census Bureau, and describes characteristics of the population including age, income, housing, and ethnic origin. A total of twenty-nine census fields of direct importance to assessing risk were placed in the provided Hazus database. Data is aggregated to the census tract level following the mining of the software's inventory and user modifications. Direct social and economic losses are then calculated by the modules. Specific data fields and their use in the modules are presented in Figure 3.2 below. 


\begin{tabular}{|c|c|c|c|c|}
\hline \multirow[b]{2}{*}{ Description of Field } & \multicolumn{4}{|c|}{ Module Usage } \\
\hline & Shelter & Casualty & $\begin{array}{c}\text { Occupancy } \\
\text { Class }\end{array}$ & Lifelines \\
\hline Total Population in Census Tract & * & & & * \\
\hline Total Household in Census Traet & * & & & * \\
\hline Total Number of People in General Quarter & * & & & \\
\hline Total Number of People $<16$ years old & * & & & \\
\hline Total Number of People 16-65 years old & * & & & \\
\hline Total Number of People $>65$ years old & * & & & \\
\hline Total Number of People - White & * & & & \\
\hline Total Number of People - Black & \# & & & \\
\hline Total Number of People - Native American & * & & & \\
\hline Total Number of People - Asian & * & & & \\
\hline Total Number of People - Hispanic & * & & & \\
\hline Total \# of Households with Income $<\$ 10,000$ & * & & & \\
\hline Total \# of Households with Income $\$ 10-\$ 20 \mathrm{~K}$ & * & & & \\
\hline Total \# of Households with Income $\$ 20$ - $\$ 30 \mathrm{~K}$ & * & & & \\
\hline Total \# of Households with Income $\$ 30-\$ 40 \mathrm{~K}$ & * & & & \\
\hline Total \# of Households with Income $\$ 40-\$ 50 \mathrm{~K}$ & * & & & \\
\hline Total \# of Households with Income $\$ 50$ - $\$ 60 \mathrm{~K}$ & * & & & \\
\hline Total \# of Households with Income $\$ 60$ - \$75K & * & & & \\
\hline Total \# of Households with Income $\$ 75-\$ 100 \mathrm{~K}$ & * & & & \\
\hline Total \# of Households with Income $>\$ 100 \mathrm{k}$ & * & & & \\
\hline Total in Residential Property during Day & & * & & \\
\hline Total in Residential Property at Night & & \# & & \\
\hline Hotel Occupants & & * & & \\
\hline Vistor Population & & * & & \\
\hline Total Working Population in Commercial Industry & & * & & \\
\hline Total Working Population in Industrial Industry & & * & & \\
\hline Total Commuting at $5 \mathrm{PM}$ & & * & & \\
\hline Total Number of Students in Grade School & & * & & \\
\hline Total Number of Students in College/University & & * & & \\
\hline Total Owner Occupied - Single Household Units & * & & * & \\
\hline Total Owner Occupied - Multi-Household Units & * & & * & \\
\hline Total Owner Occupied - Multi-Household Structure & * & & * & \\
\hline Total Owner Occupied - Mobile Homes & * & & * & \\
\hline Total Renter Occupied - Single Household Units & * & & * & \\
\hline Total Renter Occupied - Multi-Household Units & * & & * & \\
\hline Total Renter Occupied - Multi-Household Structure & 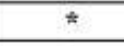 & & 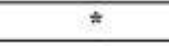 & \\
\hline Total Renter Occupied - Mobile Homes & * & & * & \\
\hline Total Vacant - Single Household Units & & & * & \\
\hline Total Vacant - Multi-Household Units & & & * & \\
\hline Total Vacant - Multi-Household Structure & & & * & \\
\hline Total Vacant - Mobile Homes & & & \# & \\
\hline Structure Age $<40$ years & & & * & \\
\hline Structure Age $>40$ years & & & * & \\
\hline
\end{tabular}

Table 3.2 2000 Census Data Included in Hazus (FEMA 2012a)

Lastly, users are encouraged to provide their own indirect economic loss data according to the user's assessment of possible change in demand and supply of products, change in 
employment, and change in tax revenues. Users can also specify the levels of potential increase in imports and exports, supply and product inventories, and unemployment rates. These data could increase accuracy in the economic loss modules. Conversely, the additional data could contribute to varying outputs in economic loss modules, as not all users will be able to provide this data into the software.

It is unknown how often the Hazus inventory database is updated. This is especially important when analyzing larger areas, and as will be discussed in Chapter 4. Database problems can also arise when considering uncategorical structures, new features to generalized areas, seismic upgrades, or demolition. Following collection of data, Hazus will calculate building replacement costs and other estimations for the study area depending on the degree of damage expected through the Potential Earth Science Hazards (PESH) algorithms. The methods for determining these figures will be explored in the proceeding section.

\section{Hazus Methods}

The previous section presented an overview of all inventory data provided within the Hazus software. This section provides detail on the methodology used in Hazus 2.1 to estimate potential earth science hazards (PESH), direct physical damage, indirect physical damage, direct loss, and indirect loss. These modules are important to consider in this analysis as the utilization and specification of each module will have a substantial influence on the output and associated costs and lost estimations. This section outlines 
each module and its respective output, and is organized in sub-sections according to module and generation type.

Hazus allows users to have freedom in determining the amount of influence that each module and risk factor can have in the region of study. For example, a user may wish to ignore induced damage when computing direct losses or to study the effect of proposed code changes upon losses to buildings without having to consider lifelines (Kircher, Whitman, and Holmes 2006). Other users may want to ignore buildings and explicitly examine lifelines or casualty estimates.

Figure 3.1 on page 71 presents the Hazus methodology in a generalized format. As the figure displays, the software begins at the top with determining "Potential Earth Science Hazards", or how the ground will react to a quake, then moves to calculate the amount of damage to be expected. The following subsections will detail each method employed by Hazus.

\section{a. Potential Earth Science Hazards}

The Potential Earth Science Hazards (PESH) category generally includes estimations for ground motion, ground failure (liquefaction, landslides, and surface fault rupture) and seiche (enclosed body of water swaying). The outputs from this module provide an understanding of how the ground and natural elements will act in a quake, thereby allowing for analysis on the built environment to be performed.

Ground motion is characterized by the amount of spectral response anticipated, the peak ground acceleration, and peak ground velocity of a given area. The user is able to define 
the spatial distribution of ground motion with three options. First, users could employ the USGS's National Seismic Hazard Maps, revised most recently in 2008 to reflect recent earthquake science and building codes. Second, users could use the methodology innate in the Hazus software, which provides maps for eight probabilistic hazard levels. Estimates are generated in the form of GIS-based contour maps and location specific demands and are stored in relational databases. Lastly, users could supply their own ground motion map created through other means. These maps must be compatible with Hazus in a pre-defined digital format and reflect soil amplification.

A census tract's ground motion properties are simplified to the centroid of that tract. Ground shaking is then calculated according to one of three scenarios: (1) deterministic calculation, or when the user specifies a scenario earthquake magnitude and location; (2) probabilistic maps, supplied with Hazus, or (3) the user's own maps created outside of Hazus. For the deterministic calculation, users select their preferred attenuation function, or how the seismic waves will move through the crust and fault type. In lieu of a userprovided soil map, Hazus will assume a standardized soil at all sites or allow the user to manually modify the soil type based on five pre-determined categories. Ground shaking is calculated according to geologic-inspired algorithms. Users with specific seismic or engineering expertise are able to modify the variables, i.e. attenuation, according to their desired analysis.

Specific inputs are required for each type of ground failure. Liquefaction requires a geologic map with the soil age, depositional environment, and material characteristics of the geologic units, a groundwater depth map, and magnitude of earthquake. Landslide 
analysis requires a geologic map, a topographic map, and a map with ground water conditions, as well as the earthquake magnitude. Lastly, surface fault rupture requires the surface trace location of the active faults that are postulated to rupture during the scenario earthquake.

Ground failure is considered following determination of shaking, and can come in the form of liquefaction, landslides, and surface fault rupture. According to the Hazus handbook, the evaluation of the hazard includes the probability of the hazard occurring and the resulting ground displacement. A liquefaction susceptibility rating is assigned to each soil type based on age, dispositional environment, and material type for a particular mapped geologic unit. The ratings are then applied to the census tracts and later considered in the building evaluations.

With the combined information entered into the model, Hazus will produce an aerial depiction map with the estimated permanent ground deformations from liquefaction and landsliding. Fault rupture will be considered in the overall output of damage and not produce an output map. As with other PESH modeling, qualified experts can refine the methods to prepare improved estimates of ground failure. These users are typically geotechnical experts with sufficient expertise in ground failure prediction.

b. Direct Physical Damage - Building Stock, Essential Facilities, Transportation, and Utility Lifeline Systems

The proceeding sub-section will describe the methods used to calculate direct physical damage from earthquakes to the built environment in a given area. As outlined in Chapter 
2, damage to a building depends on magnitude and proximity to faults, ground shaking and failure, and the structure of a building. The previous section explained the methods for determining expected geologic and ground activity in an earthquake. With this information, two primary functions are used by Hazus to measure the direct physical damage. First, fragility curves describe the probability of reaching or exceeding different states of damage given building response to the ground failure and shaking. Second, building capacity curves determine peak building response according to the building categories outlined in Section II.

Additional inputs are encouraged in order to perform detailed, building-specific analysis. As previously mentioned, Hazus provides a massive database of buildings. Users running the tool on specific sites that are smaller than the provided census tracts are directed to use more specific datasets on their area of analysis (i.e. for a small neighborhood, company headquarters, school district, etc.). The additional inputs required to determine damage comprise of model building type, including height, and seismic design level that represents the building or group of buildings of interest, and will prevent the tool from generalizing to the census tract level. The ground response spectrum at the site of interest is also required, and can be determined within the specific parameters of the small site of analysis, or extrapolated onto the site from the centroid of the census tract area.

The output of this analysis will provide the user with the estimate of the cumulative probability of being in, or exceeding, each damage state for the given level of ground shaking or failure. The outputs are then used directly as inputs to induced physical damage and direct economic and social loss modules. The Handbook states there could 
be a problem with this method, however, by noting the curves to be more reliable as predictors of damage for large, rather than small, population groups, such as the school district, building compound, or neighborhood. Specific facilities should consult a seismic/structural engineering expert for a reliable prediction of damage. The problems associated with this flaw are explored in Chapter 4.

The ground shaking and liquefaction estimates provided in the PESH module combined with the building response estimations allow Hazus to estimate casualties and injuries due to structural damage, monetary due to building damage, monetary losses from business interruption, social impacts, and other economic and social effects. The methodology then categorizes losses in four generalized ranges: Slight, Moderate, Extensive, and Complete. Explicit descriptions of individual building responses are not available due to the inability to describe building damage as a continuous function. Rather, Hazus will provide descriptors of each type of damage according to building type are provided following analysis.

In addition to shaking, Hazus accounts for building damage due to ground failure (liquefaction). Generally, damage to a building due to ground failure will contribute only to extensive and complete states of damage, thus Hazus places the affected buildings into states of either undamaged or severely damaged, as buildings rarely escape liquefaction without serious impairment. The methodologies for ground shaking are more detailed due to the extreme variance in building response to shaking, and the effect that shaking duration can have on a building. Shaking duration is assumed to be a function of 
earthquake magnitude and is described qualitatively as either short, less than magnitude 5.5, moderate, from magnitude 5.5 to 7.5 , or long, at magnitude greater than 7.5.

It is necessary to look beyond the general building stock when calculating damage. To address this, Hazus provides users with the ability to calculate damage for essential facilities, transportation, and utilities. These variables are of critical importance in order to treat those affected, reduce direct loss, begin repairs, and reinvigorate the economy following an event.

Calculating loss and damage for essential facilities (hospitals, fire stations, etc.) requires additional inputs beyond the standard data provided in the Hazus inventory. Specific model building type and seismic design level are necessary to calculate the essential facility's response. The guidebook notes that performance of essential facilities is not expected to be better than a typical building of the same structural type, but should be explicitly examined in a separate analysis.

Transportation systems include highways, roadways, bridges, tunnels, railways, light rail, bus, ports, ferries, and airports. The category "utility systems" includes potable water, waste water, oil (crude and refined), natural gas, electric power, and communication. The geographical location of these items and their specific classification is required to calculate damage. The module will then provide users with the direct repair costs of each component and the number of days required before full restoration based off of ground shaking and failure. The components are then classified into five damage states: none, slight/minor, moderate, extensive, and complete damage. 
High potential loss facilities must be considered outside of general building stock as well, but for separate reasons. These facilities require elevated seismic and engineering expertise due to the extreme damage and destruction these buildings can cause. Hazus does not account for these facilities due to the extreme variance in response. Additional information on the risks these buildings cause and how Hazus accounts fails to account for them will be explored and critiqued in Chapter 4.

c. Indirect Physical Damage - Hazards Resulting from Earthquakes

Harm to an area extends beyond explicit damage induced by shaking, soil failure, and inundation. Earthquakes can trigger a host of risky events such as fires, debris wreckage, landslides, and tsunamis. The Hazus methodology accounts for many of these events, with greater attention and detail given according to the user's provided inputs. The following sub-section will examine the module for calculating these hazards produced by inundation, fires, and hazmat release.

Inundation can occur from tsunamis (seismic sea waves), seiches (sloshing effects in lakes and bays), or dam/levee failure. The Hazus guidebook notes that the failure of a single dam or levee could result in large losses, and therefore a site-specific analysis should be done instead of using the tool. Hazus will compute the potential exposure to earthquake-caused inundation by identifying potential sources of flooding by overlaying existing inundation maps with other data. Losses resulting from these hazards are excluded, however, which could present a problem if users do not assume these structures to be vulnerable and ignore the risk inherent in these hazards. 
Earthquakes also produce serious fire hazards, and previous earthquakes have shown how losses from fire can sometimes outweigh the total losses caused by the earthquake, such as the collapse of buildings or disruption of lifelines (Ren 2004). Factors affecting the severity of post-earthquake fires include but are not limited to: ignition sources, types and density of fuel, weather conditions, functionality of water systems, and the ability of fire fighters to suppress the fires. Ignition rates for use in Hazus were determined according to an empirical statistical analysis and examining fires started following seven earthquakes in California. Spread rates account for the direction of spread, wind velocity, and fire resistance of structures. The model then accounts for suppression of the fire by the fire department, assuming it isn't damaged beyond repair, according to the timeline of discovery, reporting, arrival, control, and suppression.

The Hazus model for assessing fire damage is weak, and the guidebook notes that "the model is still considered to be a technology which is in the maturing process." (FEMA 2012a). This weakness is due to the high variability in readiness of local fire departments and the types and functionality of water systems following an earthquake, according to the guidebook. Regardless, the "fire following earthquake" results provide an estimate of the number of serious fire ignitions that require fire department response after a scenario earthquake, an estimate of the total burned area, and an estimate of the population and building exposure affected by the fire. With this information, users could study the effects of building more fire stations and improving immediate post-earthquake response to detect and suppress fires. Users can then decide which activities can be performed to reduce risk and evaluate the cost-effectiveness of each option. 
The release of hazardous materials is another serious event that can result from earthquakes. Hazardous materials refer to usable or wasted chemicals, reagents, or substances that exhibit physical or health hazards. The methodology for determining loss is restricted to identifying the location of the facilities that contain hazardous material (hazmat) which could lead to a significant immediate demand on health care and emergency response facilities, such as large toxic releases, fires, or explosions. The Hazus guidebook stresses that assessing risk and damage requires expert opinion, thus users of the software should look elsewhere. As will be noted in Chapter 4, the neglect of Hazus to include this presents many systemic problems.

Lastly, Hazus accounts for debris by splitting it into two categories. First, debris that falls into large pieces, such as steel members or reinforced concrete elements, which require special treatment to break into smaller pieces before being hauled away. The second type of debris includes smaller pieces made of materials such as brick, wood, glass, building contents, and other materials. The estimates for this model are based on observations of damage that have occurred in past earthquakes, and estimates of the weights of structural and nonstructural elements.

\section{d. Direct Loss - Casualties and Displacement}

Estimating potential casualties for any destructive event is not an easy task. An extraordinary host of scenarios can occur following an earthquake that can impact the casualty and injury rates. Potential direct physical damage from earthquakes and indirect 
physical damage from fires, inundation, hazmat releases, and other random events all threaten the built environment and affect the loss potential.

To approach this sensitive topic, Hazus created a methodology based on the assumption that there is a strong correlation between building damage and the number of causalities and severity of injuries. The handbook notes a lack of precedence in casualty estimation as well as a lack of data regarding earthquake related casualties according to building type and the "casualty generating mechanism" causing injury and death. The gaps in data prevent the most accurate model and estimation from being produced.

Regardless of the limited scope, Hazus will provide casualty and injury estimations by considering variables such as occupancy potential, collapse and non-collapse vulnerability of the building stock, time of the earthquake occurrence, and spatial distribution of the damage. The output of the module consists of a breakdown by injury severity and casualty rate calculated at the census tract level. The levels of injuries are presented in Table 3.3 below. The four-level injury scale represents a compromise between the demands of the medical community in order to plan their response and the ability of the engineering community to provide the required data. 


\begin{tabular}{|c|l|}
\hline $\begin{array}{c}\text { Injury Severity } \\
\text { Level }\end{array}$ & \multicolumn{1}{|c|}{ Injury Description } \\
\hline Severity 1 & $\begin{array}{l}\text { Injuries requiring basic medical aid that could be administered by } \\
\text { paraprofessionals. These types of injuries would require bandages or observation, } \\
\text { Some examples are: a sprain, a severe cut requiring stitches, a minor burn (first } \\
\text { degree or second degree on a small part of the body), or a bump on the head } \\
\text { without loss of consciousness. Injuries of Iesser severity that could be self treated } \\
\text { are not estimated by Hazus. }\end{array}$ \\
\hline Severity 2 & $\begin{array}{l}\text { Injuries requiring a greater degree of medical care and use of medical technology } \\
\text { such as x-rays or surgery, but not expected to progress to a life threatening status. } \\
\text { Some examples are third degree burns or second degree burns over large parts of } \\
\text { the body, a bump on the head that causes loss of consciousness, fractured bone, } \\
\text { dehydration or exposure. }\end{array}$ \\
\hline Severity 3 & $\begin{array}{l}\text { Injuries that pose an immediate life threatening condition if not treated adequately } \\
\text { and expeditiously, Some examples are; uncontrolled bleeding, punctured organ, } \\
\text { other internal injuries, spinal column injuries, or crush syndrome. }\end{array}$ \\
\hline Severity 4 & Instantaneously killed or mortally injured \\
\hline
\end{tabular}

Table 3.3 Injury Levels Calculated in Hazus (FEMA 2012a)

Additional variables and data are required of the user prior to running the module. Users are provided three different time options:

- Earthquake striking at 2:00 a.m. (nighttime scenario)

- Earthquake striking at 2:00 p.m. (daytime scenario)

- Earthquake striking at 5:00 p.m. (commute time scenario)

The different scenarios are chosen to reflect the highest number of casualties that could be expected for the population at home, at work/school, and during rush hour. The population for each census tract is distributed into six basic groups: residential, commercial, educational, industrial, commuting, and hotel. Population distribution is inferred from the data provided by the Census Bureau and Dun and Bradstreet. Inherent error is possible in the data but not accounted for in the module's calculation. Users are, however, able to make modifications to the default information considering improved knowledge. 
The other modules in Hazus provide the ground and structural conditions necessary to estimate the losses. The following default casualty rates are then provided:

- Indoor casualty rates for structural damage by model building type according to level of structural damage, with or without structural collapse;

- Outdoor casualty rates for structural damage by model building type according to level of structural damage; and

- Commuter casualty rates by bridge for the complete damage state.

Casualties are calculated using a casualty event tree beginning with the initial event (earthquake scenario) and following the possible course of events leading to loss of life or injuries. Figure 3.2 on the proceeding page provides a conceptual example of the figure trees considered in the module. Thus the number of occupants killed is a product of the number of occupants of the building at the time of the earthquake and the probability of an occupant being killed.

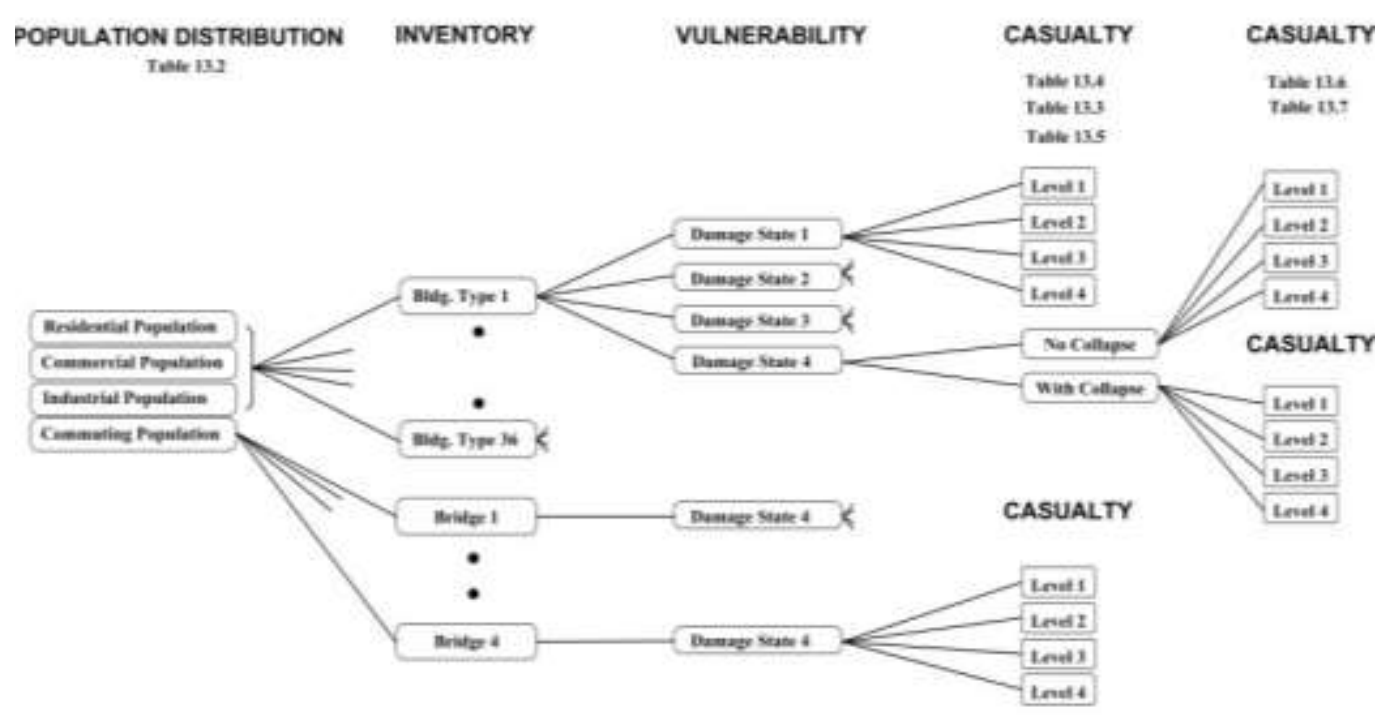

Figure 3.2 Hazus Casualty Event Tree Model (FEMA 2012a) 
The Hazus guidebook notes it is possible for differing levels of earthquake preparedness, such as the effectiveness of the emergency medical system and the training of the public in personal protective measures such as "duck and cover," might cause casualty rates to differ. Casualty patterns according to people who evacuate collapsed buildings either before or immediately after the collapse is also difficult to quantify since most postearthquake reconnaissance efforts do not take note of this information when treating patients.

Casualties may also occur due to outdoor falling hazards such as damaged parapets, loosened bricks, broken window glass, signage, awnings, or non-structural panels. In the United States, casualties due to outdoor falling hazards have been caused primarily by falling unreinforced masonry, yet it is noted that people outside of buildings are less likely to be injured or killed than those inside. For example, 20 out of 185 people killed in the Loma Prieta earthquake were outside (Wagner 1996). This earthquake occurred in a relatively suburban and rural area, thus it is quite possible for a given earthquake to occur at a time of day and in a densely built-up locale where relatively more exterior casualties would occur. Hazus assumes, however, that those who manage to evacuate are neither killed nor receive life threatening injuries. The problems associated with the assumptions in the casualty model will be explored in Chapter 4 .

The displacement of persons due to loss of housing habitability can have a substantial effect on the ability of an area to recover following an earthquake. Hazus accounts for this loss and realizes that many households may need alternative short-term shelter provided by family, friends, renting apartments or houses, or public shelters provided by 
relief organizations such as the Red Cross, Salvation Army, and others. The estimates provided by Hazus can be extremely beneficial to emergency planners in order to plan for short-term housing needs and project long-term impacts on the housing stock. As such, the module provides two estimates. First, Hazus provides an estimate of displaced households due to the loss of habitability, calculated directly from damage inflicted on the residential occupancy inventory and the loss of water and power. Second, an estimate is provided to account for the number of people requiring only short term shelter. Displaced households accounts only for homes affected due to ground shaking or failure, and neglects to account for fire, inundation, or hazmat release. Users are advised to perform specific, targeted assessments on areas to account for these types of losses.

As with the other modules, users can modify the default existing data based on improved information on the housing stock of the region of assessment. The estimated number of displaced people is then calculated by combining the number of uninhabitable dwelling units due to actual structural damage and the number of units perceived to be uninhabitable by occupants. The guidebook notes that approximately 80 percent of predisaster homeless will seek public shelter and that approximately one-third of those in public shelter come from residences with little or no structural damage. Methods to account for these residents are not provided.

The population is stratified in the model according to race and nationality due to the assumption that Hispanic populations from Central America and Mexico tend to be more concerned about reoccupying buildings than other groups, and therefore their residency in assistance housing will be longer. The guidebook states, "This tendency appears to be 
because of the fear of collapsed buildings instilled from past disastrous Latin American earthquakes..." and also notes, "Such tendencies will probably expand to all ethnic groups should a large number of casualties occur.” (FEMA 2012a). Users can also add weights to account for age and ownership, as young families tend to seek shelter in a larger proportion than other age groups due to lower per capita income.

As noted, long-term housing recovery can have a significant impact on a region. Following an earthquake, long-term needs are accommodated by importing mobile homes, reductions in vacancy rates, net emigration from an area, and eventual repair or reconstruction of the housing units. Replacement of permanent housing is subject to normal market and financial forces, thus low-income housing is the last type of housing to be replaced. Examples from the Loma Prieta and Northridge earthquakes show that housing recovery times span a wide range and are typically far longer than might be estimated from typical planning rules of thumb. Replacement of housing tends to be very dependent on settlement of insurance claims, federal disaster relief, the effectiveness of smaller contractors, and the financial viability of the home or apartment owner. Hazus attempts to account for the variability in replacement by stratifying houses according to socio-economic status, then projecting replacement cost by estimating "an appropriate mix of construction classes" classified as economy, average, custom, and luxury, then estimating replacement costs accordingly. Actions taken by the state and local government could expedite and reduce costs of the process, but rebuilding usually takes longer than most commercial, industrial, and institutional entities.

e. Direct and Indirect Economic Losses 
Prior to Hazus, loss estimation studies generally limited the consideration of loss to estimates of the required repair and replacement of the given building stock. Hazus goes beyond the former methods by providing estimates of the associated loss of building contents and inventory in addition to the structural and nonstructural repair costs caused by building damage. The direct economic loss estimates are considerably powerful and useful for communicating risk to the public, setting insurance rates, and crafting mitigation strategies. The "Indirect Economic Losses" module includes additional estimates for losses accrued from lack of functionality, such as business interruption and rental income losses. The "Direct Economic Losses" module thus explicitly focuses on losses resulting from physical damage.

To calculate economic effects, commercial buildings are stratified according to sector type. Using the sector as an indicator, the methodology will project default values for each business's recovery and interruption time. Hazus then uses the building data provided to produce estimations for relocation expenses, inventory losses, loss of proprietors' income, rental income losses for businesses, relocation cost, and recovery costs. Relocation costs are incurred when the level of building damage is such that the building or portions of the building are unusable while repairs are being made. Hazus limits its scope to determining disruptions costs and the cost of renting temporary space. Relocation expenses are a function of the floor area, the rental costs per day per square foot, disruption costs, the expected days of loss of function for each damage state, the type of occupancy, and the structural damage state itself. 
Direct losses due to transportation and utility systems are also considered but are limited to the cost of replacement or repairing damage to the lifeline system. Loss estimates are not given for high potential loss facilities or hazmat stores. Thus the "Direct Economic Losses" module is considerably limited. The guidebook notes, "The real socio/economic picture is much more complex: economic impacts may have major societal effects on individuals or discrete population groups, and there may be social impacts that ultimately manifest themselves in economic consequences." (FEMA 2012a). These correlations between damage and long-term loss are hard to discern, quantify, and model due to unavailable data and complexity of issues. Yet these additional burdens and losses must be considered despite their complexity due to the considerable amount of influence they can have on a community. For example, losses from business interruption and lack of building space to operate in may cause significant unemployment in the region and have a lasting effect on the region's prosperity. Thus estimates to account for losses from business interruption and job losses could provide mitigation planners with tools to plan for resources needed following an event.

Indirect economic losses include losses that are not directly related to the physical components of the area of study, hence their "indirect" title. Hazus limits indirect economic loss calculations to businesses, and excludes losses that could occur for residential home damage. Accounting for indirect economic losses requires the user to think of potential losses from induced supply shortages (forward linkages) and demand reductions (backward linkages). Forward linking businesses rely on regional customers to purchase their output while backward-linked businesses rely on regional suppliers to 
provide their inputs. Both are equally vulnerable to earthquakes. Businesses will have three options: 1) secure additional supplies from outside regions (imports); 2) obtain additional supplies from the undamaged factory (excess capacity); and 3) draw from other business's unsold stock. Hazus does not deal with the varying outcomes of business decisions, as it is impossible to unquestionably know individual business response, despite the impact these decisions will have on long-term economic recovery.

Study regions for the Indirect Economic Loss module may consist of single counties, several counties comprising a metropolitan area, or lower levels of aggregation such as census tracts. The estimates will be most accurate, however, when applied to areas with cohesive economic tendencies, as Hazus can then meaningfully represent the region's economic structure. Additionally, focusing this module on small census tracts may misrepresent the relationship between place of work and place of residence, as many people do not work in their census tract.

Timelines are provided at various levels of temporal resolution for the fifteen year period following the earthquake to project short and long-term economic effects. Weekly time intervals are used for the first two months. Monthly intervals are then used between month two and twenty four. Lastly, annual evaluations are used from year two to fifteen. The timelines provide useful estimations for recovery planning.

Hazus will use an input-output model to trace inter-industry ripple effects. Input-output modeling traces the flows of goods and services among industries and from industries to households, governments, investments, and exports. The trade flows indicate how much 
of each industry's output is comprised of its regional suppliers' products, as well as the inputs of labor, capital, imported goods, and the services of government. The model can be manipulated to reveal the economy's interconnectedness in terms of direct transactions and dependencies between businesses and the built environment. Critics claim that this type of modeling is insensitive to price changes, technological improvements, and the potential for input substitution at any given point in time. Regardless, the creators of Hazus have assumed this method to be the best for estimating damage and recovery time.

The Indirect Economic Loss module is linked to other modules through three channels in which damage is introduced. First, building damage will cause loss of function and thereby cut output. Hazus accounts for this by creating specific modules for each type of occupancy class (i.e. agriculture, mining, manufacturing, service, etc.). Second, Hazus considers the stimulus effect caused by post-disaster spending on reconstruction, repair, and replacement of damaged buildings and their cotenants. Lastly, the reconstruction inputs for transportation and utility lifeline damage will also provide a stimulus effect and is accounted for in Hazus accordingly. Reconstruction spending, financed by both private and public initiatives, exerts a powerful influence on indirect loss and recovery time; therefore it is crucial for this factor to be accounted for in the module.

To create the most accurate indirect economic loss estimates possible, users are encouraged to provide the variables listed in Table 3.4 below. 


\begin{tabular}{|c|c|c|c|}
\hline Variable & Definition & Units $^{(a)}$ & $\begin{array}{l}\text { Default } \\
\text { Value }\end{array}$ \\
\hline $\begin{array}{l}\text { Current Level of } \\
\text { Employment }\end{array}$ & $\begin{array}{l}\text { The number of people gainfully employed, by } \\
\text { place of work (not residence). }\end{array}$ & Employed persons & $\begin{array}{l}\text { Region- } \\
\text { specific }\end{array}$ \\
\hline $\begin{array}{l}\text { Current Level of } \\
\text { Income }\end{array}$ & Total personal income for the study region. & Million dollars & $\begin{array}{l}\text { Region- } \\
\text { specific }\end{array}$ \\
\hline $\begin{array}{l}\text { Composition of } \\
\text { the Economy } \\
\text { (Default Data } \\
\text { Analysis only) }\end{array}$ & $\begin{array}{l}\text { 1. Primarily manufacturing } \\
\text { 2. Primarily service, secondarily manufacturing- } \\
\text { 3. Primarily service, secondarily trade. }\end{array}$ & 1,2 , or 3 & 1 \\
\hline $\begin{array}{l}\text { Supplemental } \\
\text { Imports }\end{array}$ & $\begin{array}{l}\text { In the event of a shortage, the amount of an } \\
\text { immediate product unavailable from local } \\
\text { suppliers which may be obtained from new } \\
\text { imports. }\end{array}$ & $\begin{array}{l}\text { Percent of current } \\
\text { total current annual } \\
\text { imports (by } \\
\text { industry) }\end{array}$ & $\begin{array}{l}\text { Defaults } \\
\text { for } \\
\text { "distinct } \\
\text { region" }\end{array}$ \\
\hline $\begin{array}{l}\text { Inventories } \\
\text { (Supplies) }\end{array}$ & $\begin{array}{l}\text { In the event of a shortage, the amount of a good } \\
\text { that was supplied from within a region that can } \\
\text { be drawn from inventories within the region. }\end{array}$ & $\begin{array}{l}\text { Percent of annual } \\
\text { sales (by industry) }\end{array}$ & $\begin{array}{l}0 \text { (for all } \\
\text { industries) }\end{array}$ \\
\hline $\begin{array}{l}\text { Inventories } \\
\text { (Demand) }\end{array}$ & $\begin{array}{l}\text { In the event of a surplus, the amount of a good } \\
\text { placed in inventory for future sale. }\end{array}$ & $\begin{array}{l}\text { Percent of current } \\
\text { annual sales (by } \\
\text { industry) }\end{array}$ & $\begin{array}{l}0 \text { (for all } \\
\text { industries) }\end{array}$ \\
\hline $\begin{array}{l}\text { New Export } \\
\text { Markets }\end{array}$ & $\begin{array}{l}\text { In the event of a surplus, the amount of a good } \\
\text { which was once sold within the region that is } \\
\text { now exported elsewhere. }\end{array}$ & $\begin{array}{l}\text { Percent of current } \\
\text { annual exports (by } \\
\text { industry) }\end{array}$ & $\begin{array}{l}\text { Defaults } \\
\text { for } \\
\text { "distinct } \\
\text { region" }\end{array}$ \\
\hline $\begin{array}{l}\text { Percent } \\
\text { Rebuilding }\end{array}$ & $\begin{array}{l}\text { The percent of damaged structures that are } \\
\text { repaired or replaced }\end{array}$ & Percent & $95 \%$ \\
\hline $\begin{array}{l}\text { Unemployment } \\
\text { Rate }\end{array}$ & $\begin{array}{l}\text { The pre-event unemployment rate as reported by } \\
\text { the U.S. Bureau of Labor Statistics }\end{array}$ & Percent & $6 \%$ \\
\hline $\begin{array}{l}\text { Outside } \\
\text { Aid/Insurance }\end{array}$ & $\begin{array}{l}\text { The percentage of reconstruction expenditures } \\
\text { that will be financed by Federal/State aid } \\
\text { (grants) and insurance payouts. }\end{array}$ & Percent & $50 \%$ \\
\hline Interest Rate & $\begin{array}{l}\text { Current market interest rate for commercial } \\
\text { loans. }\end{array}$ & Percent & $5 \%$ \\
\hline $\begin{array}{l}\text { Restoration of } \\
\text { function }\end{array}$ & $\begin{array}{l}\text { The percent of total annual production capacity } \\
\text { that is lost due to direct physical damage, taking } \\
\text { into account reconstruction progress. }\end{array}$ & $\begin{array}{l}\text { Percent (by } \\
\text { industry, by time } \\
\text { interval for } 5 \text { years) }\end{array}$ & $\begin{array}{l}\text { Defaults } \\
\text { for } \\
\text { moderate- } \\
\text { major event }\end{array}$ \\
\hline $\begin{array}{l}\text { Rebuilding } \\
\text { (buildings) }\end{array}$ & $\begin{array}{l}\text { The percent of total building repair and } \\
\text { reconstruction that takes place in a specific year. }\end{array}$ & $\begin{array}{l}\text { Percent (by time } \\
\text { interval for } 5 \text { years) }\end{array}$ & $\begin{array}{l}56 \%(\mathrm{yr} .1) \\
36 \%(\mathrm{yr} .2) \\
10 \%(\mathrm{yr} .3) \\
\end{array}$ \\
\hline $\begin{array}{l}\text { Rebuilding } \\
\text { (lifelines) }\end{array}$ & $\begin{array}{l}\text { The percent of total transportation and utility } \\
\text { lifeline repair and reconstruction that takes place } \\
\text { in a specific year. }\end{array}$ & $\begin{array}{l}\text { Percent (by time } \\
\text { interval for } 5 \text { years) }\end{array}$ & $\begin{array}{l}70 \%(\mathrm{yr} .1) \\
25 \%(\mathrm{yr} .2) \\
5 \%(\mathrm{yr} .3) \\
\end{array}$ \\
\hline Stimulus & $\begin{array}{l}\text { The amount of reconstruction stimulus } \\
\text { anticipated in addition to buildings and lifelines } \\
\text { repair and reconstruction. }\end{array}$ & $\begin{array}{l}\text { Percent (by } \\
\text { industry, by Time } \\
\text { interval for } 5 \text { years) }\end{array}$ & $0 \%$ (for all) \\
\hline
\end{tabular}

Table 3.4 User-Supplied Inputs for Calculating Economic Loss (FEMA 2012a)

The model was built considering patterns from previous disasters, suggesting the

following: 1) normal spending patterns are not significantly altered post-disaster; 2) the

workforce is highly mobile, particularly in the construction sector; and 3) relative prices 
do not change appreciably. If excess demand is detected, the algorithm will check to see if sufficient capacity exists in the relative sector.

The output of this module is released in two reports. The first provides users with the percent and level of indirect economic impact for the study region economy in terms of employment and income effects for a region that receives outside aid after the disaster. The second report will provide the percent and level of indirect economic impact for the study region's economy in terms of employment and income effects for a region that does NOT receive outside aid.

The guidebook also suggests the following alterations that could be considered and incorporated into the overall loss:

1. Expand the number of industries to better reflect building classes and individual lifelines (i.e. beyond the standard agricultural, mining, construction, etc. categories).

2. Investigate the implications of how shortages and surpluses are addressed. It is assumed in the module that producers will look to regional excess capacities, yet local producers may look to imports as a source of replacement. Performing survey research on the area businesses to ascertain how producers might actually respond.

3. Make parameter values sector specific, instead of having supply and demand be identical across all sectors.

4. Approximate price effects. Significant relative price changes generally do not occur due to the illegality of price gouging, but can happen for certain goods regardless.

5. Extend the model to assess indirect loss/gain incurred by surrounding regions and the national economy. Demands elsewhere may suffer as a result of federal money being directed to disaster zones. 
Lastly, the Hazus guidebook also instructs users to consider the long term national effects of providing disaster assistance. As with households, governments cannot escape the financial implications of increased spending for disaster relief. Additional debt must be taken on to provide assistance and make repairs, thereby forcing budgetary decisions to compensate for the additional payments. The Hazus guidebook notes that the government will need to choose to raise taxes, cut low-priority programs, curtail services, or amass additional debt, shifting the burden onto future taxpayers. Thus from a national stance, indirect losses can be measured by deriving the regional indirect impacts, adjusted for the liability the Federal government incurs in providing disaster relief, and for offsetting increases in outputs elsewhere.

Most analyses are not done on a national level, thus this type long-term, indirect economic effect is not accounted for. Yet the amount of disaster assistance provided by the federal government will undoubtedly influence the indirect economic effects of a region. For example, a higher rate of unemployment could cause normal household demands to erode, thereby decreasing demand for many products and services from areas of the nation unaffected by the event. Thus while Hazus is useful to provide localized impact of an earthquake, the national forces that help determine the region's economic loss, recovery, and general well-being should not be overlooked.

\section{Conclusion}

This section and chapter has presented the Hazus tool and the multiple modules that lie within the software. As a review, the following modules and their inputs/outputs have been presented: 
1. Potential Earth Science Hazards - ground motion and failure;

2. Direct Physical Damage - general building stock, essential and high potential loss facilities, lifelines, transportation systems, and utilities;

3. Indirect Physical Damage - inundation, fire, hazardous material release, and debris;

4. Direct Loss - building stock, casualties, and displacement; and

5. Economic Loss - direct and indirect.

The calculations are performed using both data provided by the Hazus inventory and through sources acquired by the user. As this chapter shows, Hazus users have many options in performing an analysis. The outstanding number of variables, data inputs, calculations, and outputs that are embedded within and produced through Hazus attest to the tool's power.

Yet, as the following chapter will attest, Hazus is not perfect. Furthermore, the blackboxing of Hazus and the data assumptions within it attest to multiple problems in the proclamation of its results. FEMA does not do a standard review of all Hazus productions. The sheer complexity of the tool and individual decisions during use prevents a systematic review of existing reports from occurring, thus it is likely that many outputs could be questionable and/or invalidated with further examination. Thus raising awareness of the tool's major shortcomings and the potential abuse of its outputs is the soundest form of analysis possible for the scope of this thesis. 


\section{Chapter 4: Hazus Critique and Analysis}

As noted thus far, society's perception of risk and its ability to act to reduce that risk is dependent upon a variety of variables. Seismic risk in the context of Portland has been heavily influenced by the history of earthquake knowledge and the region's late awareness of its own seismic threat. This thesis has demonstrated how translating the knowledge on seismic risk from purely geologic speak and into monetary, casualty, or structural damage estimates is required in order to promote awareness and enact change. Several lines of evidence and research presented demonstrate the influential power of risk frameworks on society's judgment of acceptable risk. Essentially, tools such as Hazus create cognitive shortcuts; these shortcuts then influence personal judgments and actions; and a region's state of damage and recovery is effected if and when the disaster occurs according to decisions made prior (Bostrom, Turaga, and Ponomariov 2006). Failure to communicate the hazards and provide necessary shortcuts results in detrimental consequences two parties: first, for the public at large, as greater casualties and economic loss occur from lack of preparedness; and second, for the holders of the hazard knowledge, as demonstrated by the five scientists charged with manslaughter in L'Aquita, Italy. Thus Hazus plays a vital role in this process by communicating the complexities of esoteric geologic knowledge and the built environment into simple, understandable numbers for the greater public.

Explicit power is therefore embedded in the tool's outputs. The consequences of Hazus being seriously wrong on a given estimation could cause the relative population to be unaware of their own risk and grossly underprepared. As noted, predicting the 
consequences of earthquakes to the built environment and societies is of significant importance for local and national emergency planners, civil protection services, governmental agencies, and reinsurers, as well for global organizations as United Nations and the World Bank; thus the potential for a tool to have varying outputs should be a large concern of users, researchers, and policymakers alike (Erduran and Lindholm 2012). This chapter will examine the major flaws noted in the Hazus system according to the literature, user comments, and personal examination.

This analysis is done in the context of Portland, with special attention given to the gaps in the tool that do not account for Portland-specific vulnerabilities. Many of these criticisms could likely be applied to other regions with similar seismic problems or environmental vulnerabilities. The chapter will first examine the problems with inaccurate or outdated data provided in the Hazus database or user inputs, then consider the tool's failed ability to include multiple variables that are vital to the risk estimation process and are of particular concern to the Portland region. Finally, attention will be given to the inability of Hazus to account for casualties, and the impact of casualty information on public perception.

\section{Data}

The quality of data used in any model influences the accuracy of the model's output. Incorrect, outdated, or mismatched values are likely to occur in many, if not all, modeling and estimation techniques, and are particularly dangerous in input-output modeling 
methods, as data quality is crucial to results (Okuyama 2007). To address this problem, the Hazus technical manual states the following:

"Uncertainties are inherent in any loss estimation methodology - arising in part from incomplete scientific knowledge concerning earthquakes and their effects upon buildings and facilities. They also result from the approximations and simplifications that are necessary for comprehensive analyses. Incomplete or inaccurate inventories of the built environment, demographics, and economic parameters add to the uncertainty." (FEMA 2012a)

This statement from FEMA insists that inaccurate or varying estimations are largely the fault of the software user. The software handbook does not, however, divulge into the likely errors that could occur from using incorrect data provided in the Hazus inventory. It is unlikely for all users to bring all of their own data into the program due to the sheer quantity of data required to produce most outputs. Thus the deference to potentially inaccurate data is problematic for multiple reasons.

First, the inventory data on building stock, lifelines, and transportation systems is likely to be considerably outdated. The building inventory provided in Hazus is stocked with data from 2000, currently making it thirteen years old. In the context of Portland, hundreds of buildings have been built in the residential, office, and industrial sectors in the past thirteen years. A large portion of these buildings are located within the Pearl District, which sits atop highly liquefiable soil, according to Yumei Wang of the Oregon Department of Geology and Mineral Industries (OPB 2012). For example, according to RLIS data provided by Portland State University, approximately 200 buildings have been built or restructured in the Pearl District in between the years of 2000-2011, all of which 
would not be accounted for in the Hazus inventory. Utility lines and transportation infrastructure were also built to accommodate the new growth, which Hazus inventory will also miss.

Seismic updates to existing buildings or infrastructure could also have occurred within the gap between data collection and Hazus operation. The software classifies the transportation systems according to their seismic strength, or whether the equipment is anchored down or not. Thus changes in the study region's composition will possibly lead to a considerably inaccurate estimate of loss and damage.

The decision to of Hazus to generalize buildings to the centroid of the census tract is also a large flaw. The guidebook states, "The entire composition of the general building stock within a given census tract is lumped at the center of the census tract." (FEMA 2012a) Buildings are classified and grouped according to a set of pre-defined building classes, allowing damage and loss prediction models to be developed for the average characteristics of the total population of buildings within each class. This can be problematic for the study area when considering non-categorical buildings, buildings that have recently lost or gained tenants, seismic upgrades, new buildings, or demolition of old buildings. Hazus will not be able to capture a fully accurate loss estimate if a census tract's building composition is comprised of buildings that are in reality unrelated to the pre-determined categories, or if the tract has changed through the aforementioned means.

On a smaller, building-by-building analysis, the guidebook suggests users defer to seismic/structural engineering expertise to estimate specific building damage, as the 
models are "more reliable as predictors of damage for large, rather than small, population groups." The discouraging of Hazus use on specific buildings alludes to two problems: first, the stark differences between buildings prevents the Hazus algorithm from being adequately accurate across all types of buildings; and second, the multitude of users that disregard this section and use the software on a small number of buildings or considerably small region are likely to be unacceptably wrong. There is no way to account for these cases, however, as the FEMA department administering Hazus does not review each user's projections.

In addition to flawed data for buildings, transportation systems, and utilities, Hazus users could neglect to provide updated census data. The inventory was built with data from the 2000 Census, thereby excluding any migration into or out of the region of study. This is troublesome, as additional persons contribute to higher density, additional economic loss, displacement, and casualties. According to data provided by the U.S. Census Bureau, the City of Portland has gained approximately 70,000 people from 2000 to 2011 . Other cities, especially in regions of high seismic activity along the West Coast, have also witnessed substantial population changes. Therefore, a user equipped exclusively with 2000 inventory data will be considerably inaccurate when projecting losses. Population growth and change has undoubtedly occurred in other regions of Hazus analysis, and users should take caution when mining the software's inventory.

Hazus also uses population data to acquire demographic composition of an area to provide a more accurate assessment of loss and housing requirements. The inventory data is provided as a generalization to the census block level, yet it is likely that the census 
blocks have changed in composition, thereby affecting the relocation, economic loss, and homeless estimates generated in the model. This is especially important to consider in light of the software's decision to stratify census block residents according to race. As noted in Chapter 3, Hazus assumes all Hispanic populations will reside within temporary housing for longer periods of time. This assumption is made based off of the rationale that Hispanics have lasting memories instilled from past disastrous Latin American earthquakes. Hazus assumes these tendencies for all ethnic groups, yet provides no justification or literature to support this assumption. Areas with higher proportions of minorities will appear to be more costly due to their preference to stay in temporary housing for longer periods of time. A negative perception of the communities will be reinforced as a result of the higher cost assumptions. Furthermore, the tool makes the decision to stratify users by age or ownership status optional, even though both options appear to have more of an effect on temporary housing decisions than race. Thus regional composition changes and illegitimate projections of housing tendencies and economic loss should be considered when performing an analysis.

This section has demonstrated the inaccuracies likely to occur with outdated and inexact data. The modeling and algorithms could be perfect within the software, yet inaccurate data will completely invalidate the study, and fail to be a legitimate reflection of the region. Users of Hazus are hopefully aware of the affect inaccurate data can have on their loss estimations, and take this into consideration before presenting their findings.

\section{Additional Hazards}


The previous section highlighted the serious problems with using inaccurate data to estimate loss. The failure to use accurate data is a major problem for most modeling schemes. The proceeding section will examine a Hazus-specific problem: failure to account for hazards that are a byproduct of earthquakes. Fires, flooding, volcanos, and hazardous material (hazmat) are a few of the consequential events that are not fully considered in the model, yet often cause more damage to an area. This section will examine this failure and the affect it can have on the overall output, users' perception of risk, and neglect in policy solutions as a result of unaccounted for risk.

The most concerning secondary hazard is the incomplete methodology to calculate losses from fires. Hazus will provide users with estimates describing the number of ignitions, total burned area, population exposed to the fires, and building value consumed by the fire, yet the guidebook notes the fire coverage to be incomplete. The software will not provide estimates of household displacement, direct economic loss, and indirect economic loss. In turn, these values will not be included in the study area's overall damage, casualty, and economic loss estimates. The Hazus guidebook suggests users examine these separately through the assistance of experts, thus making this estimate an additional monetary and time cost for the user and inhibiting their ability to generate a complete picture of expected loss.

Failing to include fires in the estimates is misleading and erroneous, as fires resulting from earthquakes can often outweigh the total losses from direct damage caused by an earthquake. Academic research has shown fires following earthquakes in Japan and North America to be a major factor for post-earthquake damage in the twentieth century. For 
example, over 203 acres (approximately 70 U.S. city blocks) of urban land and 5,500 buildings were consumed by fires in the 1995 Kobe Earthquake. The Kobe fires resulted from the incomplete performance of the water system, the traffic congestion, and the building density of the city. Despite this loss, little attention has been given to reducing post-earthquake fires through individual building design or urban design (Mousavi, Bagchi, and Kodur 2008). Thus a gap exists on the damage estimation end to account for losses from fire and relay the information to relevant persons with the ability to mitigate and reduce the fire risk.

According to literature on post-earthquake fires, factors that influence a fire hazard following an earthquake include construction material type, building usage and amenities, loss of water supply for extinguishing fires, response time of occupants and emergency crews that might be affected by obstructed access and insufficient resources, and architectural configuration including improper building separation (Mousavi, Bagchi, and Kodur 2008). In attempt to account for the fire-related variables, the Hazus database will provide the number of fire stations, number of engines at each fire station, and geographical location of the station. The user is also provided with optional inputs including wind speed, wind direction, and speed of fire trucks after earthquakes. These optional variables are certainly difficult to assess independently, and expert opinion may not suffice. For example, generalizing the speed of fire trucks is one critical input that could impact human life, building damage, and overall well-being of an area. Thus there is not a sufficient match between variables that affect fire damage according to the literature and variables Hazus accounts for. 
The ability for firefighters to sufficiently respond in Portland post-quake is largely a question of the fire station's building seismic capacity and the status of the transportation network's infrastructure (buildings, roads, etc.). Specifically, Portland's neighboring suburb of Vancouver, Washington, has five of their ten fire stations housed in unreinforced masonry buildings, thus rendering their trucks useless in the case of a large earthquake (Albrecht 2011). The stations within Portland are mostly structurally sound, yet could suffer damage depending on the quake's strength (OPB 2012). The inability of Vancouver's trucks to respond to damaged buildings will undoubtedly cause strain on the entire region's mitigation effort. Hazus will not be able to account for the entirety of strain, especially given that an analysis on Portland would exclude neighboring Vancouver in the state of Washington. The effect of damaged roads or bridges on fire truck transportation is also excluded; both factors that would have a significant effect on response time. Users hopefully take this into consideration when using the tool, and account for these vulnerabilities accordingly.

An estimate of casualties from post-earthquake fires is also excluded from the casualty module. The Hazus guidebook asserts these types of casualties to have a low probability historically, yet recent earthquakes provide opposing evidence. For example, approximately 700 Kobe residents were lost in fires following the devastating 1995 earthquake (Horwich 2012). In March 2011, Japan lost approximately 165 residents to fire in the great Tohoku earthquake. Lastly, approximately 115 residents of Christchuch, New Zealand perished in fires as a result of the February 2012 earthquake (Bayer 2012). These accounts provide evidence that fires from earthquakes must be taken seriously 
when estimating potential damages. The failure to do so may result in surprise and underpreparation by fire departments and emergency bureaus when earthquakes hit, as was demonstrated in Christchurch. Additional detail on the miscalculation of casualties is provided in Section IV.

As noted by Mousavi et al., (2008), the availability of water has a profound effect on the amount of fire damage within a region. Portland's post-quake water availability is particularly vulnerable due to the region's outdated water infrastructure. According to the Portland Bureau of Emergency Management (PBEM), the Portland water system is susceptible to earthquake shaking which will damage water pipelines, reduce water flow/pressure, inhibit firefighting abilities, and threaten public health. Some of the water infrastructure is more than one hundred years old and at a high risk of damage from a seismic event. The PBEM Earthquake Response Appendix also notes that the Portland Water Bureau supplies water to more than 800,000 retail and wholesale facilities, thereby implying major economic losses to occur from loss of water (PBEM 2012). Hazus does not consider the increase in fire damage resulting from the lack of water for suppression or the long term effects of water-loss on a region. Again, this prevents Hazus from accounting for a holistic picture of indirect economic damage. With this in mind, Hazus is considerably lacking in estimating the long-term effects resulting from post-earthquake fires.

Economic loss caused by inundation and release of hazardous materials (hazmat) is also not considered. The handbook requests the user to undertake specific studies to estimate these losses despite the substantial damage they could cause. For example, a 6.8 
magnitude earthquake in the Nisqually Valley, Washington, caused a number of hazmat releases, including a leak and explosion of a natural gas line, release of asbestos, metal plating solution, and petroleum. Liquefaction of the fill material underlying the storage facility contributed to the release of these materials, affecting the storage facility as well as several others nearby that were severely damaged and subsequently abandoned (Santella and L. J. Steinberg 2011). Similar incidences occurred in the Loma Prieta and Northridge earthquakes in California that damaged the region and caused due concern among residents.

The evacuation and demolition of buildings affected by a serious hazmat release certainly contributes to the region's economic loss and recovery. The inability to account for this is highly problematic in the context of Portland due to the city's large number of industrial facilities situated directly atop liquefiable soil. PBEM comments on this vulnerability in the city's Earthquake Response Appendix by noting:

"Portland's critical energy infrastructure, including high voltage electricity transmission, fuel pipelines, tank farms, ports and facilities, is concentrated along the Willamette River in the Northwest Industrial and Swan Island areas. Much of the existing infrastructure was constructed prior to current seismic safety specifications and many of the petroleum storage tanks, piers, marine docks and buildings are inadequately hardened. This area consists primarily of artificial fill and is vulnerable to liquefaction and lateral spreading. The concentration of facilities and hazardous materials in this area has the potential to produce damaging cascading effects including fires from ruptured natural gas and fuel lines, hazardous material releases and debris blockage of the Willamette River." 
The PBEM's concern highlights the immense danger and potential economic loss for the Portland region that Hazus fails to account for. The damage that could occur to the industrial region is unimaginable and difficult to estimate, yet necessary in order to communicate risk, enact serious solutions to reducing vulnerability, and optimally prevent long-term economic loss. PBEM Director Carmen Merlo also expressed concern over the industrial region's vulnerable gas, hazmat, and water supply lines and storage facilities in an interview conducted as research for this thesis, and noted that her department realizes the extreme vulnerability and are looking at strategies for risk reduction. Portland is not currently undergoing any review of these problems to discover solutions, and public knowledge of this vulnerability is very low, thereby preventing apt outcry from Portland residents to enact change.

The noted secondary effects of earthquakes unaccounted or under-accounted for in the loss estimation modules should be of serious concern to users communicating the results of Hazus to the public. The inability to translate these hazards into loss estimations prevents residents from fully comprehending the risk at hand. The simple verbal warnings and prophecies from emergency management officials do not suffice in communicating the risk that fires, water unavailability, and hazmat release could cause. This section has uncovered these failings of Hazus and vulnerabilities within Portland. Hopefully additional action will be taken to reduce the risk and raise awareness.

III. Measuring Casualties 
Modeling potential casualties and injuries from hazards is difficult due to the lack of a systemic and consistent source of hazard mortality data. A lack of academic research from engineering, hazard mitigation, and urban planning fronts also contributes to light information on causes of casualties, thereby preventing strategies for casualty reduction from properly developing (Peek-Asa et al. 1998). The Hazus guidebook acknowledges the scholarly gap by noting, "Available data often have insufficient information about the type of structure in which casualties occurred and the casualty generating mechanism. Thus an attempt to develop very sophisticated models based on such data is neither feasible nor reliable.” (FEMA 2012a).

Chapter 3 outlined the methodology employed by Hazus to estimate casualties. The available literature on casualty estimation varies from the Hazus model assumptions, however. Bostrom, Turaga, and Ponomariov (2006) note that potential injuries and deaths from earthquake related building collapses are likely to be valued differently depending on factors such as the following:

1. Whether the building is presented as one of many, and what other attributes are evaluated at the same time;

2. The relative emphasis given various causal factors in the description of the collapse, for example whether the building was up to code at the time of input into the database and analysis;

3. Who might be injured and die, as value of statistical life is contingent on age; and

4. Recent experience, which helps to anchor the frame of reference for evaluating consequences (Bostrom, Turaga, and Ponomariov 2006). 
The four factors provide a basis for reflection and critique on the Hazus casualty estimation methodology. Bostrom's second factor regarding a building's seismic code status is particularly relevant to the Hazus critique, as data provided in the Hazus inventory and user-provided data are often outdated and missing a considerable amount of building specificities. This is especially true in estimations of large regions, such as the State of Oregon or the entire Cascadian region.

Bostrom's third factor, age, is also in disagreement with the Hazus methodology. A metaanalysis performed by Shoaf, et al., found that age is an influential variable that should be considered when performing injury and casualty estimations. They noted that a range of cultural factors, such as who sleeps where, are a major explanation of differential mortality observed across vulnerable sub-populations. For example, in the Kobe, Japan earthquake, over half of all fatalities were for people over sixty years old. Many of these fatalities were a result the elderly's residence preference for the ground floor of a building; an area that tends to result in higher mortality than higher floors (Shoaf et al. 1998). Thus the failure to include age in the casualty module and rely exclusively on a building's composition may result in an inaccurate count. Furthermore, estimates stratified by age may be beneficial to communicate and target specific groups for mitigation efforts. Hazus only considers age in regard to those under the age of 16 and whether or not the resident will be attending school.

The casualty module also excludes other causes of death that could substantially affect the overall toll. Many secondary causes of injury or loss include heart attacks, car accidents, and power failure which cause failure of a respirator or other necessary 
medical devise. Incidents during the post-earthquake search and rescue or postearthquake clean-up and construction activities, such as electrocution or explosion, could also occur. Lastly, secondary casualties could result from tsunami, landslides, liquefaction, fault rupture, dam failures, fires or hazardous material releases. To account for these possibilities, if the user is concerned, the guidebook suggests the user simply "initiate specific studies directed towards the problem," and does not provide advisable alternatives.

A final critique on estimation of casualties concerns the ability to access hospitals. First, Hazus is unable to account for the essential facility locations in relation to the facility's accessibility by the greater public. For example, if a hospital is unreachable due to blocked roads from debris, liquefaction, or broken bridges, it is likely that many of the injured will be unable to seek necessary care. This is a problem in Portland due to the location of its hospitals and seismic vulnerabilities of the structures. The PBEM is aware of these risks and notes, "All of the area hospitals are vulnerable to seismic damage which would result in a diminished ability to meet the healthcare needs of the region." (PBEM 2012). Furthermore, a few of Portland's major hospitals lie on the west side of the Willamette River, rendering them inaccessible to the majority of the population living on the east side. This vulnerability cannot be accounted for in Hazus despite the large risk it poses to the city.

The casualty projections made by Hazus are therefore questionable in their reliability, which is a significant problem due to the tendency for the public to fixate on casualty estimates as a measure for risk. Carmen Merlo, Director of the Portland Bureau of 
Emergency Management, also noted in an interview for this thesis that the casualty estimates provided in Hazus would not be something her department would publicize or trust due to the potential inaccuracies. In contrast, the Oregon Resiliency Plan blatantly states the Hazus projected casualties resulting from a major Cascadian quake. The plan estimates deaths ranging from 650 to 5,000, with another 600 to 5,000 deaths resulting from a tsunami (OSSPAC 2013). This announcement sent shockwaves into Oregon and across the nation due to the high estimates and scare tactics. A host of articles produced locally and nationally proclaimed the estimation of fiscal and personal loss, thereby instilling fear and concern into readers and the communities at risk. This scare tactic is considered useful by some for communicating seismic awareness and encouraging residents to personally improve their seismic safety activities. There is warrant for concern, however, if these estimates are grossly off base.

As outlined, the use of the Hazus casualty estimates is skewed for four overarching reasons. First, the lack of empirical studies and data examining causes of earthquake casualties precedes and prevents a fully accurate model from being produced. Second, the inability to account for the entire population in the inventory data forces and inaccurate reflection of current occupancy rates in the building stock. Third, Hazus does not stratify building occupants according to age, which would provide greater accuracy and communicate risk with an ability to strategically target mitigation efforts. Lastly, the failure of Hazus to account for casualties caused by car accidents, heart attacks, and power failure reduces the accuracy of the projected death toll. This combination of factors, in conjunction with the potential for the estimates to be grossly mishandled and 
misinterpreted by the public at large, provide evidence to potentially invalidate the entire module.

Modules and tools used to estimate casualties will never provide a perfect fatality count or reflection of the study region. Regardless, the emotional tie to human life embeds these estimations with attention-grabbing power. For example, the Oregon Resilience Plan's casualty and monetary loss estimations inspired dozens of articles with titles such as "Hurricane Sandy Will Be Dwarfed by an Earthquake," "Scientists warn Oregon legislators of cataclysm when earthquake, tsunami strike," and "Scientists predict thousands will die from earthquake expected anytime on US West Coast.” As noted, these attention-grabbing titles serve to often serve to scare the public into preparedness and increase readership, as opposed to actually equipping the readers with knowledge on increasing their seismic safety. It is also likely that the sensationalist articles and casualty estimates could have a reverse effect by causing residents to adopt apathetic attitudes given the stark projection of the situation. Thus these estimations must be taken with a grain of salt, and providers of the information must take caution when relaying it to the public.

\section{Conclusion}

This chapter considered the largest flaws in the Hazus software and the impact these inaccuracies could have in the context of Portland, Oregon. As noted, loss estimations aid to establish public desire for minimum seismic safety standards, and provide necessary evidence to promote seismic safety, typically framed as establishing "acceptable risks" 
from the perspective of society. Hazus outputs will present the current standard of acceptable risks and project the information to the public for their interpretation, thereby providing ammunition to the public's pleas to increase mitigation activities. By not accounting for many of the most hazardous aspects of Portland's environment, Hazus is failing to provide the public with firmer estimates for loss, thereby weakening the case for additional mitigation efforts. Furthermore, Hazus is weakened by failing to reflect the current environment of the study region by using outdated data and misinformed building categories.

Additional problems are likely to exist in Hazus that remain outside of the scope of this thesis or require specific technological knowledge to assess. Furthermore, the migration of Hazus onto an online platform will likely be accompanied by additional or exacerbated flaws in data management, hazard exclusion, and casualty estimation. Regardless, the critiques presented here will stand as substantial to furthering the loss estimation process. This examination is important due to the black-boxing of tools such as Hazus, and the public's tendency to take the outputs of these tools at literal value. Thus additional knowledge on the tool's failings is intended to provide clarity for those interpreting the values, and realize the power Hazus holds in shaping public opinion in light of these flaws.

It must be noted that regardless of the discovered flaws, models can never be perfect. The randomness of human activity, natural forces, and response capacity is in constant flux. Each disaster is unique, and exactly the same hazard will never occur again, thus the outputs are not a forecast, but rather, a suggestion of what might happen (Okuyama 
2007). Models therefore are limited by uncertainty, and are sequestered to focusing on behaviors and responses according to previous events, using probability as a guide for future occurrences.

Specifically, it has been noted that the simplicity of input-output models such as Hazus to model economic loss creates a set of limitations, including linearity, rigid structure with respect to input and import substitutions, a lack of explicit resource constraints, and a lack of response to price changes (Rose 2004). While this is not optimal given the seriousness of the outputs and blind, unquestioning technological trust in models, these mechanisms must exist and continue to be used to enhance knowledge and prevent catastrophe. 


\section{Conclusion}

The primary goal of hazard estimation tools is to equip stakeholders, policymakers, and the public at large with knowledge on threats to the built environment. Failing to communicate nature-induced risks would be to partake in vindictive and shrewd behavior by the fault of governments, organizations, and all holders of this knowledge. In addition to raising awareness, communicating risk and providing heuristics for public understanding is of vital necessity to build support for policy, infrastructure improvement, and personal risk-reduction strategies. Thus it is hoped that universal understanding of the natural threats facing communities, cities, and nations can allow for greater cooperation and participatory action in order to assure a resilient and safe future for every person.

As this thesis has shown, problems arise when the risks and threats are not accurately estimated nor communicated properly. The late awareness of seismic risk in the Portland region has prevented the region from having seismically fit buildings and infrastructure, thereby putting the region at a serious disadvantage when compared to other at-risk cities such as Seattle and San Francisco, both of which have had longer periods of seismic risk awareness. This problem has been reflected in the sheer number of buildings, bridges, and other elements in Oregon that are going to face serious destruction in an earthquake due to their lacking seismic capacity.

In general, sheer complexity of an event may produce epistemic uncertainty, even if more knowledge about that event is found, as in the context of Portland and its recently discovered hazards. Earthquake risk embodies uncertainty, as the randomness of these 
events completely negates the ability to accurately predict them. The uncertainty of the exact date of a Juan de Fuca rupture prevents realistic solutions and upgrades from occurring, as it is easier for stakeholders to procrastinate than develop concrete solutions to these problems. Rather, to counter the uncertainty and promote change, tools estimating loss for these events are produced. These estimations tell the public "We don't know when the damage will occur, but we know how much the price tag will be."

Thus while scientific geologic knowledge fails to provide specific time estimations, engineering, structural, and social knowledge on the built environment and it's response to known geologic hazards fills the void in communicating risk to the public. Hazus translates the combined hazard estimation knowledge into real numbers - numbers of people dying, of businesses closing, and of economic peril. Providing these stark visuals to a non-expert public is the only way to overcome uncertainty and enact change.

The state of Oregon and city of Portland has remained blissfully ignorant in enacting earthquake policy despite the awareness of respective seismic risks. The state in particular has finally committed to reducing risk only after a Hazus assessment was performed this year in the Oregon Resilience Plan. The policy repercussions of this plan have not reached fruition due its newness. However, the commitment by the Oregonian legislature and outcry by the public following realization of Oregon's risk provides hope for the enactment of substantial risk-reduction strategies.

The research and assessment provided in this thesis has shown how Hazus and the information it produces to be considerably powerful yet potentially inaccurate. This was 
shown in Chapter 4 through three substantial critiques: outdated or imprecise data, unaccounted hazards, and casualty errors. These combined flaws justify the Office of Budget and Management's ineffective rating, and suggests that users take caution when using the tool and relaying the outputs to the greater public.

The likelihood of Hazus outputs to be inaccurate and misused is high. Users must counter this by realizing the clout embedded in the outputs and the consequences that arise from the rallied knowledge. The public will make decisions according to perceptions shaped by Hazus. These decisions can ultimately influence their survival and recovery from an earthquake. Thus the lasting and irreversible effects of Hazus outputs should be treated with sensitivity by its users, policymakers, and others with full awareness of the risks at hand.

Preparedness for disasters requires knowledge. As noted, a population will never be fully prepared to face all potential disasters. Cities will continue to come up with innovative and meaningful strategies to cope with unprecedented disaster risk and climate change, and hopefully provide knowledge to resources to the vulnerable population. A new era of disaster preparation has dawned in this way; the built environment must continuously adapt to unsuspecting or unanticipated situations. Hazus helps to model those situations and generate the necessary effects in spite of uncertainty.

Yet there is a need for sensitivity and analysis in projecting loss and risk knowledge. This thesis has demonstrated how the frameworks used to define risk now will have an effect on mitigation efforts and recovery later. This was demonstrated in the evolution of 
Portland's seismic awareness, how this evolution has affected the region's capacity to deal with earthquakes and created extreme vulnerability. The uncertainty initially experienced in the 1980's prevented mitigation action and seismic restructuring from taking place, and hindered full understanding and awareness from occurring on a public level. Furthermore, the results provided by Hazus in the past year through the Oregon Resilience Plan have finally given legislators the necessary push to begin enacting substantial changes and policy solutions to raise awareness and build resiliency in Oregon.

The tendency for users and the public to grant Hazus black-box status is worrisome, as this tool will be used to craft decisions that affect a community's capacity to cope with and recover from disasters. This thesis has also demonstrated the substantial problems within the black box of Hazus arising from unreliable and outdated data, missing hazards, and erroneous casualty calculations; all of which seriously affect the reliability of the tool, and null accuracy and usefulness as a predictor of loss.

Horrendous disasters will continue to occur nationally and globally to demonstrate nature's unyielding capabilities and inglorious destruction. Accordingly, Hazus will continue to grow in use and adopt additional hazard modeling methods to reflect the growing threats to the built environment. I can only hope for Hazus users to realize the immense power imbedded in their outputs, and retain sensitivity in relaying the information to the general, uninformed public. The livelihood of the built environment and its residents depend on it. 


\section{Works Cited}

Adger, W.N. 2000. "Social and ecological resilience: are they related?" Progress in Human Geography 24(3): 347-364.

http://phg.sagepub.com/cgi/doi/10.1191/030913200701540465 (February 12, 2013).

Albrecht, Bob. 2011. "Five-alarm fears." The Columbian.

http://www.columbian.com/news/2011/apr/11/five-alarm-fears/.

Bayer, Kurt. 2012. "Fire chiefs failed to cope with Christchurch earthquake - report." New Zealand Herald. http://www.nzherald.co.nz/nz/news/article.cfm?c_id=1\&objectid=10841368.

Berman, Eric. 2011. 33-34 FEMA's HAZUS Program. Seattle, WA. http://www.multibriefs.com/briefs/nsps/acsm254pp3334.pdf.

Bostrom, Ann, Rama Mohana R. Turaga, and Branco Ponomariov. 2006. "Earthquake Mitigation Decisions and Consequences." Earthquake Spectra 22(2): 313-327. http://earthquakespectra.org/doi/abs/10.1193/1.2190668 (December 1, 2012).

CGS. 2007. Seismic Hazards Mapping Act. San Francisco: California Geological Survey. http://www.conservation.ca.gov/cgs/shzp/Pages/SHMPAct.aspx.

Clark, Stuart. 2012. "From Galileo to the L'Aquila earthquake: Italian science on trial." The Guardian. http://www.guardian.co.uk/science/across-theuniverse/2012/oct/24/galileo-laquila-earthquake-italian-science-trial.

Cochrane, Hal. 2004. "Economic loss: myth and measurement." Disaster Prevention and Management 13(4): 290-296.

http://www.emeraldinsight.com/10.1108/09653560410556500 (October 28, 2012).

Collier, Stephen J, and Andrew Lakoff. 2008. "Distributed preparedness: the spatial logic of domestic security in the United States." Environment and Planning D: Society and Space 26(1): 7-28. http://www.envplan.com/abstract.cgi?id=d446t (October 29, 2012).

Cowen, Robert C. 1981. "An earthquake warning has been discounted: now Peru can relax." Christain Science Monitor. http://www.csmonitor.com/1981/0304/030426.html.

CREW. 2011. "About CREW." Cascadia Region Earthquake Workgroup. http://www.crew.org/about-crew (April 10, 2013). 
Davoudi, Simin, Elizabeth Brooks, and Abid Mehmood. 2013. "Evolutionary Resilience and Strategies for Climate Adaptation." Planning Practice and Research (May): 116. http://www.tandfonline.com/doi/abs/10.1080/02697459.2013.787695 (May 2, 2013).

DOGAMI. 2010. “Oregon's Earthquake Risk and Resiliency.” Cascadia. http://www.oregongeology.com/sub/quarpub/CascadiaWinter2010.pdf.

. 2013. "General Department Information." History and General Operations. http://www.oregongeology.org/sub/portoff/portoffice.htm (April 2, 2013).

Editorial. 2012. "Italian earthquake case is no anti-science witch hunt." NewScientist. http://www.newscientist.com/article/dn22416-italian-earthquake-case-is-noantiscience-witchhunt.html.

Erduran, Emrah, and Conrad Lindholm. 2012. "A Critical Look at the Use of Design Spectrum Shape for Seismic Risk Assessment.” Earthquake Spectra 28(4): 17111721. http://earthquakespectra.org/doi/abs/10.1193/1.4000086 (April 8, 2013).

FEMA. 2012a. Hazus -MH 2.1. http://www.fema.gov/library/viewRecord.do?id=5120. - 2012b. "HAZUS: The Federal Emergency Management Agency's (FEMA's) Methodology for Estimating Potential Losses from Disasters." http://www.fema.gov/hazus.

. 2013a. "National Earthquake Hazards Reduction Program." http://www.fema.gov/national-earthquake-hazards-reduction-program (February 23, 2013).

—. 2013b. "National Earthquake Hazards Reduction Program."

Flynn, James, Paul Slovic, C. K. Mertz, and Cathie Carlisle. 1999. "Public Support For Earthquake Risk Mitigation In Portland, Oregon.” Risk Analysis 19(2): 205-216. http://doi.wiley.com/10.1111/j.1539-6924.1999.tb00400.x.

Fortun, Kim, and Scott Frinkel. 2012. "Making a case for disaster science and technology studies." An STS Forum on Fukushima. http://fukushimaforum.wordpress.com/online-forum-2/online-forum/making-a-casefor-disaster-science-and-technology-studies/ (November 13, 2012).

Hamilton, Robert M. 2003. "Milestones in Earthquake Research.” Geotimes. http://www.agiweb.org/geotimes/mar03/comment.html. 
Hill, Richard L., and Noelle Crombie. 2001. "A discovery at a middle school is the first direct proof that the Portland Hills Fault could generate an earthquake." The Oregonian. http://www.oregongeology.org/sub/earthquakes/PortHillsFault.htm.

Horwich, George. 2012. "Economic Lessons of the Kobe Earthquake *." 48(3): 521-542.

Hunsberger, Brent. 2010. "Earthquake insurance? A good bet." The Oregonian. http://blog.oregonlive.com/finance/2010/03/earthquake_insurance_a_good_be.html.

Jacoby, GC, DE Bunker, and BE Benson. 1997. "Tree-ring evidence for an AD 1700 Cascadia earthquake in Washington and northern Oregon." Geology. http://geology.gsapubs.org/content/25/11/999. short (March 27, 2013).

Jasanoff, S. 1999. "The Songlines of Risk.” Environmental Values 8(2): 135-152. http://openurl.ingenta.com/content/xref?genre=article\&issn=0963$2719 \&$ volume $=8 \&$ issue $=2 \&$ spage $=135$.

Johnson, EJ, and J Hershey. 1993. "Framing, probability distortions, and insurance decisions." Journal of risk and .... http://www.springerlink.com/index/x535827t2m525776.pdf (March 21, 2013).

Kircher, Charles a., Robert V. Whitman, and William T. Holmes. 2006. "HAZUS Earthquake Loss Estimation Methods." Natural Hazards Review 7(2): 45-59. http://ascelibrary.org/doi/abs/10.1061/\%28ASCE\%291527$6988 \% 282006 \% 297 \% 3 \mathrm{~A} 2 \% 2845 \% 29$.

Kunreuther, Howard. 1996. "Mitigating disaster losses through insurance." Journal of Risk and Uncertainty 12(2-3): 171-187. http://link.springer.com/10.1007/BF00055792.

Liberty, Lee M., Mark a. Hemphill-Haley, and Ian P. Madin. 2003a. "The Portland Hills Fault: uncovering a hidden fault in Portland, Oregon using high-resolution geophysical methods." Tectonophysics 368(1-4): 89-103. http://linkinghub.elsevier.com/retrieve/pii/S0040195103001525 (April 5, 2013).

_ 2003b. "The Portland Hills Fault: uncovering a hidden fault in Portland, Oregon using high-resolution geophysical methods." Tectonophysics 368(1-4): 89-103.

Machlis, Gary E. 1990. "Timber, minerals and social change: an exploratory test of two resource dependent communities." Rural Sociology 55(3): 411.

Matsen, A.S., K. Best, and N. Garmezy. 1990. "Resilience and Development: Contributions from the Study of Children who Overcame Adversity." Development and Psychopathology 2: 425-444. 
May, Peter J. 2001. "Societal Perspectives about Earthquake Performance: The Fallacy of 'Acceptable Risk'." Earthquake Spectra 17(4): 725-737.

http://earthquakespectra.org/doi/abs/10.1193/1.1423904 (April 8, 2013).

Mileti, Dennis S., and Colleen Fitzpatrick. 1993. The Great Earthquake Experiment: Risk Communication and Public Action. Boulder, CO: Westview Press, Inc.

Moffatt, Stuart, and Debra Laefer. 2009. “An Open-Source Vision for HAZUS.” Journal of Computing in Civil Engineering (February): 1-2.

http://ascelibrary.org/doi/pdf/10.1061/(ASCE)CP.1943-5487.0000022 (December 2, 2012).

Monroe, Linda Roach. 1987a. “Great NW Quake: future or fantasy?” The Oregonian: G1-G3.

—. 1987b. "Scientists fear big jolt can happen in Oregon." The Oregonian: E1-E3.

Montoya, Kacey. 2011. "Portland bridges are likely not ready for 9.0 quake." KOIN Local News. http://www.koinlocal6.com/news/local/story/Portland-bridges-likelynot-ready-for-9-0-quake/qcjPWX5JXUG4_tQKxlbDdA.cspx.

Mousavi, Shahab, Ashutosh Bagchi, and Venkatesh K.R. Kodur. 2008. "Review of postearthquake fire hazard to building structures.” Canadian Journal of Civil

Engineering 35(7): 689-698.

http://www.nrcresearchpress.com/doi/abs/10.1139/L08-029 (April 8, 2013).

NEHRP. 2009. "Background \& History." About Us.

http://www.nehrp.gov/about/history.htm (March 1, 2013).

Ng, Peter. 2010. HAZUS-MH Data Extractor (Beta Version 1.0) User's Guide.

Nigg, Joanne M. 2000. "Predicting Earthquakes: Science, Pseudoscience, and Public Policy Paradox." In Prediction: Science, Decision Making, and the Future of Nature, eds. Daniel Sarewitz, Roger A. Pielke, and Radford Byerly. Island Press, p. $135-157$.

O’Hare, Paul, and Iain White. 2013. "Deconstructing Resilience: Lessons from Planning Practice." Planning Practice and Research (April 2013): 1-5. http://www.tandfonline.com/doi/abs/10.1080/02697459.2013.787721 (May 1, 2013).

Okuyama, Yasuhide. 2007. "Economic Modeling for Disaster Impact Analysis: Past, Present, and Future." Economic Systems Research 19(2): 115-124. http://www.tandfonline.com/doi/abs/10.1080/09535310701328435 (June 18, 2013). 
OOEM. 2013. "OSSPAC." Oregon Office of Emergency Management. http://www.oregon.gov/omd/oem/pages/osspac/osspac.aspx (April 15, 2013).

OPB, Oregon Public Broadcasting. 2012. "How Would Portland Fare in An Earthquake?" http://www.opb.org/news/article/how-would-portland-fare-earthquake/.

Oreskes, Naomi. 2000. "Why Predict? Historical Perspectives on Prediction in Earth Science." In Prediction: Science, Decision Making, and the Future of Nature, eds. Daniel Sarewitz, Roger Pielke, and Radford Byerly. Island Press, p. 23-40.

OSSPAC. 2013. "The Oregon Resilience Plan.” (February).

Palm, Risa. 1995. Earthquake Insurance: A Longitudinal Study of California Homeowners. Boulder, CO: Westview Press, Inc.

PBEM. 2012. City of Portland Earthquake Response Appendix. Portland, OR. $\mathrm{http}: / / \mathrm{www}$. portlandoregon.gov/pbem/article/382005.

Peek-Asa, C, J F Kraus, L B Bourque, D Vimalachandra, J Yu, and J Abrams. 1998. "Fatal and hospitalized injuries resulting from the 1994 Northridge earthquake." International journal of epidemiology 27(3): 459-65. http://www.ncbi.nlm.nih.gov/pubmed/9698136.

Picard, Pierre. 2008. "Natural Disaster Insurance and the Equity-Efficiency Trade-Off." Journal of Risk and Insurance 75(1): 17-38. http://onlinelibrary.wiley.com/doi/10.1111/j.1539-6975.2007.00246.x/full (March 20, 2013).

Porter, Keith a., James L. Beck, and Rustem Shaikhutdinov. 2004. "Simplified Estimation of Economic Seismic Risk for Buildings." Earthquake Spectra 20(4): 1239-1263. http://earthquakespectra.org/doi/abs/10.1193/1.1809129 (October 28, 2012).

Ren, a. Z. 2004. "The Simulation of Post-Earthquake Fire-Prone Area Based on GIS." Journal of Fire Sciences 22(5): 421-439. http://jfs.sagepub.com/cgi/doi/10.1177/0734904104042440 (April 13, 2013).

Rojas-Burke, Joe. 2011. "Comparing Portland's quake risk to that of devistated Christchurch, New Zealand." The Oregonian. http://www.oregonlive.com/environment/index.ssf/2011/02/comparing_portlands_q uake_risk.html.

Rose, Adam. 2004. "Defining and measuring economic resilience to disasters." Disaster Prevention and Management. 
http://www.emeraldinsight.com/journals.htm?articleid=871056\&show=abstract (January 30, 2013).

Rueter, Patty. 2010. "Portland Natural Hazard Mitigation Plan 2010.”

Santella, Nicholas, and Laura J. Steinberg. 2011. "Accidental Releases of Hazardous Materials and Relevance to Terrorist Threats at Industrial Facilities." Journal of Homeland Security and Emergency Management 8(1). http://www.degruyter.com/view/j/jhsem.2011.8.issue-1/1547-7355.1809/15477355.1809.xml (May 9, 2013).

Sarewitz, Daniel. 2012. "The L'Aquila Earthquake and the Importance of Scientists Saying 'I Don't Know'.” Slate: Future Tense.

Sarewitz, Daniel, and Roger Pielke. 2000. "Prediction as a Science and Policy." In Prediction: Science, Decision Making, and the Future of Nature, eds. Daniel Sarewitz, Roger Pielke, and Radford Byerly. Island Press, p. 11-22.

Satake, Kenji, K Shimazaki, Y Tsuji, and K Ueda. 1996. "Time and size of a giant earthquake in Cascadia inferred from Japanese tsunami records of January 1700." Nature 379: 246-249. http://www.nature.com/nature/journal/v379/n6562/abs/379246a0.html (March 27, 2013).

Schneider, Philip J., and Barbara a. Schauer. 2006. "HAZUS - Its Development and Its Future." Natural Hazards Review 7(2): 40-44. http://ascelibrary.org/doi/abs/10.1061/\%28ASCE\%291527$6988 \% 282006 \% 297 \% 3 \mathrm{~A} 2 \% 2840 \% 29$.

Shaw, Rajib, Koichi Shiwaku Hirohide Kobayashi, and Masami Kobayashi. 2004. "Linking experience, education, perception and earthquake preparedness." Disaster Prevention and Management 13(1): 39-49. http://www.emeraldinsight.com/10.1108/09653560410521689 (March 21, 2013).

Shoaf, K I, H R Sareen, L H Nguyen, and L B Bourque. 1998. "Injuries as a result of California earthquakes in the past decade." Disasters 22(3): 218-35. http://www.ncbi.nlm.nih.gov/pubmed/9753812.

Smit, Barry, and Johanna Wandel. 2006. "Adaptation, adaptive capacity and vulnerability." Global Environmental Change 16(3): 282-292. http://linkinghub.elsevier.com/retrieve/pii/S0959378006000410 (February 12, 2013). 
Steinberg, Ted. 2006. Acts of God: The Unnatural History of Natural Disasters in America. 2nd ed. New York, NY: Oxford University Press.

Tseng, Chun-Pin, and Cheng-Wu Chen. 2011. "Natural disaster management mechanisms for probabilistic earthquake loss." Natural Hazards 60(3): 1055-1063. http://link.springer.com/10.1007/s11069-011-9889-2 (May 3, 2013).

USGS. 2012. "Understanding Plate Motions." http://pubs.usgs.gov/gip/dynamic/understanding.html (May 5, 2013).

Wagner, R. M. 1996. “A Case-Control Study of Risk Factors for Physical Injury During the Mainshock of the 1989 Loma Prieta earthquake in the County of Santa Cruz, California." John Hopkins University.

Wetmore, Jameson M. 2007. "Distributing Risks and Responsibilities: Flood Hazard Mitigation in New Orleans." Social Studies of Science 37(1): 119-126.

Wolf, Edward. 2011. "Oregon's best-kept secret? Seismic grants an unsung bright spot in Oregon's gloomy spring." Oregonian. http://www.oregonlive.com/opinion/index.ssf/2011/04/oregons_bestkept_secret_seism.html.

Yeats, Robert S. 1998. Living with Earthquakes in the Pacific Northwest. Corvallis, OR: Oregon State University Press.

Yeats, RS, KE Sieh, and CR Allen. 1997. The geology of earthquakes. New York, NY: Oxford University Press.

Zeiderman, Austin. 2012. "On shaky ground: the making of risk in Bogotá." Environment and Planning A 44(7): 1570-1588. http://www.envplan.com/abstract.cgi?id=a44283 (October 28, 2012). 